LASER-ERROR-CORRECTION CONTROL UNIT FOR MACHINE TOOLS

R. R. Burleson 


\section{DISCLAIMER}

This report was prepared as an account of work sponsored by an agency of the United States Government. Neither the United States Government nor any agency Thereof, nor any of their employees, makes any warranty, express or implied, or assumes any legal liability or responsibility for the accuracy, completeness, or usefulness of any information, apparatus, product, or process disclosed, or represents that its use would not infringe privately owned rights. Reference herein to any specific commercial product, process, or service by trade name, trademark, manufacturer, or otherwise does not necessarily constitute or imply its endorsement, recommendation, or favoring by the United States Government or any agency thereof. The views and opinions of authors expressed herein do not necessarily state or reflect those of the United States Government or any agency thereof. 


\section{DISCLAIMER}

Portions of this document may be illegible in electronic image products. Images are produced from the best available original document. 
Reference to a company or product name does not imply approval or recommendation of the product by Union Carbide Corporation or the Department of Energy to the exclusion of others that may meet specifications.

Printed in the United States of America. Available from National Technical Information Service

U.S. Department of Commerce

5285 Port Royal Road, Springfield, Virginia 22161

Price: Printed Copy\$7.25; Microfiche $\$ 3.00$

This report was prepared as an account of work sponsored by an agency of the United St ates Government. Neither the United States Government nor any agency thereof, nor any of their employees, nor any of their contractors, subcontractors, or their employees, makes any warranty, express or implied, nor assumes any legal liability or responsibility for any third party's use or the results of such use of any information, apparatus, product or process disclosed in this report, nor represents that its use by such third party would not infringe privately owned rights. 
Date of Issue: May 23, 1978

Distribution Category: UC-38

\title{
LASER-ERROR-CORRECTION CONTROL UNIT FOR MACHINE TOOLS
}

\author{
R. R. Burleson \\ Fabrication Systems Department \\ Y-12 Development Division
}

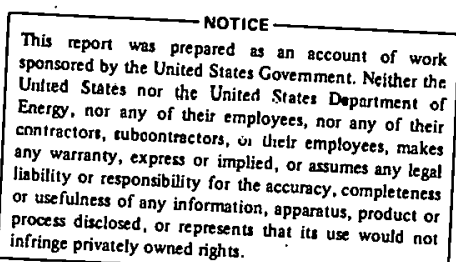

Oak Ridge $Y-12$ Plant

P. O. Box Y, Oak Ridge, Tennessee 37830

Prepared for the Department of Energy Under US Government Contract W-74U5·eng. 26 


\section{ABSTRACT}

An ultraprecision machining capability is needed to meet the requirements for aspherical, optical-quality surfaces for the laser fusion program. A minicomputer-based control system was developed for use on a Moore Number 3 measuring machine as part of its transformation into a very accurate contouring machine tool. This control system is a marriage of the "stepping-motor", open-loop, positioning system and the interferometricfeedback system. A 30-cm-diameter aluminum disc was machined to a 133-cm-radius spherical contour. A contour error of $250 \mathrm{~nm}(2500 \AA)$ was observed. 


\section{CONTENTS}

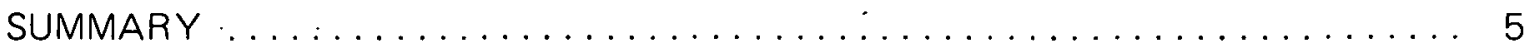

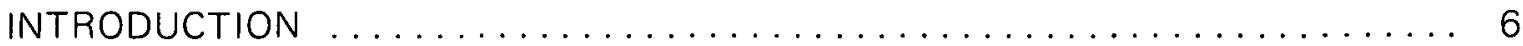

MACHINE-TOOL CONTROL UNIT $\ldots \ldots \ldots \ldots \ldots \ldots \ldots \ldots \ldots \ldots \ldots$

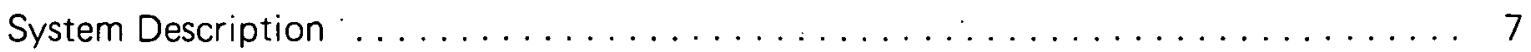

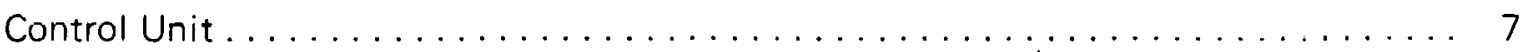

Theory ......................... 7

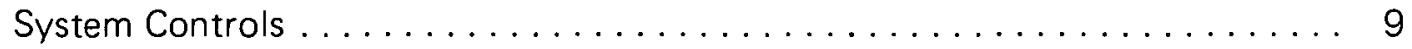

Status Displays . . . . . . . . . . . . . . . . . . . . . . . 11

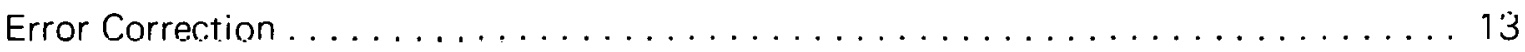

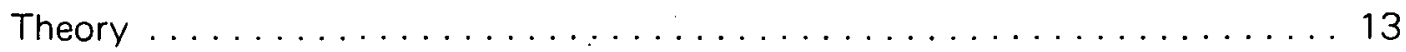

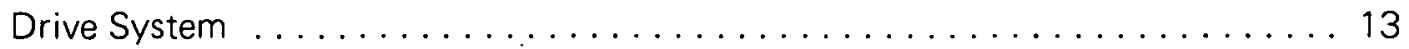

Feedback Element . . . . . . . . . . . . . . . . . . . . . . . 13

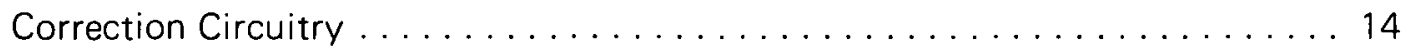

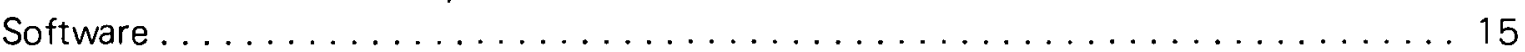

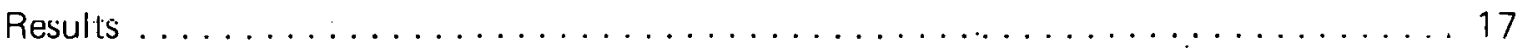

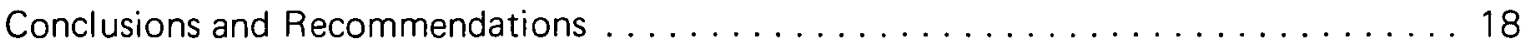

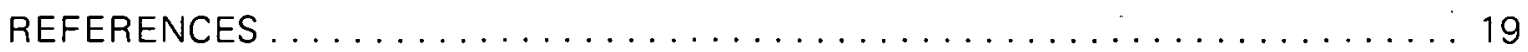

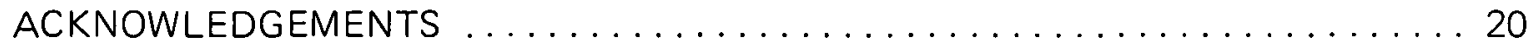

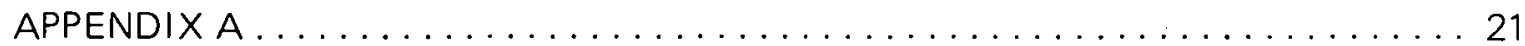

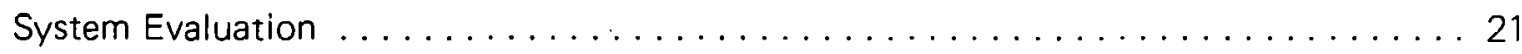

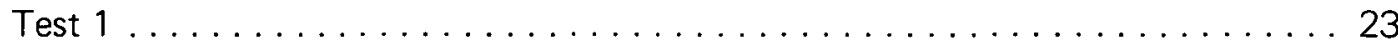

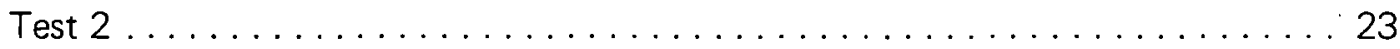

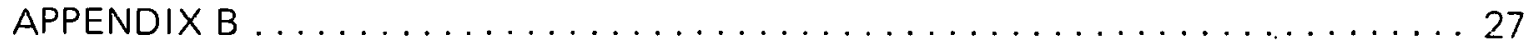

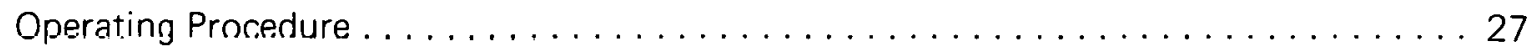

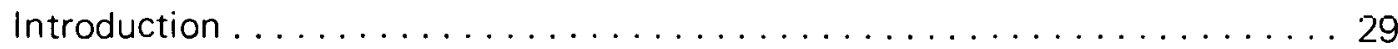

Rapid Feed Movement . . . . . . . . . . . . . . . . . . . . . . 29

Incremental Movement . . . . . . . . . . . . . . . . . . . . . . . . . . . . . . . 29

Storing Part Programs . . . . . . . . . . . . . . . . . . . . . . . . . . 29

Retrieving Part Programs . . . . . . . . . . . . . . . . . . 30

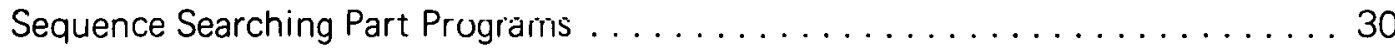

Running a Part Program . . . . . . . . . . . . . . . . . . . . . . 30

Entering Laser Compensation . . ... . . . . . . . . . . . . . . . 30

Listing Part Tapes . . . . . . . . . . . . . . . . . . . . . . . . 30

Initial Startup . . . . . . . . . . . . . . . . . . 31 


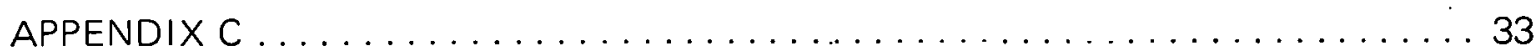

Requirement for Standard RS-274-B NC Tape $\ldots \ldots \ldots \ldots \ldots \ldots \ldots \ldots \ldots$

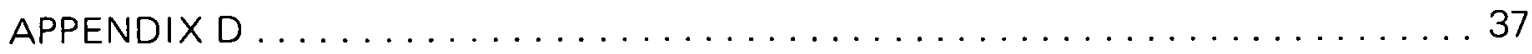

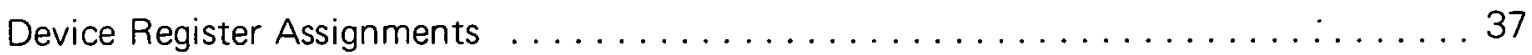

Device Register - Manual [(164000) input of manual increment and rapid feed from control panel] ................... 39

Device Register - Mode [(164002) input of switches from control

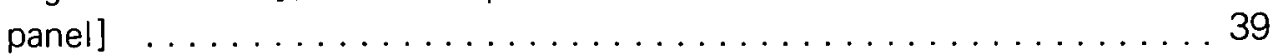

Device Register - Seq. No. [(164004) input sequence number $]$. . . . . . . . . 40

Device Register - Feed [(164006) input of feedrate override switch] . . . . . . . 40

Device Register - Laser [(164010) input laser status] . . . . . . . . . . . . . . . . 41

Device Register - LMT [(164012) input limit switches and motor drive status $] \ldots \ldots \ldots \ldots \ldots \ldots \ldots \ldots \ldots \ldots \ldots \ldots \ldots \ldots \ldots \ldots$

Device Register - Status $[(164014)$ input automatic controls $] \ldots \ldots \ldots \ldots \ldots 42$

Device Register - Lights $[(164040)$ output to status lights $]$. . . . . . . . . . . . 42

Device Register - Control [(164042) output of control parameters] . . . . . . . 43

Device Register - DSEQNO [(164044) output of sequence number] . . . . . . . 43

Device Register - Display [(164046) output of lights to control panel] . . . . . 44

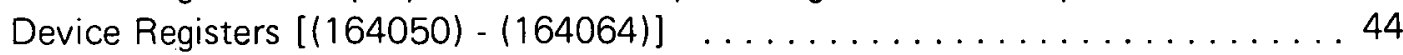

Device Register - Feedback [(164066) output of feedback control

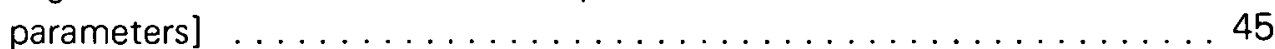

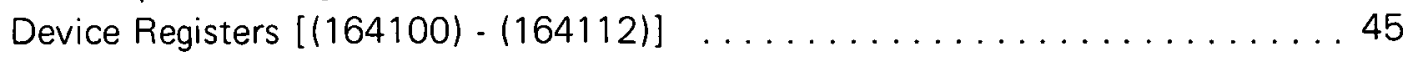

Device Registers $[(164114)-(164146)] \ldots \ldots \ldots \ldots \ldots \ldots \ldots \ldots$

APPENDIXE .............................. 47

Software Listings . . . . . . . . . . . . . . . . . . 47

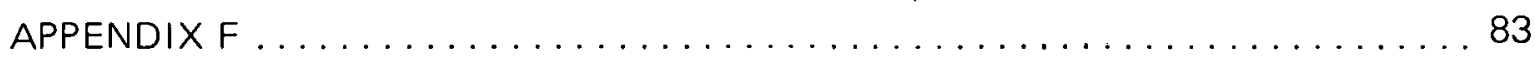

Hardware Drawings $\ldots \ldots \ldots \ldots \ldots \ldots \ldots \ldots \ldots \ldots \ldots \ldots \ldots \ldots \ldots$ 


\section{SUMMARY}

An ultraprecision machining capability is needed to meet the requirements for aspherical, optical-quality surfaces for the laser fusion program. A minicomputer-based control system was developed for use on a Moore Number 3 measuring machine as part of its transformation into a very accurate contouring machine tool. The objectives of this project were to: (1) attain an optimum tradeoff between hardware and software; (2) use a modular design for easy maintenance; ( 3 ) use the EIA standard RS-274-B numerical control tape service; (4) drive the $x$ and $y$ axes with a positioning resolution of $5.08 \mathrm{~nm}$ and a feedback resolution of $10 \mathrm{~nm}$; (5) drive the $x$ and $y$ axes at a velocity of $0.05 \mathrm{~cm} / \mathrm{sec}$ in the contouring mode and $0.18 \mathrm{~cm} / \mathrm{sec}$ in the positioning mode; (6) eliminate the possibility of tape reader errors, and (7) allow edlting of the part description data.

Based upon experience with the control systems currently in use on diamond-turning machine tools, a new control concept has been devised. It is a marriage of the "stepping-motor", open-loop, positioning system and the interferometer-feedback system. In this dual system, pulse trains are generated by the computer and fed to the stepping-motor-like drives for the slides. A laser interferometer feedback system was added which "corrects" the pulse train to the stepping motor by adding or deleting individual pulses. As long as the drive-system errors do not have wavelength components that are too short to be corrected by the interferometer feedback, adequate tool position control is obtainable.

This systern was designed to provide a flexible and easily maintainable control unit for a machine tool. Flexibility was built into the system through the use of the minicomputer. The operator-panel switch settings, the machine parameters, and the part-description data are all read into the minicomputer. The software in the minicomputer then decides whether the action requested is allowed; and, if so, it will load the interpolators, read a block of part description data from the disk, or whatever else is requested. The position readouts and the machine and laser status lights are continuously updated by the minicomputer. Since the minicomputer is the controlling element of the system, most changes that may be required simply nes.essitate a r.hange in software.

A $30-\mathrm{cm}$-diameter aluminum disc was machined to a $133-\mathrm{cm}$-radius spherical contour to evaluate the system. A contour error of $250 \mathrm{~nm}(2500 \AA)$ was observed. Based upon the results obtained, two additional control systems are being assembled to handle the production workload. 


\section{INTRODUCTION}

An ultraprecision machining capability is needed for the laser fusion program. For this work, a precision air-bearing spindle has been mounted horizontally on a modified vertical column of a Moore Number 3 measuring machine base located in a development laboratory at the Oak Ridge Y-12 Plant. (a) An open-loop control system previously installed on this machine ${ }^{1}$ was inadequate to meet the upcoming requirements since accuracy is limited to $0.5 \mu \mathrm{m}$ by the errors in the machine's gears and leadscrew. A new controller was needed that could monitor the actual position of the machine and perform real-time error correction on the programmed tool path. It was necessary that this project: (1) attain an optimum tradeoff between hardware and software; (2) use a modular design for easy maintenance; (3) use a standard NC tape service; (4) drive the $x$ and $y$ axes with a positioning resolution of $5.08 \mathrm{~nm}$ and a feedback resolution of $10 \mathrm{~nm}$; (5) drive the $x$ and $y$ axis motors at $a$ velocity of $0.05 \mathrm{~cm} / \mathrm{sec}$ in the contouring mode and $0.18 \mathrm{~cm} / \mathrm{sec}$ in the positioning mode; (6) eliminate the possibility of tape-reader errors; and (7) allow editing of the part description data. This report describes the work that was done to develop and install the new machine controller.

(a) Operated by the Union Carbide Corporation's Nuclear Division for the Department of Energy. 


\section{MACHINE-TOOL CONTROL UNIT}

\section{SYSTEM DESCRIPTION}

This system is to control a three-axis $(x, y, c)$ turning machine with full and continuous-path positioning capability. The major components of the control system, consisting of the pedestal controls, the video terminal, and the electronics cabinet with status displays, can be seen in Figure 1.

A block diagram of the control system is presented in Figure 2. Commands are received by the minicnmputer from the perdestal controls. If the system is in the manual, sinqle-block, or automatic mode, the minicomputer loads the digital differential analyzer (DDA) ${ }^{2}$ with the correct distance, then loads the timing and add-command generator with the correct speed. The laser correction is then loaded with the requested error bound, and the clock is turned on. The command signals from the DDAs are corrected by the laser correction circuitry, and the corrected command signals cause the motors to move the slides in the required direction at the specified feedrate. The laser is used to measure the distance traveled by the slides. This information is then routed to the position-display and laser-correction circuitry. During this process, the minicomputer is used to monitor and display the status of the laser, machine, and program. A computer routine is used to check for any change in the pedestal controls that would require the system to change operations.

\section{CONTROL UNIT}

\section{Theory}

This system was designed to provide a flexible and easily maintainable control unit for a machine tool. Flexibility was built into the system through the use of the minicomputer. The operator-panel switch settings, the machine parameters, and the part-description data are all read into the minicomputer, shown in Figure 3.

The software in the minicomputer then determines whether the action requested is allowed; if so, it will load the DDAs, read a block of part description data from the disk, or do whatever else is requested. The position readouts and the machine and laser status lights are continuously updated by the minicomputer. Since the minicomputer is the controlling element of the system, most changes in the system strategy will only require a change in the software.

Modular design has been incorporated into the hardware system for ease of maintenance. This was done through the use of an Input/Output (I/O) Bus that allows all modules to be interconnected at a common point. Each axis of the machine is controlled independently so that a failure in one axis will not affect the operation of the total machine. All similar functions are contained on a single printed circuit board. That is, an input receiver board was designed that takes the signals from switches, filters them, then puts them on the $1 / 0$ Bus when requested. Several of these boards are used in the system to filter all switches. The 


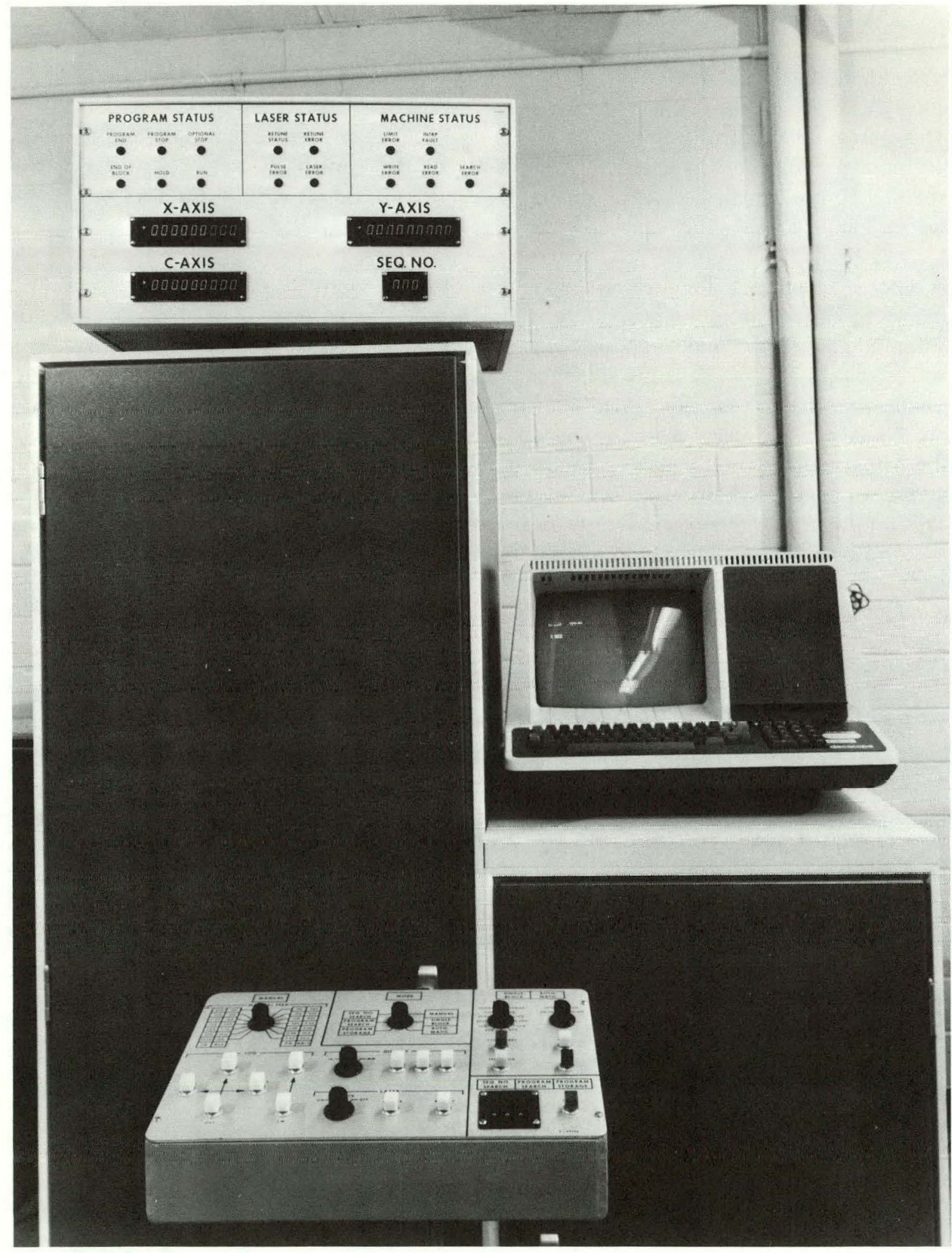

170657

Figure 1. LASER-ERROR-CORRECTION MACHINE-TOOL CONTROL SYSTEM. 


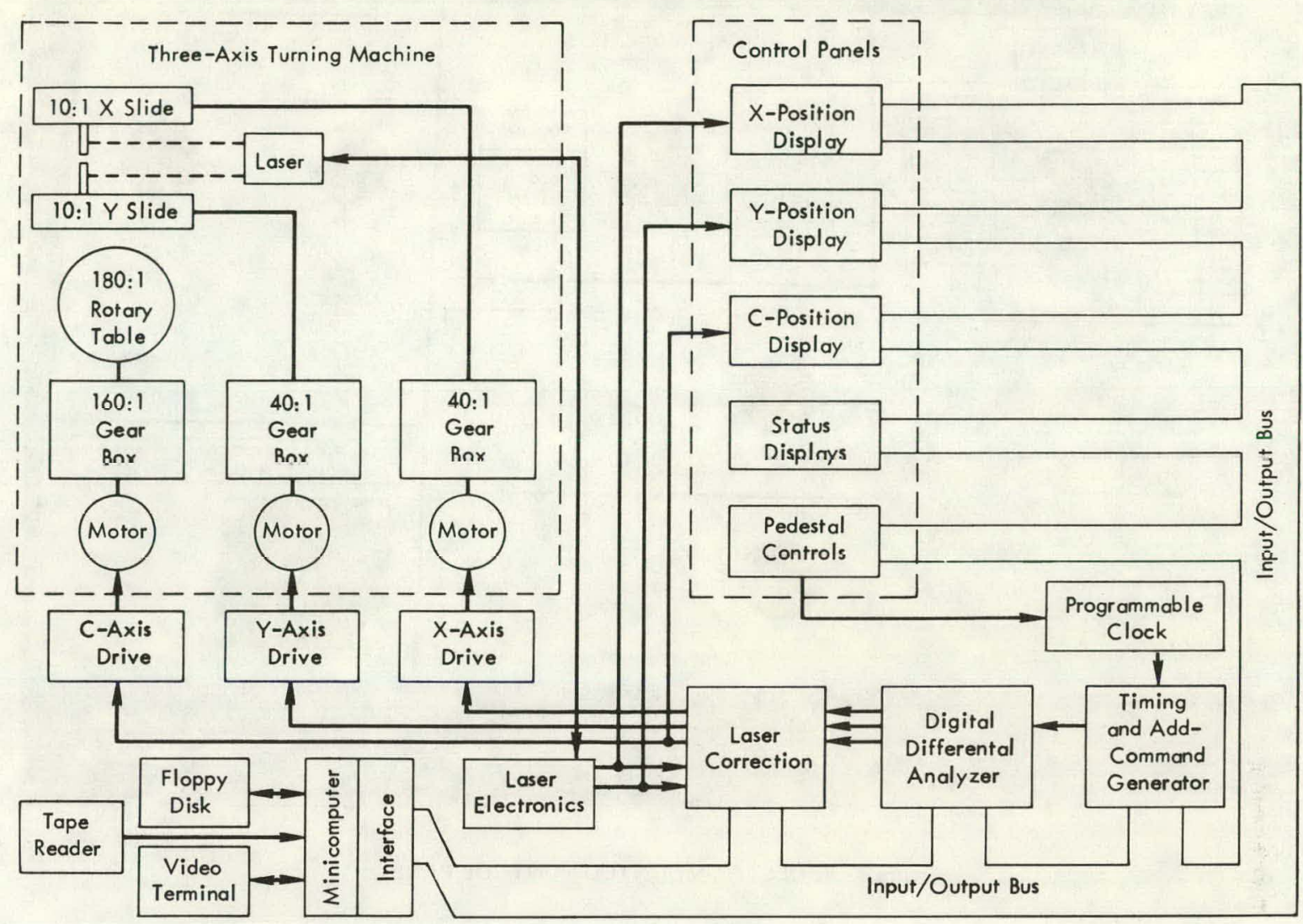

Figure 2. CIRCUITRY FOR THE MACHINE-TOOL CONTROL UNIT AND THE THREE-AXIS TURNING MACHINE.

entire control unit is composed of only nine different types of printed circuit boards. This modular design, combined with software that allows fault isolation down to a single board, results in an easily maintainable system.

\section{System Controls}

The system controls are contained on a remote pedestal, seen in Figure 4, for easy access by the operator. These controls are:

1. Mode - This switch allows the operator

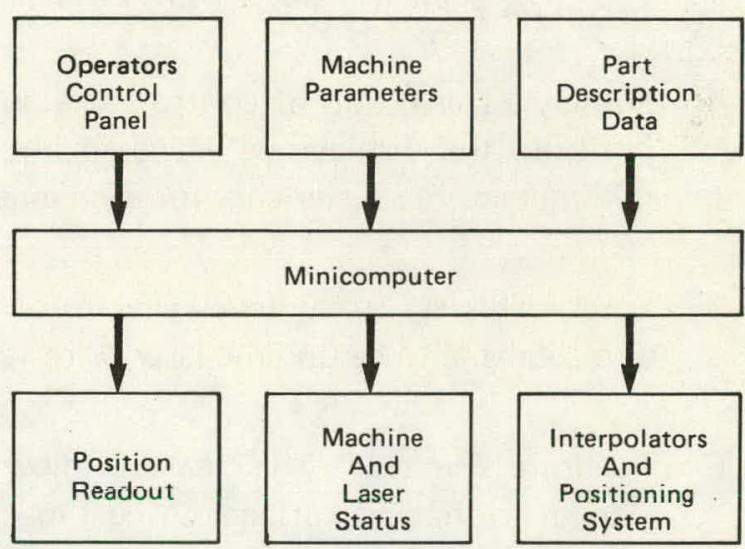

Figure 3. PRINCIPAL COMPONENTS OF THE MACHINE-TOOL CONTROL SYSTEM. to select one of six modes of operation.

The controls that are in effect in each mode are contained in the area of the panel labeled with that particular mode.

2. Manual Feed - Incremental feeds from 0.02 to $2.500 \mu \mathrm{m}$ ( 0.001 to 100 mils) can be selected, and rapid feeds from 0.005 to $25 \mathrm{~mm} / \mathrm{sec}(0.001$ to $5.0 \mathrm{ipm})$ are also selectable. 


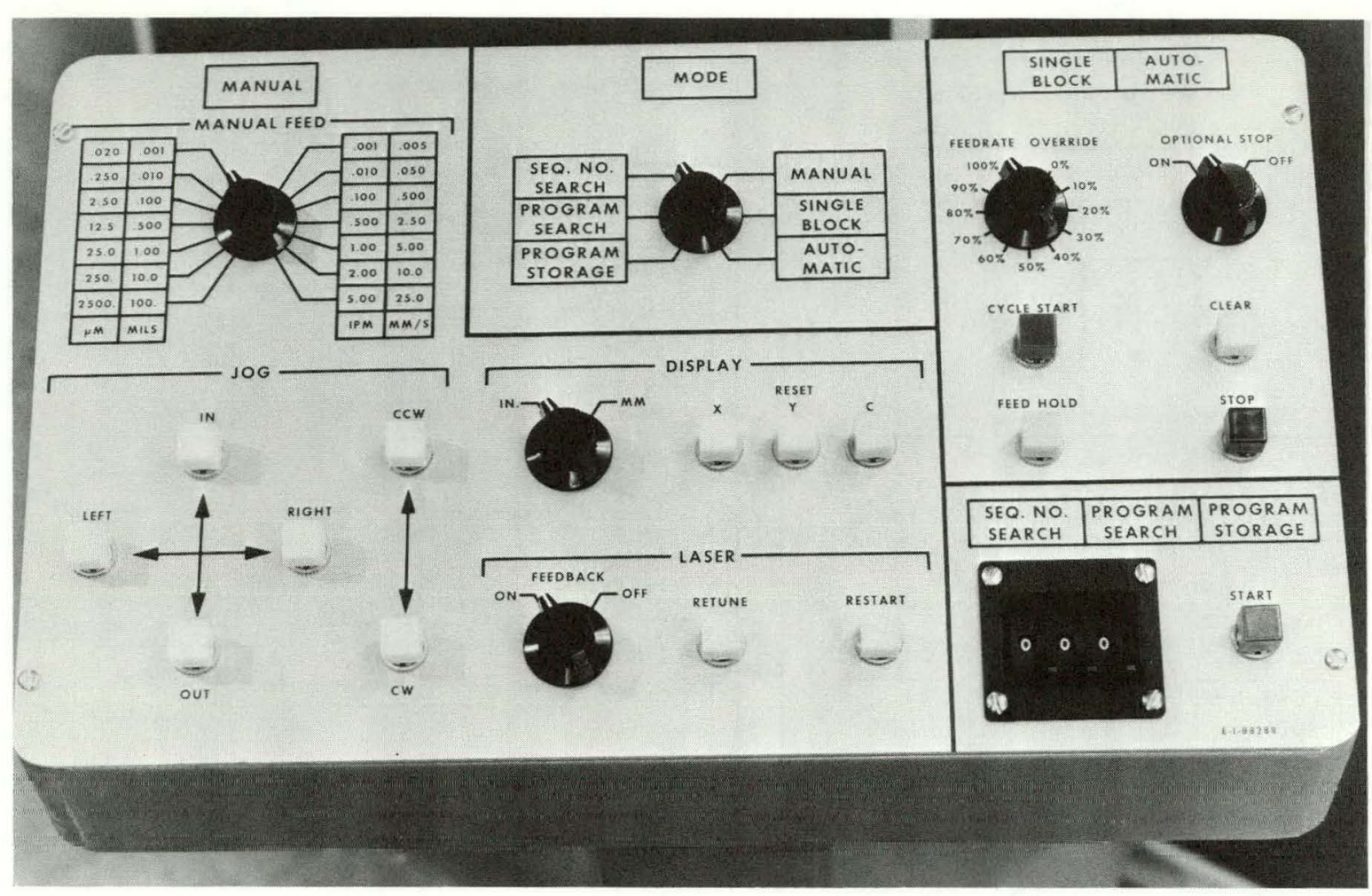

Figure 4. PEDESTAL-MOUNTED CONTROL PANEL.

170654

3. Jog-This feature allows the operator to move any axis in either direction. The manual-feed control sets either the distance or the speed that the selected axis will move. The "jog" light will stay on until the machine has stopped.

4. Display - This group of controls selects either English or metric resolution. In the "in" position, the displays will read inches; in the " $\mathrm{mm}$ " position, the displays will read millimeters. Reset switches for each axis are also provided.

5. Laser - This set of switches enables or disables the laser error correction. Controls are also available to retune the laser or restart the laser electronics.

6. Feedrate Override - This feature allows the operator to vary the tool velocity with respect to the part surface during a machining pass without changing the tool path. This feature is also operational in the manual mode.

7. Optional Stop - At various times during a machining process, it may be advantageous to stop the cycle. Certain points on the tape contain optional stops. Through the use of this feature, the operator has the option to stop at these points.

8. Cycle Start - Through the use of this feature, a machining cycle is continued from the last block executed. 
9. Clear - This feature resets all error conditions and resets the machining cycle to the first block.

10. Feed Hold - After completion of a block, the machine will stop if this feature has been initiated. The "feed-hold" light will stay on until the machine has stopped.

11. Stop - This control immediately stops all slide motion. After this button has been activated, the machining cycle must be restarted.

12. Start - This feature allows the operator to store a program on the disk, read a program from the disk into memory preparatory to machining, or execute a sequence search of a program already in memory. The "start" light will stay on until the search is complete.

\section{Status Displays}

The functionally grouped status displays, shown in Figure 5, are:

1. Program End - The machine cycle has come to its programmed end. An attempt to continue from this point will cause the machining cycle to be reset to the first block.

2. Program Stop - The machining cycle has come to a programmed stop. The program will continue with the next block when the "cycle-start" button is activated.

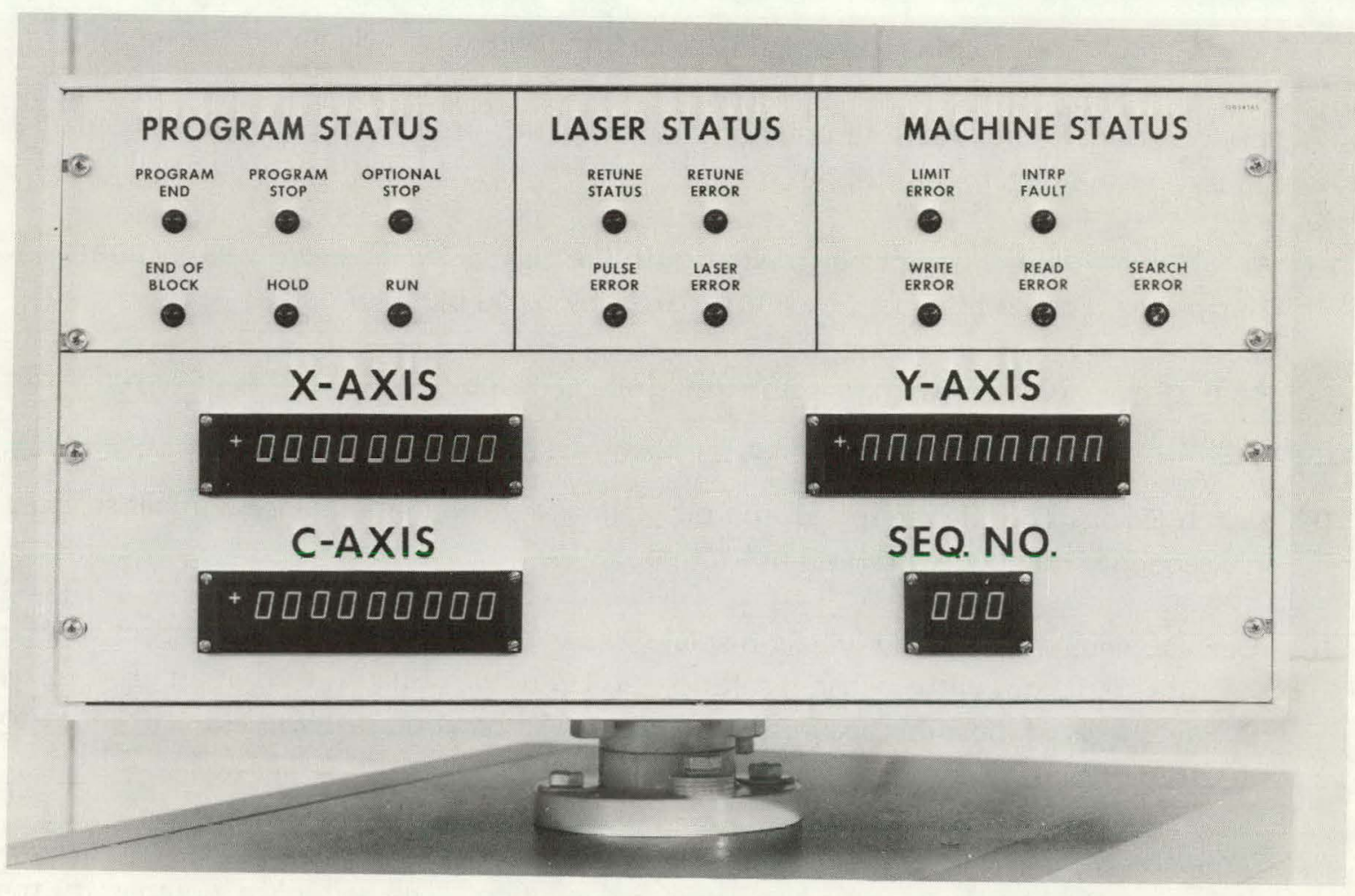

Figure 5. SYSTEM-STATUS UISPLAY PANEL. 
3. Optional Stop - An optional stop has been encountered with the "optional-stop" switch in the "on" position. The program will continue with the next block when the "cycle-start" button is activated.

4. End of Block - The machine is at the end of a block of data and is waiting to continue.

5. Hold - The "feed-hold" button has been activated, and the system will stop at the end of the present block.

6. Run - A machining cycle is in the process of being executed.

7. Retune Status - Indicates that the laser PZT tuning/check is in process.

8. Retune Error - The laser is out of tune and the "retune" button should be activated.

9. Pulse Error - The laser signal and the receiver signals are out of phase, and the "restart" button should be activated.

10. Laser Error-There is an over-current condition in the laser. The laser should be retuned.

11. Limit Error - The machine has encountered a limit switch or a clamp is engaged.

12. Interpolation Fault - An interpolation fault has occurred during the execution of a block, and the system has stopped.

13. Write Error - While attempting to write onto the disk, a "write error" was encountered. This problem could be caused by a full disk or by a bad block of data.

14. Read Error-While reading from the disk or tape reader, a "read error" was encountered.

15. Search Error - The file requested in a program search or the sequence number selected in a sequence number search was not found.

16. Axis Displays - The $x$ and $y$-axis displays show the position of their respective axis accurate to $10 \mathrm{~nm}$ with metric resolution or $1 \mu$ in with English resolution. The c-axis display shows its position accurate to $2 \mu \mathrm{deg}$. All position displays are referenced to the NC part tape setup point.

17. Sequence Number - A part program is broken down into various machining processes which are identified by separate sequence numbers. The sequence number of the machining process in operation is displayed. 


\section{ERROR CORRECTION}

\section{Theory}

Based upon experience with the control systems currently in use on diamond-turning machine tools, a new control concept has been devised. It is a combination of the stepping-motor, open-loop positioning system, used successfully on the previous Moore turning machines, and the interferometer feedback system used on the larger-opticalcomponent turning machines. In this dual system, pulse trains are generated by the computer and fed to the stepping-motor-like drives for the slides.

If the reduction unit, the leadscrew, and llie mul were dimensionally perfect, the tool would be positioned exactly as commanded except for the very small lag introduced by the finite compliance of the drive shaft and gearing, and the finite mass of the slide. Unfortunately, they are not dimensionally perfect, nor is it felt to be cost effective to make them dimensionally "adequate" for providing 0.1- $\mu \mathrm{m}$ optical components. Therefore, a laser-interferometer feedback system has been added which "corrects" the pulse train to the stepping motor by adding or deleting individual pulses. As long as the drive-system errors do not have wavelength components that are too short to be corrected by the interferometer feedback, adequate tool-position control is obtainable. The lag problem is eliminated by utilizing very high gains on the two axes.

\section{Drive System}

The first problem to be overcome was to obtain a very-high-gain, stepping-motor-like drive for the slides. A system was purchased with a resolution of 10,000 steps per revolution $(S / R)$ and a maximum following error of 10 steps (Figure 6$)$. These drive systems utilize a permanent-magnet DC motor with a resolver mounted on the same shaft as the motor. This arrangement creates a very stable system. This system is driven by a two-state, pulse-width-modulated motor driver. Since these motors were limited to 100,000 steps per second, with available gearing this restriction meant a maximum rapid traverse speed of 0.04 $\mathrm{cm} / \mathrm{sec}$. A method was developed to change the resolution of the drive system so that, by turning a switch, the resolution could be changed to $2000 \mathrm{~S} / \mathrm{R}$ and, therefore, a maximum rapid traverse speed of $0.2 \mathrm{~cm} / \mathrm{sec}$. In the manual mode, they have a resolution of $2000 \mathrm{~S} / \mathrm{R}$, while in the automatic mode they have a resolution of $10,000 \mathrm{~S} / \mathrm{R}$.

\section{Feedback Element}

The next major obstacle to overcome was to develop a method for accurately measuring the displacement of the slides. A laser interferometer was selected for the job. A layout of the components of the laser interferometer is presented in Figure 7. A picture of the laser mounted on the machine, with the oil-tight covers removed, is included as Figure 8 . The available electronic systems had a resolution of $\lambda / 4$, where $\lambda$ is the wavelength of a $\mathrm{He} / \mathrm{Ne}$ laser. This resolution was electronically extended to $\lambda / 40$ through the use of a laser extender. Since $\lambda / 40$ is an awkward number with which to work, a fringes-to-inches 


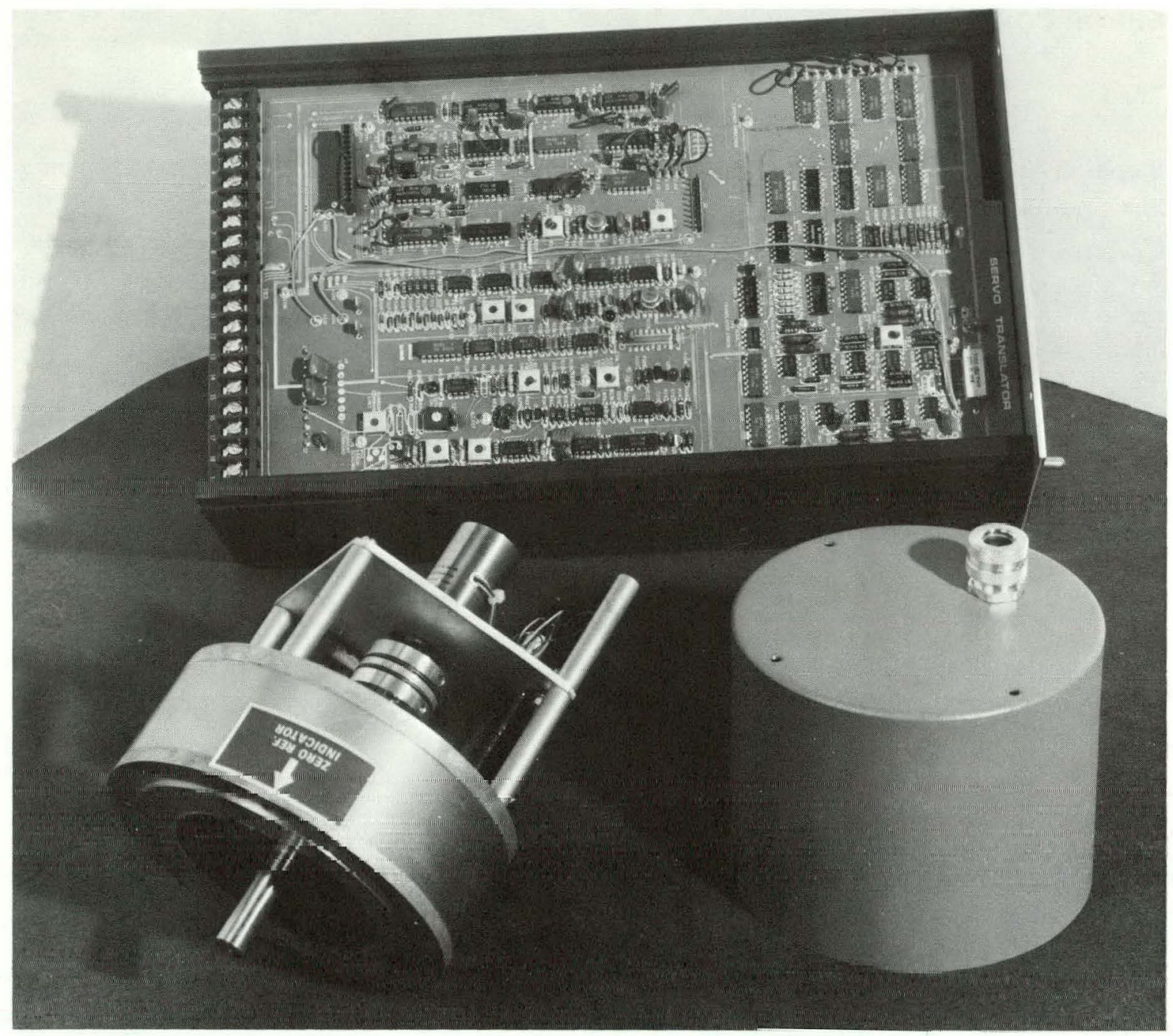

176755

Figure 6. STEPPING-MOTOR-LIKE DRIVE SYSTEM THAT IS USED TO POSITION THE MACHINE.

converter was utilized to convert $\lambda / 40$ to 10 -nm pulses in metric resolution, or $1 \mu$ in pulses with English resolution. The fringes-to-inches converter is compensated for barometric pressure, temperature, and relative humidity by the computer system.

\section{Correction Circuitry}

Having now obtained a high-gain drive system and a high-resolution feedback element, the remaining problem was to develop the circuitry to compare the commanded position with the actual position and correct for any errors. This development takes the command pulse to the motors and either adds, subtracts, or takes no action, depending on the amount and sign of the error. The laser up-and-down pulses, the command pulses, and the command sign enter the anticoincidence logic where an up-and-down error signal is developed (see Figure 9). The error signal is then brought to an up/down counter and stored. The error signal stored in the counter is then compared to the error limit stored in the limit-bound register. 


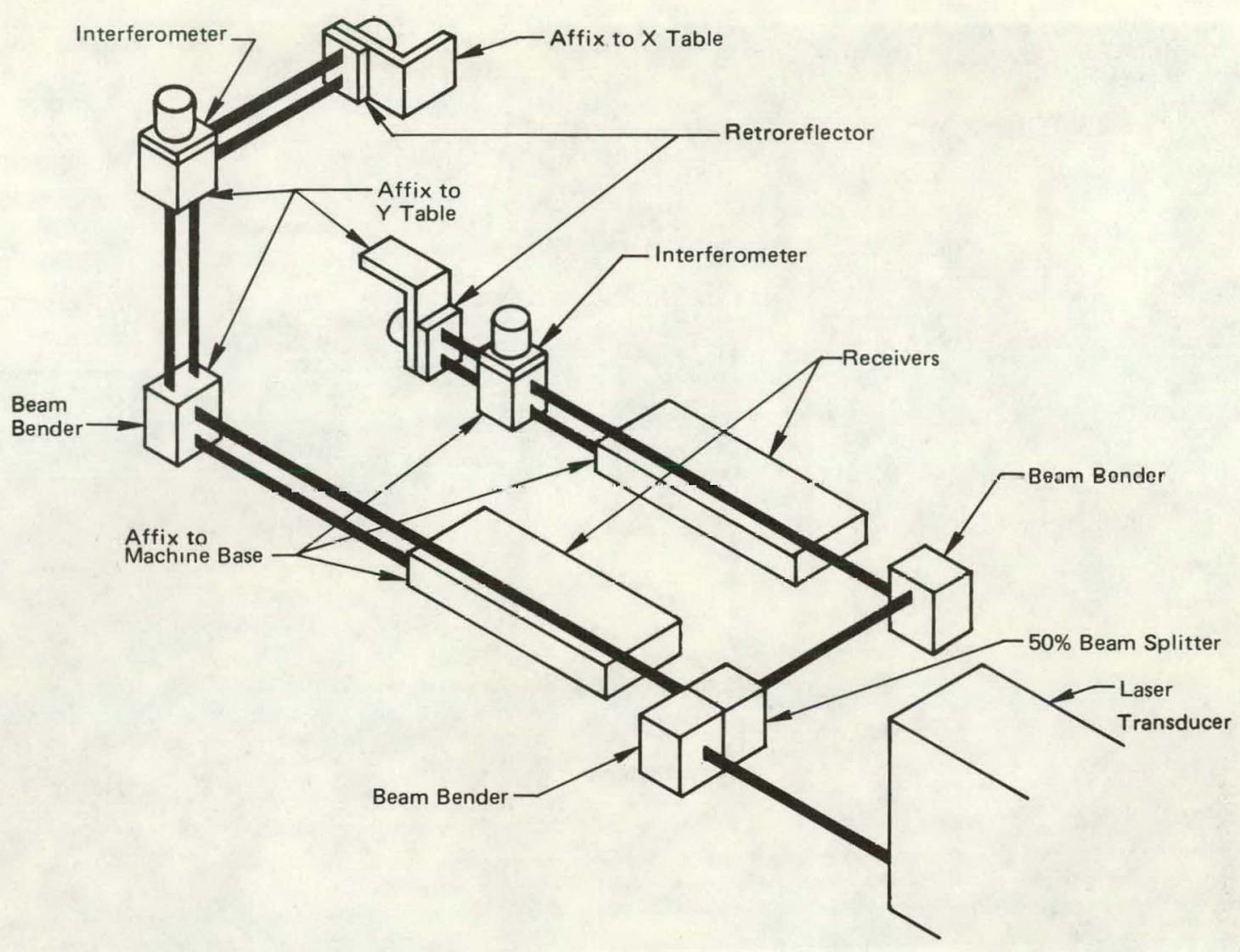

Figure 7. MAJOR COMPONENTS OF THE LASER INTERFEROMETER SYSTEM.

When the error is greater than the error limit, a signal is developed that tells the Add/Sub (a pulse circuit) to begin correcting. The Add/Sub will then either insert or delete one pulse, depending on the sign of the error. The velocity-loop circuitry enables the Add/Sub only every nth command pulse. The smaller the value of $n$, the tighter the loop.

The unique feature of this development is the makeup of the motor-drive signal. In a standard numerical control (NC) controller with interferometric feedback, the system is required to build up an crror before the controller is able to drive the motors. With this development, no error is required to drive the motors; and, consequently, a tighter loop is obtained. This development is also unique in that it is a completely digital approach, whereas a standard NC controller uses an almost totally analog approach.

\section{SOFTWARE}

The control system is capablc of operating under six different modes. The software for each mode has been written into a program that runs under the Digital Equipment Corporation RT-11 disk operating system. Following is a brief discussion about the operation of each mode.

When a part-description tape is received, it must be transferred to a disk file before any machining can take place. This transfer is made by inserting the tape into the tape reader, 


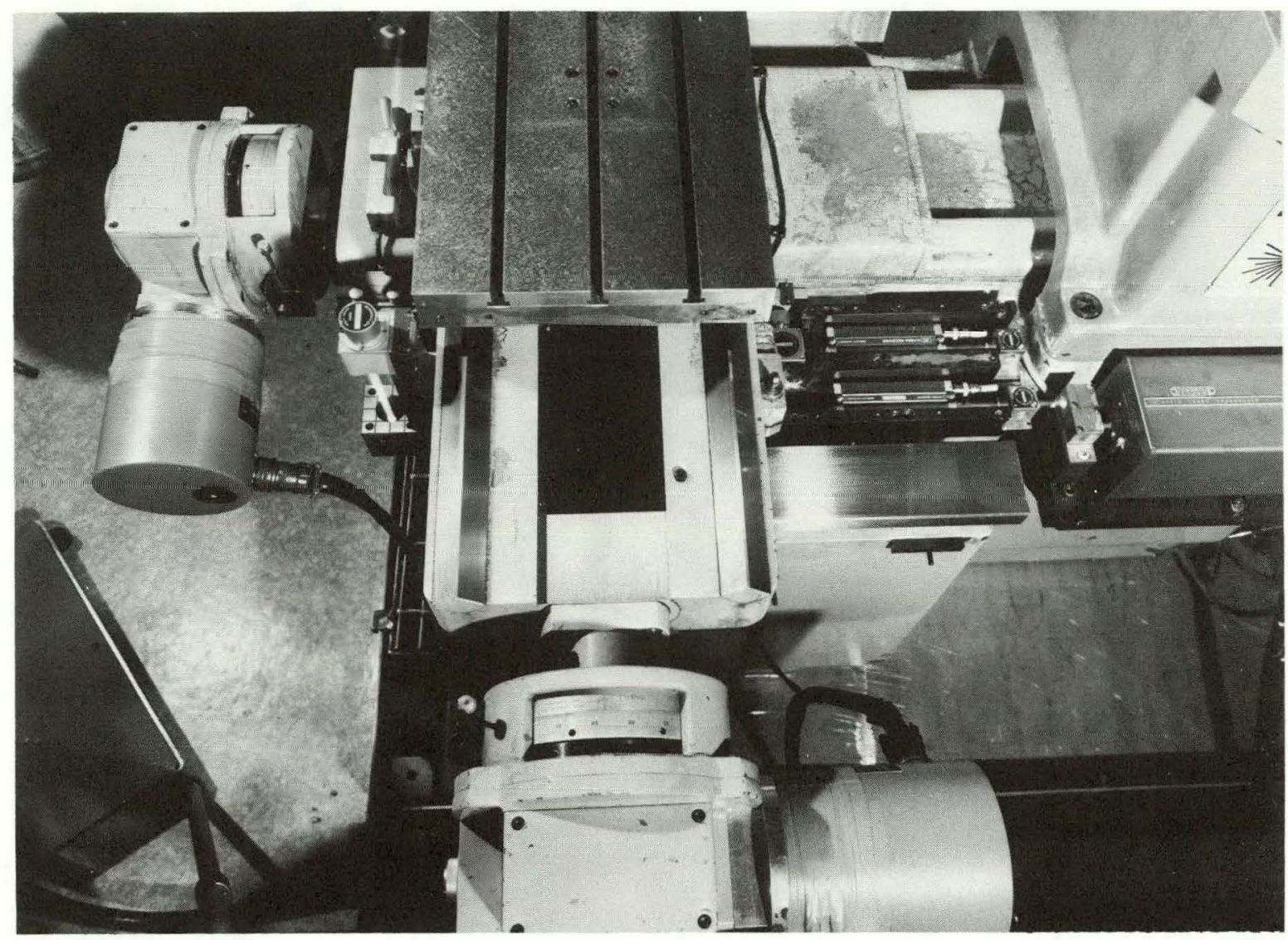

Figure 8. LASER SYSTEM THAT IS MOUNTED ON THE MACHINE.

176762

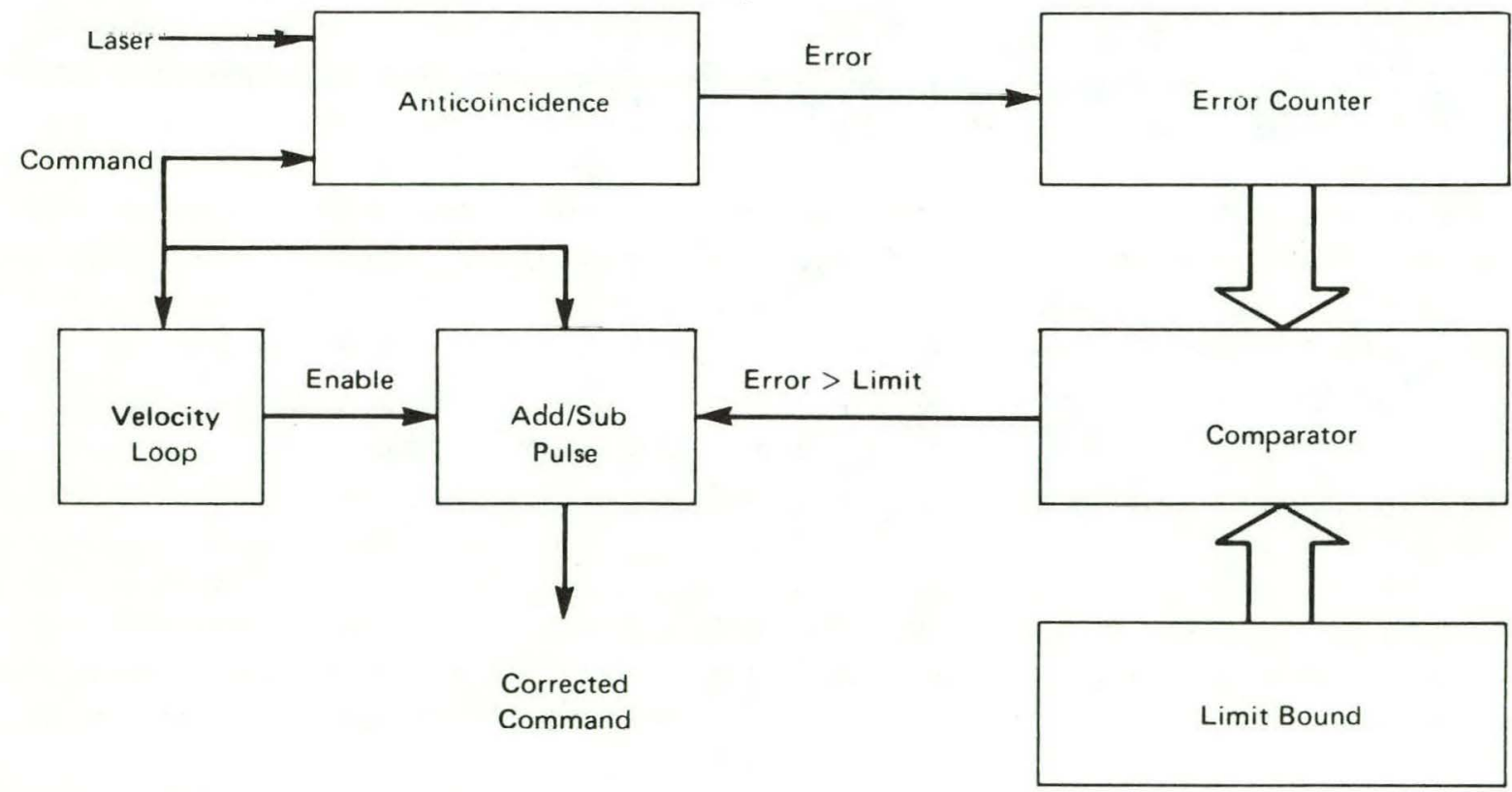

Figure 9. ERROR-CORRECTION CIRCUITRY. 
selecting the program storage mode, dialing in the part number, then pushing the "start". button. The tape will be read in and stored in a file on Disk 1. The file will be called "PADS. $x x x$," where $x x x$ is the part number. If an editing of the part description is required, the "feed-hold" button must be pushed after the "start" button. This action will cause the program to exit to the system monitor where the editor can be used to modify the part description. The program can then be reentered. The "start" light will stay on until the program storage is complete. The stored part description can then be accessed by the program search mode. The part number should be entered, then the "start" button pushed. The "start" light will stay on until the search is complete.

Oncc the part deecription has been Inaded, the operator can do a sequence search at any time by entering the sequence search mode, entering the desired sequence number, and pushing the "start" button. The "start" light will stay on until the search is complete.

When in the manual mode, the operator has complete control of the machine. The "manual-feed" switch is used to select either a distance movement or a rapid feed speed. Then, by pressing the appropriate "jog" button, any axis can be moved in either direction. If a distance movement is selected, a momentary pressing of the appropriate "jog" button is sufficient; but, if a rapid feed is selected, the appropriate axis will continue moving only as long as the "jog" button is pressed. The appropriate "jog" light will stay on as long as that axis is in motion.

The single-block and automatic modes are very similar. The only difference is that when in the single-block mode, the system halts after each block is executed and waits for a "cycle start" to continue. When the system is in the automatic mode, the part description, loaded with a program search, is in control of the machine. When the "cycle-start" button is pressed, the controller will begin executing the part description data from the point selected by the sequence search, or if the "clear" button was pressed from the first block. The "cycle-start" light will stay on as long as the machine is in the "run" state. A "feed hold" can be used to stop the machine after the present block is finished being executed, after which a "cycle start" will continue on from that point. The "stop" button will cause the machine to stop immediately and reset the part description to the first block.

\section{RESULTS}

Several test parts (133-cm spherical radius on a $30-\mathrm{cm}$-diameter aluminum disc) were cut to a tolerance of $10 \mu \mathrm{in}$. A complete set of positioning tests were also run successfully. The results are given in Appendix $A$. The system performed as designed. During these tests it was found that precautions must be taken to ensure that the laser equipment has come to thermal equilibrium with the machine tool before beginning operation. This adjustment can be accomplished by keeping power on the laser system continuously during its day-to-day operation.

An outline of the operating procedure is included in this report (Appendix $B$ ); requirements for the standard RS-274-B NC tape are listed (Appendix C); a listing of the device register 
assignments is provided (Appendix D); a printout of the software listings is available (Appendix E); as well as drawings of all hardware items (Appendix F).

\section{CONCLUSIONS AND RECOMMENDATIONS}

This control unit has proven that an open-loop, stepping-motor-like drive coupled with a laser interferometer offers a good method of control for a precision machine tool. Because the machine operators were involved in the layout of the operator's controls, this control unit has been extremely well received and easily used by machine-shop personnel.

Due to the versatility of this control unit, two additional units are being assembled for the production facility. Using the minicomputer as the system controller also permits certain adaptive control features or gaging features to be incorporated into the system in the future. To this end, a study is now in progress to determine the feasibility of using this control system on an ultraprecision inspection machine. 


\section{REFERENCES}

1. Burleson, R. R.; A Minicomputer Control System for An Ultraprecision Turning Machine, Y-1951: Union Carbide Corporation-Nuclear Division, Oak Ridge Y-12 Plant, Oak Ridge, Tennessee; November 11, 1974.

2. Bowers, G. L.; Machine Tool Control Via a Minicomputer, Y-1870; Union Carbide Corporation-Nuclear Division, Oak Ridge Y-12 Plant, Oak Ridge, Tennessee; April 18. 1973. 


\section{ACKNOWLEDGEMENTS}

The author wishes to thank the following $Y-12$ personnel for their significant contributions: G. L. Bowers of the Instrumentation and Characterization Department, Y-12 Development Division and C. M. Lay of the $Y-12$ Fabrication Division for the basic hardware DDA; J. Blackerby of the Numerical Control Engineering Department for the APT-generated part description tapes; J. B. Arnold, P. J. Steger, and R. R. Williams of the Fabrication Systems Development Department for their involvement in the mechanical phase of the project and also for their help in evaluating the machining system, and R. P. Dickert of Fabrication

Systems Development Department for his assistance in installing and debugging the control system. 
APPENDIX A

SYSTEM EVALUATION 
THIS PAGE.

WAS INTENTIONALLY

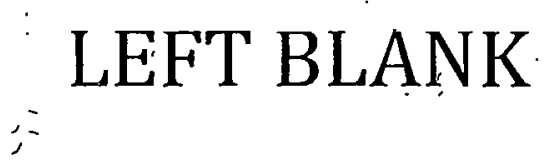


A series of positioning checks were run on the machine, utilizing the dynamic-error monitor system. This system compares the commanded position of the machine with the actual position of the machine as measured by a test laser interferometer. Two tests were run on the machine.

\section{Test 1}

Test laser was mounted at the same height as the positioning laser to determine the accuracy of the positioning system. A view of the test setup that was used is provided in Figure A-1; the results are seen in Figure $\mathrm{A}-2$.

\section{Test 2}

Test laser was mounted at the tool height to determine the viability of the machine and control system. The test setup used is shown in Figure A-3; the results are reported in Figure A-4.

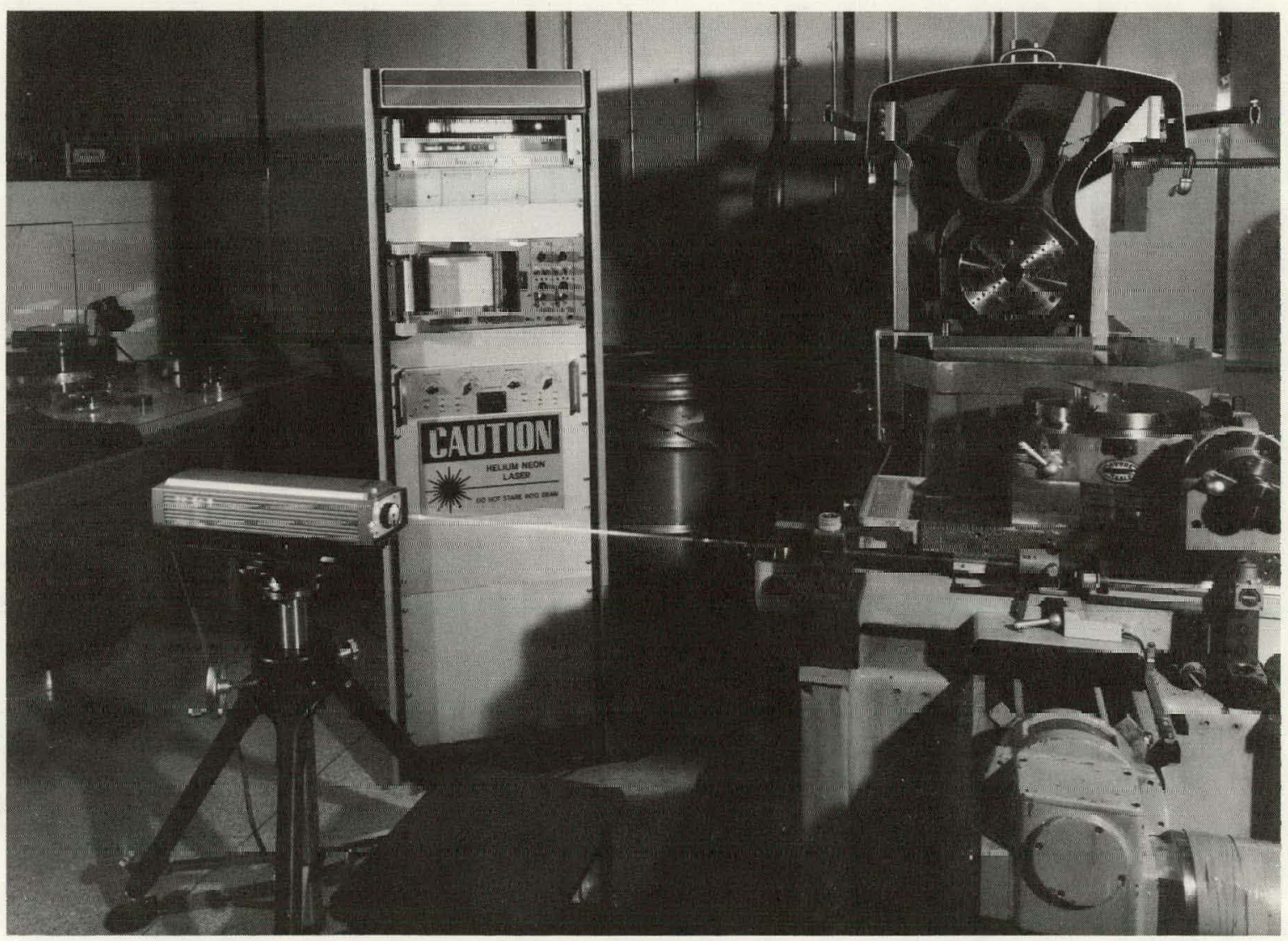

176764

Figure A-1. TEST ARRANGEMENT FOR MEASUREMENTS MADE AT THE POSITIONING LASER HEIGHT. 


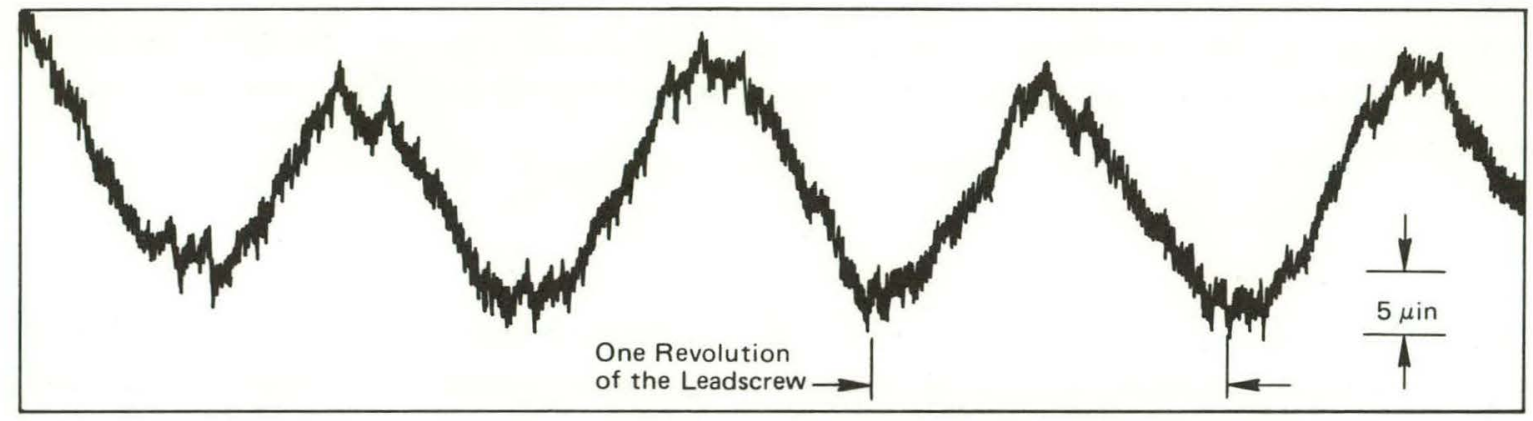

(a) No Correction.

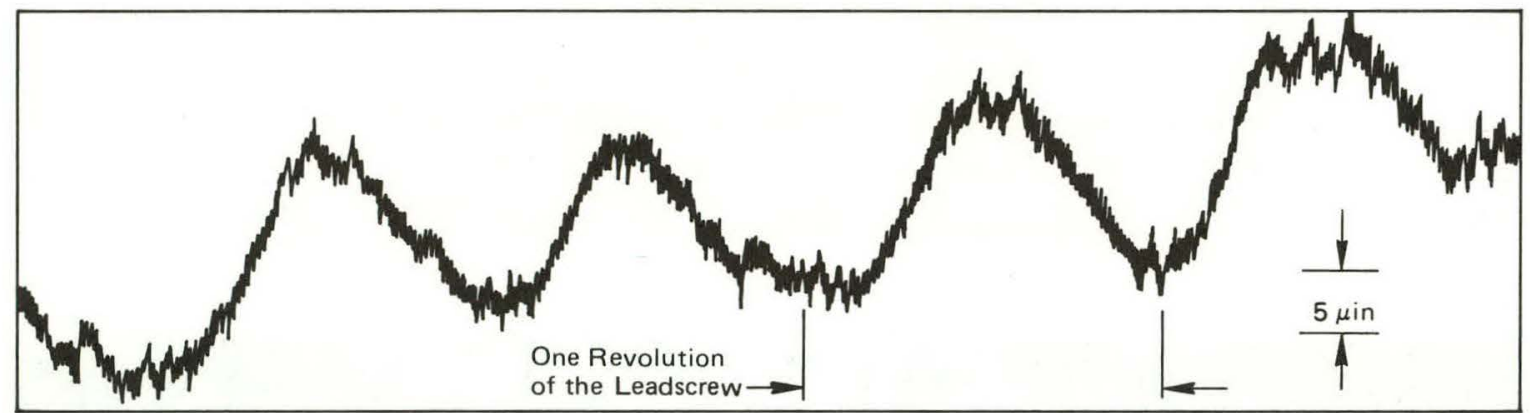

(b) $A \pm 10-\mu$ in Error Bound.

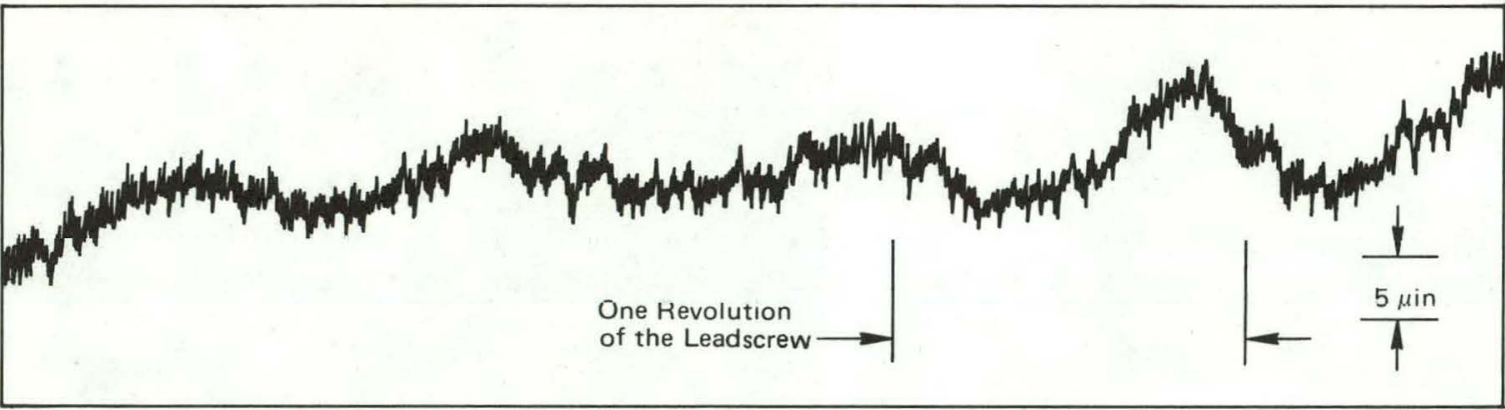

(c) A \pm 4- $\mu$ in Error Bound.

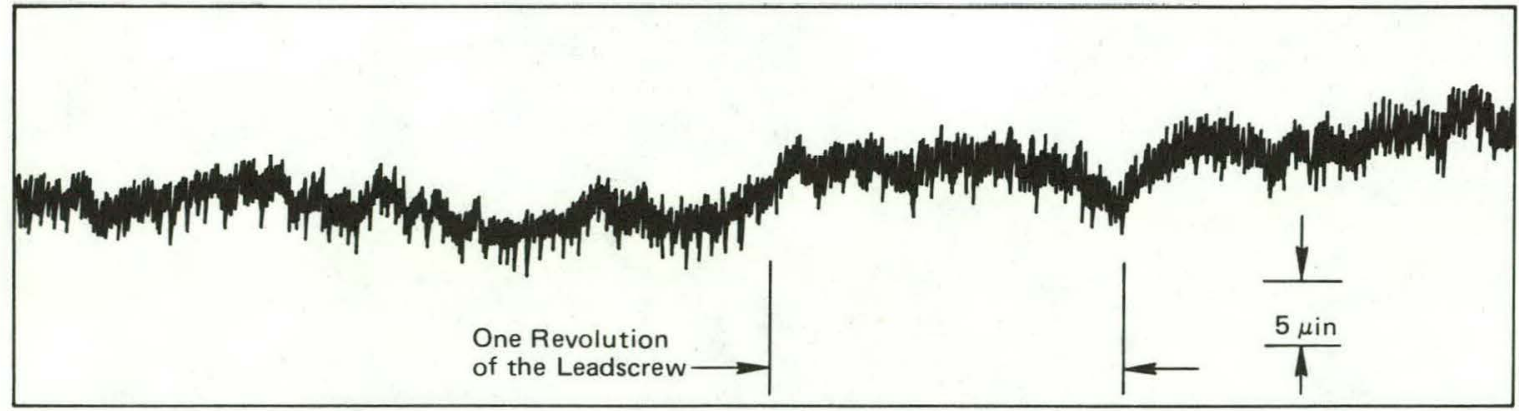

(d) $\mathrm{A} \pm 1-\mu$ in Error Bound.

Figure A-2. DYNAMIC-ERROR-MONITOR PLOT OF THE POSITIONING ERROR AT THE POSITIONING LASER HEIGHT, MOVING AT 0.2 ipm. 


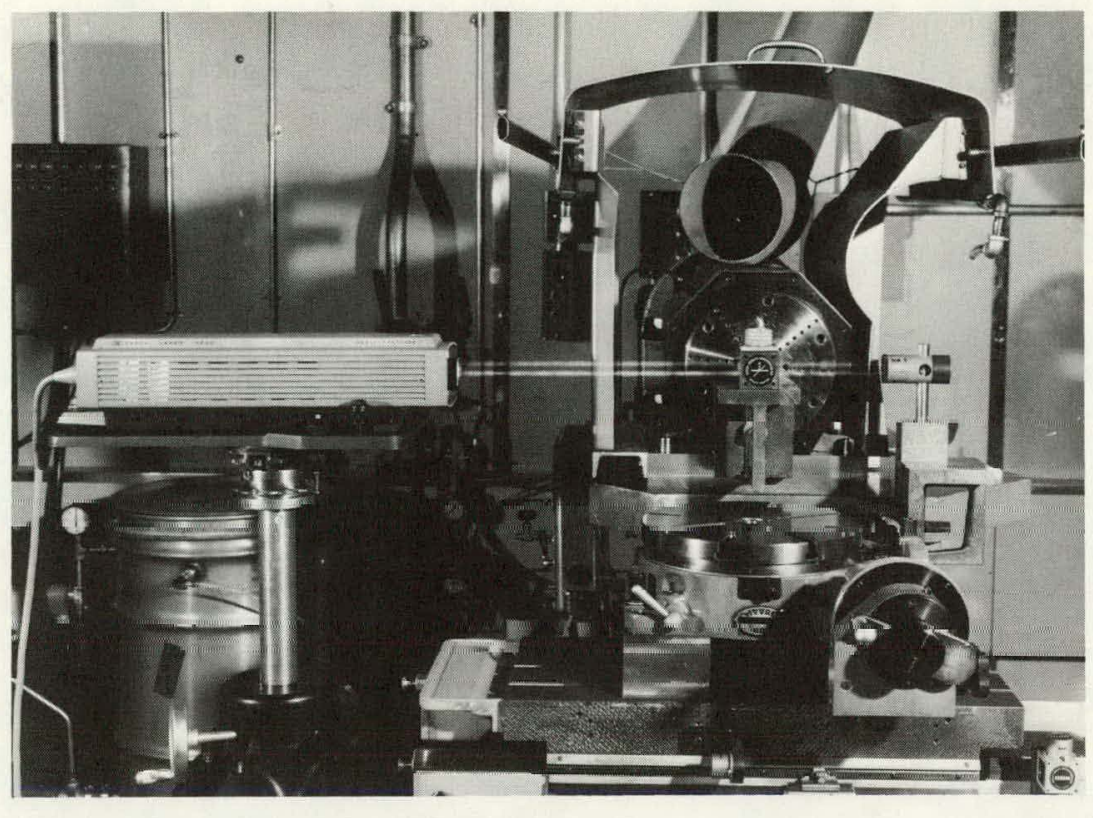

176759

Figure A-3. TEST ARRANGEMENT FOR MEASUREMENTS MADE AT THE TOOL HEIGHT.

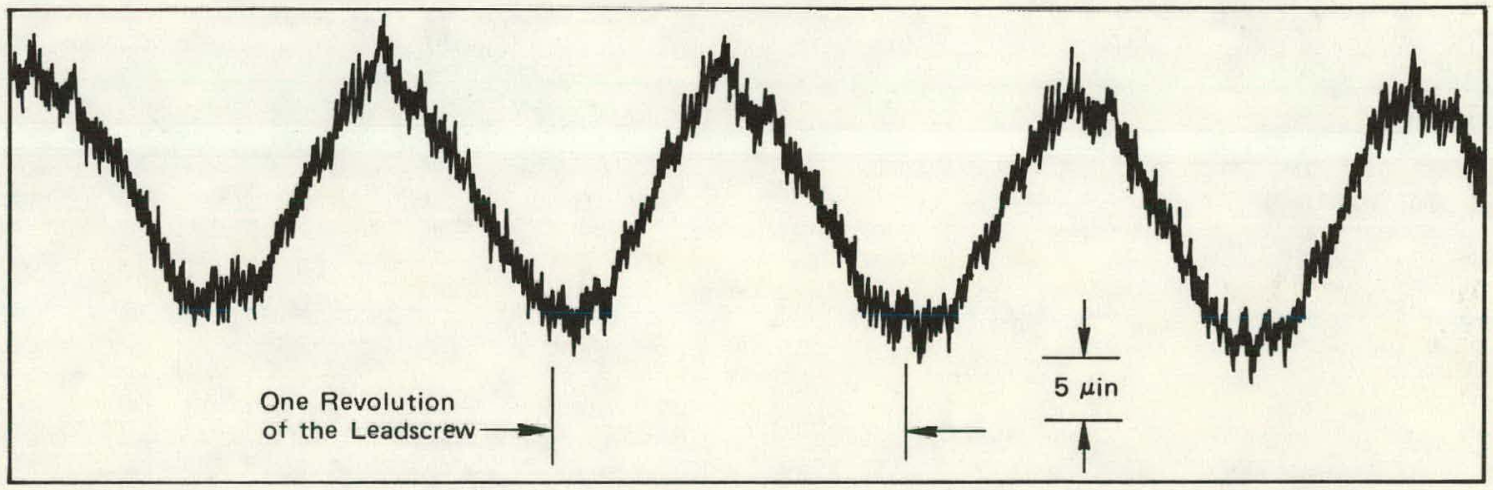

(a) No Correction.

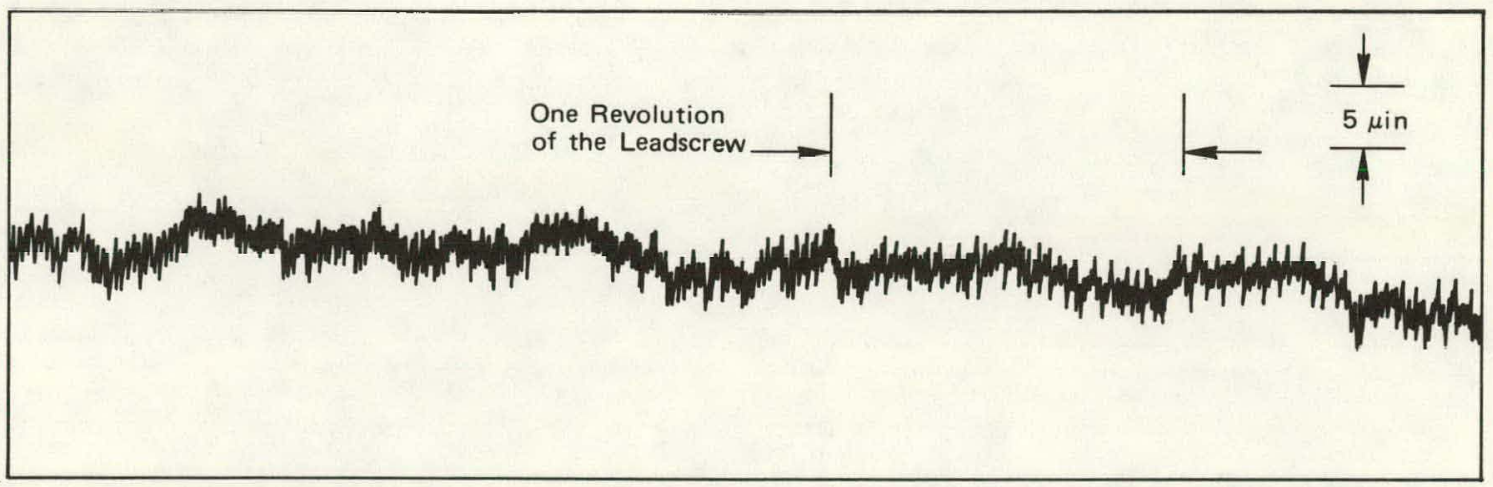

(b) $\mathrm{A} \pm 1-\mu$ in Error Bound.

Fiqure A-4. DYNAMIC-ERROR-MONITOR PLOT OF THE POSITIONING ERROR AT THE TOOL HEIGHT, MOVING AT $0.2 \mathrm{ipm}$. 
The charts obtained are a plot of positioning error versus position. A graph of the error bound (ie, the error allowed before the system would attempt correcting) versus the positioning error is given in Figure A-5.

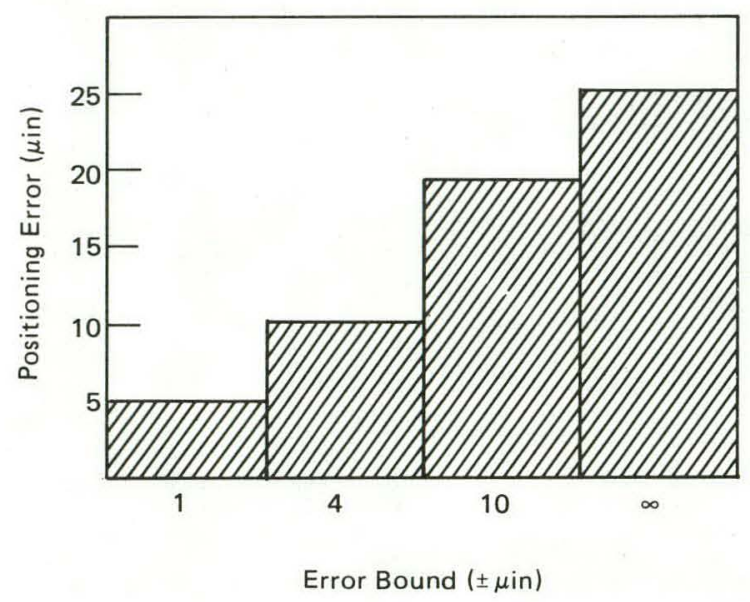

Figure A-5. SUMMARY OF THE POSITIONINGERROR TESTS. 
APPENDIX B

OPERATING PROCEDURE 


\section{THIS PAGE , \\ WAS INTENTIONALLY \\ LEFT BLANK \\ $\therefore$}

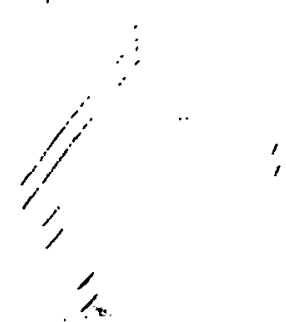

\&

。 


\section{Introduction}

Basic information required to operate this control system is described in the sections to follow. The last two sections contain information that the advanced user may need but is not required for operation of this system. This Appendix should be read only after a thorough understanding of the pedestal controls and status displays has been obtained, since these functions are discussed here.

\section{Rapid Feed Movement}

1. Place the "mode" switch in the "manual" position.

2. Select the desired feedrate from the right side of the "manual feed" switch.

3. Push the appropriate "jog" button.

4. The machine will rapid feed as long as the "jog" button is pushed.

\section{Incremental Movement}

1. Place the "mode" switch in the "manual" position.

2. Select the increment desired from the left side of the "manual feed" switch.

3. Push the appropriate "jog" button.

4. The machine will now increment the selected distance.

\section{Storing Part Programs}

1. Place the "mode" switch in the "program storage" position.

2. Enter the last three digits of the parl lape number into the thumbwheel switches.

3. Load the part tape into the tape reader, sprocket out.

4. Turn the tape reader on.

5. Push the "start" button.

6. When the tape reader stops moving, remove the par' l läpe.

7. The "start" light will go out when the storage is complete.

8. Should the "read error" or "write error" light come on, an error was found in the part tape. 


\section{Retrieving Part Programs}

1. Place the "mode" switch in the "program search" position.

2. Enter the last three digits of the part tape number into the thumbwheel switches.

3. Push the "start" button.

4. Should the "search error" light come on, that part program is not in storage.

\section{Sequence Searching Part Programs}

1. Program should have been previously retrieved.

2. Place the "mode" switch in the "seq. no. search" position.

3. Enter the sequence number into the thumbwheel switches.

4. Push the "start" button.

5. Should the "search error" light come on; that sequence number does not exist.

\section{Running a Part Program}

1. Program should have been previously retrieved.

2. Place the "mode" switch in the "automatic" position.

3. Push the "clear" button.

4. Push the "cycle start" button.

5. The part program will now begin execution.

\section{Entering Laser Compensation}

1. Push the "retune" button.

2. Follow the information displayed on the terminal.

\section{Listing Part Tapes}

1. Type on the terminal twice:

(CTRL) C 
2. A period will appear on the terminal.

3. To enter the date, type on the terminal:

. DATE DD-MMM-YY (RETURN);

where DD is the day, MMM is the month, and $Y Y$ is the year.

4. Type on the terminal:

$$
\text { . R PIP (RETURN) }
$$

5. An asterisk will apnear on the terminal.

6. To list the part tapes, type on the terminal:

${ }^{*} \mathrm{D} \times 1: / L$ (RETURN)

7. To delete a part tape, type on the terminal:

*DX1:PADS.NNN/D (RETURN) *DX1:/S (RETURN);

where NNN is the part tape number.

8. To list the mylar tape just stored, type on the terminal:

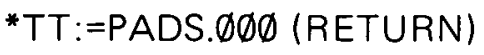

9. To return to the machining program, type on the terminal:

(CTRL) C

10. A period will appear on the terminal.

11. Type on the terminal:

.R MACHG (RETURN)

Initial Startup

1. Turn on control system power.

2. Place disk labeled "16K system" into the left disk drive.

3. Place disk labeled "machining programs" into the right disk drive.

4. Set computer switch register to 1111011100000000. 
5. Lower, then raise the computer "halt" switch.

6. Push the computer "load adrs" switch.

7. Push the computer "start" switch.

8. The terminal will display: RT-11SJ Vø2C- $\emptyset 2$.

9. Type on the terminal: .R MACHG (RETURN).

10. Turn on the motor power. 
APPENDIX C

REQUIREMENT FOR STANDARD RS-274-B NC TAPE 


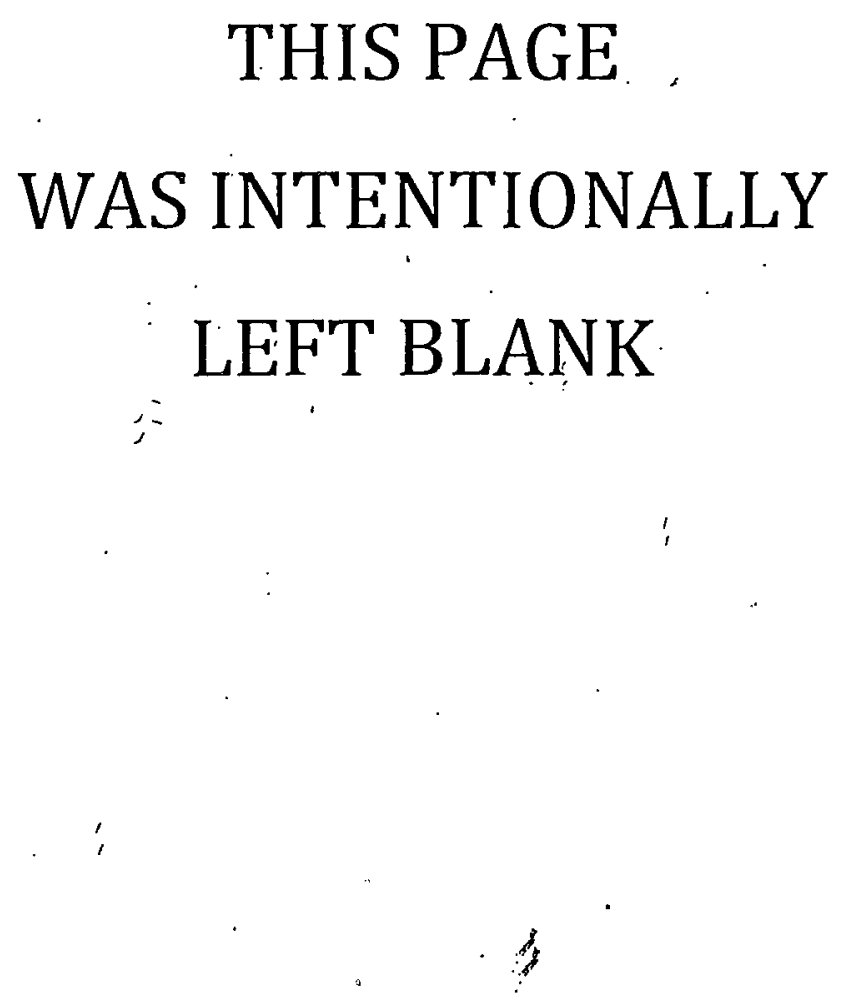


Position: $\quad x$ and $y$ resolution (point to point) $=1.25 \mu \mathrm{in}$.

$x$ and $y$ resolution (contour) $=0.25 \mu$ in

c resolution (point to point) $=2 \mu^{\circ}$

C resolution (contour) $=2 \mu^{0}$

Present data incrementally drop leading zeros.

$x$ maximum travel $=18$ in

$\mathrm{y}$ maximum travel $=11$ in

c maximum travel $=360^{\circ}$

Feedrate $=$ Present data in inverse time $F=1 / T$ (minutes)

$F$ format shall always be 6.4

$\mathrm{T}$ maximum $=5 \mathrm{~min}$

$\mathrm{T}$ minimum $=5 \mathrm{msec}$

$5>$ ipm (point to point) $>0.001$

$1>\mathrm{ipm}$ (contour) $>0.001$

Maximum change in ipm per data block is ipm $=0.1$; and, in addition, this change must be followed by $10 \mathrm{msec}$ of constant ipm.

G Codes: $G \emptyset \emptyset$ Point to Point

Gø1 Linear Interpolation

M Codes: $M \emptyset \emptyset$ Program Stop

Mø1 Optional Stop

Mø2 Program End

M3Ø Tape End

N Codes: The block sequence number address " $n$ " followed by three digits shall be the first word in a block. 


\section{THIS PAGE , \\ WAS INTENTIONALLY \\ LEFT BLANK \\ ;}

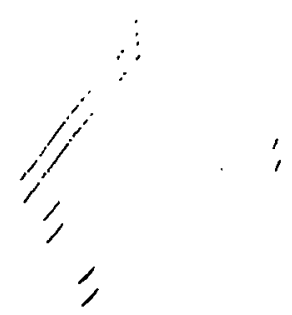

3 
APPENDIX D

DEVICE REGISTER ASSIGNMENTS 


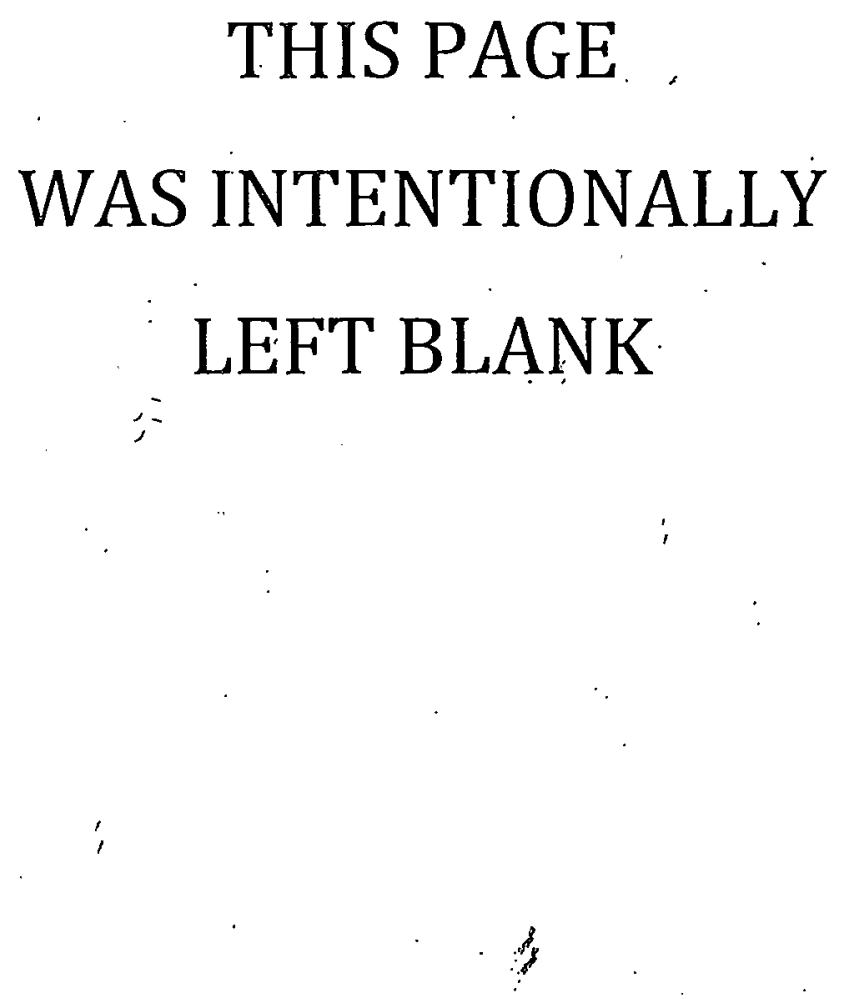

THIS PAGE ,

WAS INTENTIONALLY

LEFT BLANK

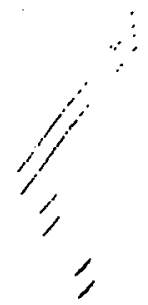

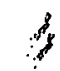

o 
Device Register - Manual [(164000) input of manual increment and rapid feed from control panel]

\begin{tabular}{lll} 
Bit & Mnemonic & \multicolumn{1}{c}{ Description } \\
00 & MI 1 & Manual increment of $0.001 \mathrm{mil}$ \\
01 & MI 2 & Manual increment of $0.010 \mathrm{mil}$ \\
02 & MI 3 & Manual increment of $0.1 \mathrm{mil}$ \\
03 & MI 4 & Manual increment of $0.5 \mathrm{mil}$ \\
04 & MI 5 & Manual increment of $1.0 \mathrm{mil}$ \\
05 & MI 6 & Manual increment of $10.0 \mathrm{mils}$ \\
06 & MI 7 & Manual increment of $100.0 \mathrm{mils}$ \\
07 & STOP & Stop all movement \\
08 & RF 1 & Rapid feed at $0.001 \mathrm{ipm}$ \\
09 & RF 2 & Rapid feed at $0.01 \mathrm{ipm}$ \\
10 & RF 3 & Rapid feed at $0.1 \mathrm{ipm}$ \\
11 & RF 4 & Rapid feed at $0.5 \mathrm{ipm}$ \\
12 & RF 5 & Rapid feed at $1.0 \mathrm{ipm}$ \\
13 & RF 6 & Rapid feed at $2.0 \mathrm{ipm}$ \\
14 & RF 7 & Rapid feed at $5.0 \mathrm{ipm}$ \\
15 & IN & Set to inches mode
\end{tabular}

Device Register - Mode [(164002) input of switches from control panel]

Bit Mnemonic

$\begin{array}{lll}00 & X I & \text { Run or increment } x \text { axis left } \\ 01 & \text { XR } & \text { Run or increment } x \text { axis right } \\ 02 & \text { YI } & \text { Run or increment } y \text { axis in } \\ 03 & \text { YO } & \text { Run or increment } y \text { axis out } \\ 04 & \text { CC } & \text { Run or increment } c \text { axis CCW } \\ 05 & \text { CW } & \text { Run or increment } c \text { axis CW } \\ 06 & \text { PS } & \text { Program storage mode } \\ 07 & \text { SNS } & \text { Sequence number search mode } \\ 08 & \text { M } & \text { Manual mode } \\ 09 & \text { SB } & \text { Single block mode } \\ 10 & \text { A } & \text { Automatic mode } \\ 11 & \text { FO } & \text { Laser feedback on } \\ 12 & \text { LE } & \text { Limit error } \\ 13 & \text { IF } & \text { Interpolation fault } . \\ 14 & \text { PF } & \text { Program search mode } \\ 15 & \text { ID } & \text { Interpolation done }\end{array}$


Device Register - Seq. No. [(164004) input sequence number]

\begin{tabular}{lll} 
Bit & Mnemonic & \multicolumn{1}{c}{ Description } \\
& & \\
00 & SN 11 & Sequence number digit 1, bit 1 \\
01 & SN 12 & Sequence number digit 1, bit 2 \\
02 & SN 14 & Sequence number digit 1, bit 4 \\
03 & SN 18 & Sequence number digit 1, bit 8 \\
04 & SN 21 & Sequence number digit 2, bit 1 \\
05 & SN 22 & Sequence number digit 2, bit 2 \\
06 & SN 24 & Sequence number digit 2, bit 4 \\
07 & SN 28 & Sequence number digit 2, bit 8 \\
08 & SN 31 & Sequence number digit 3, bit 1 \\
09 & SN 32 & Sequence number digit 3, bit 2 \\
10 & SN 34 & Sequence number digit 3, bit 4 \\
11 & SN 38 & Sequence number digit 3, bit 8 \\
12 & & \\
13 & & \\
14 & & \\
15 & &
\end{tabular}

Device Register - Feed [(164006) input of feedrate override switch]

\begin{tabular}{lll} 
Bit & Mnemonic & \multicolumn{1}{c}{ Description } \\
00 & $F \emptyset 1$ & Feedrate override at $10 \%$ \\
01 & $F \emptyset 2$ & Feedrate override at $20 \%$ \\
02 & $F \emptyset 3$ & Feedrate override at $30 \%$ \\
03 & $F \emptyset 4$ & Feedrate override at $40 \%$ \\
04 & $F \emptyset 5$ & Feedrate override at $50 \%$ \\
05 & $F \emptyset 6$ & Feedrate override at $60 \%$ \\
06 & $F \emptyset 7$ & Feedrate override at $70 \%$ \\
07 & $F \emptyset 8$ & Feedrate override at $80 \%$ \\
08 & $F \emptyset 9$ & Feedrate override at $90 \%$ \\
09 & $F 1 \emptyset$ & Feedrate override at $100 \%$ \\
10 & $F 11$ & Stop \\
11 & OSO & Optional stop on \\
12 & & \\
13 & & \\
14 & & \\
15 & &
\end{tabular}


Device Register - Laser [(164010) input laser status]

\begin{tabular}{lll} 
Bit & Mnemonic & \multicolumn{1}{c}{ Description } \\
00 & RF & Retune failure \\
01 & RS & Retune status \\
02 & LCS & Laser current status \\
03 & HE & Laser head error \\
04 & ROK & Reference OK \\
05 & XE & x pulso converter error \\
06 & YE & y pulse converter error \\
07 & & \\
08 & & \\
09 & & \\
10 & & \\
11 & & \\
12 & & \\
13 & & \\
14 & & \\
15 & &
\end{tabular}

Device Register - LMT [(164012) input limit switches and motor drive status]

\begin{tabular}{lll} 
Bit & Mnemonic & \multicolumn{1}{c}{ Description } \\
& & \\
00 & XRL & x axis right limit \\
01 & XLL & x axis left limit \\
02 & XHL & x axis home limit \\
03 & $X B$ & x axis busy limit \\
04 & XH & x axis home limit \\
05 & YIL & y axis in limit \\
06 & YOL & y axis out limit \\
07 & YHL & y axis home limit \\
08 & YB & y axis busy limit \\
09 & YH & y axis home limit \\
10 & $\mathrm{CCL}$ & c axis CCW limit \\
11 & $\mathrm{CCWL}$ & c axis CW limit \\
12 & $\mathrm{CHL}$ & $\mathrm{c}$ axis home.limit \\
13 & $\mathrm{CB}$ & $\mathrm{c}$ axis busy limit \\
14 & $\mathrm{CH}$ & $\mathrm{c}$ axis home limit \\
15 & &
\end{tabular}


Device Register - Status [(164014) input automatic controls]

\begin{tabular}{lll} 
Bit & Mnemonic & \multicolumn{1}{c}{ Description } \\
& & \\
00 & SCH & Start search \\
01 & CSTART & Cycle start \\
02 & FH & Feed hold \\
03 & CLEAR & Clear \\
04 & STP & Stop \\
05 & RST & Laser restart \\
06 & RTU & Laser retune \\
07 & XDR & x display reset \\
08 & YDR & y display reset \\
09 & CDR & C display reset \\
10 & ID & Interpolation done \\
11 & & \\
12 & & \\
13 & & \\
14 & & \\
15 & &
\end{tabular}

Device Register - Lights [(164040) output to status lights]

\begin{tabular}{lll} 
Bit & Mnemonic & \multicolumn{1}{c}{ Description. } \\
00 & PRE & Program end \\
01 & PST & Program stop \\
02 & OS & Optional stop \\
03 & End of block \\
04 & HD & Holding \\
05 & RN & Running \\
06 & LE & Limit error \\
07 & ITF & Interpolation fault \\
08 & WE & Write error \\
09 & RE & Read error \\
10 & SE & Search error \\
11 & LSE & Laser error \\
12 & RTS & Retune status \\
13 & RTE & Retune error \\
14 & PE & Pulse error \\
15 & &
\end{tabular}


Device Register - Control [(164042) output of control parameters]

\begin{tabular}{lll} 
Bit & Mnemonic & \multicolumn{1}{c}{ Description } \\
00 & FL & First load to DDA \\
01 & CL & Clear all \\
02 & RG & Reset "start" button \\
03 & RC & Reset "clear" button \\
04 & RH & Reset "hold" button \\
05 & RN & Reset "stop" button \\
06 & RS & Reset "search" button \\
07 & RR & Retune laser \\
08 & RP & Restart laser converters \\
09 & IC & Interrupt control \\
10 & & \\
11 & & \\
12 & & \\
13 & & \\
14 & & \\
15 & &
\end{tabular}

Device Register - DSEQNO [(164044) output of sequence number]

Bit Mnemonic Description

00 SN 11 Sequence number digit 1, bit 1

01 SN 12 Sequence number digit 1, bit 2

02 SN 14 Sequence number digit 1, bit 4

03 SN 18 Scquenco number digit 1, bit 8

04 SN 21 Sequence number digit 2, bit 1

05 SN 22 Sequence number digit 2, bit 2

06 SN 24 Sequence number digit 2, bit 4

07 SN 28 Secfuence number digit 2, bit 8

08 SN 31 Sequence number digit 3, bit 1

09 SN 32 Sequence number digit 3 , bit 2

10 SN 34 Sequence number digit 3, bit 4

11 SN 38 Sequence number digit 3, bit 8

12

13

14

15 
Device Register - Display [(164046) output of lights to control panel]

\begin{tabular}{lll} 
Bit & Mnemonic & \multicolumn{1}{c}{. Description } \\
00 & LXL & Light $\times$ left \\
01 & LXR & Light $\times$ right \\
01 & LYI & Light $y$ in \\
02 & LYO & Light $y$ out \\
03 & Light $\mathrm{CCW}$ \\
04 & LCC & Light $\mathrm{CW}$ \\
05 & LCW & Light cycle start \\
06 & LCSTART & Light feed hold \\
07 & LFH & Light clear \\
08 & LCLEAR & Light stop \\
09 & LSTP & Light start search \\
10 & LSCH & \\
11 & & \\
12 & & \\
13 & & \\
14 & & \\
15 & &
\end{tabular}

Device Registers [(164050) - (164064)]

Device Register - IT

(164050) Output of interval timer

Device Register - XLDDA

(164052) Output of least significant 16 bits of $x$ distance

Device Register - XMDDA

(164054) Output of most significant 16 bits of $x$ distance

Device Register - YLDDA

(164056) Output of least significant 16 bits of $y$ distance

Device Register - YMDDA

(164060) Output of most significant 16 bits of y distance

Device Register - CLDDA

(164062) Output of least significant 16 bits of c distance

Device Register - CMDDA

(164064) Output of most significant 16 bits of $c$ distance 
Device Register - Feedback [(164066) output of feedback control parameters]

\begin{tabular}{lll} 
Bit & Mnemonic & \multicolumn{1}{c}{ Description } \\
& & \\
00 & & \\
01 & LF & Laser feedback on \\
02 & SX & x axis sign \\
03 & SY & y axis sign \\
04 & SC & c axis sign \\
05 & CC & Clock control \\
06 & IC & Interrupt control \\
07 & XER & x axis extended resolution \\
08 & SRH & x axis return home \\
09 & YER & y axis extended resolution \\
10 & YRH & y axis return home \\
11 & CER & c axis extended resolution \\
12 & CRX & c axis return home \\
13 & & \\
14 & & \\
15 & &
\end{tabular}

Device Registers [(164100) - (164112)]

Device Register - LPX

(164100) Input least significant 4 digits of $x$ position

Device Register - IPX

(164102) Input next significant 4 digits of $x$ position

Device Register - MPX

(164104) Input most significant digit and sign of $x$ position

Device Register - LPY

(164106) Input least significant 4 digits of y position

Device Register - IPY

(164110) Input next significant 4 digits of $y$ position

Device Register - MPY

(164112) Input most significant digit and sign of $y$ position 
Device Registers [(164114) - (164146)]

Device Register - LPC

(164114) Input least significant 4 digits of c position

Device Register - IPC

(164116) Input next significant 4 digits of $c$ position

Device Register - MPC

(164120) Input most significant digit and sign of $c$ position

Device Register - XEROR

(164140) Output error bound to $x$ axis

Device Register - YEROR

(164142) Output error bound to $y$ axis

Device Register - LFNO

(164144) Output least significant 4 digits of $\lambda$

Device Register - HFNO

(164146) Output most significant 4 digits of $\lambda$ 
APPENDIXE

SOFTWARE LISTINGS 


\section{THIS PAGE , \\ WAS INTENTIONALLY \\ LEFT BLANK \\ $\therefore$}

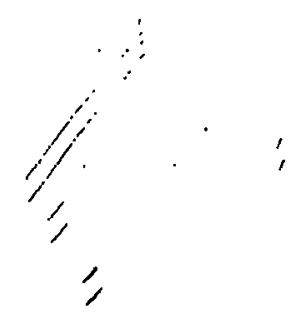

. 
-GLUEL IKAUSO,CUMP,FSTART,FDATA, \$UTI, SUSRSW, SNLCHN, SLRECL

.MCALL ..VZ.... . REGUEF,..ENTER, .WRITW,.CLOSE, .EXIT, .FETCH;.LOCK

.MCALL .LUOKUP,.OSET,.READN,.READC,.PHOTECT,. INTEN, .SYNCH

. VVZ..

- REGUEF

SUSRSW $=1$

SNLCHN $=6$

\$LKECL $=210$

$P S=177776$

MOU $=177777$

$M O 1=177776$

$M \cup 2=177775$

$M 30=36$.

$600=17777 \%$

GU1 $=177776$

LAS $=174000$

$\forall X S=100000$

$\forall Y S=40000$

$B C S=20000$

PKE $=177776$

PST $=177775$

US $=177773$

$E B=177767$

$H U=177757$

$R N=177737$

LME $=177677$

II $F=171571$

WE $=177377$

$K E=176777$

$S E=175777$

LSE $=4000$

KI $S=10000$

RIE $=20000$

PLE $=40000$

$F L=1001$

$C L=2$

$H G=4$

$K C=10$

$K H=20$

$\mathrm{HNU}=40$

$K S C=100$

$R K=200$

RF $=400$

INTKC $=1000$

$\operatorname{Siv} 11=1$

SN1 $2=2$

$S N 14=4$

SN $18=10$

SN21 $=20$

SN22 $=40$

$\sin 24=100$

Siv $28=200$

$\sin 31=460$

$\sin 32=1000$

$\sin 34=2000$

$\sin 38=4060$

$E K=1200$

$L F=2$

$S \lambda=4$

$S Y=10$

$S C=20$

$C C T=40$

$I C=100$

$M I 1=1$ 


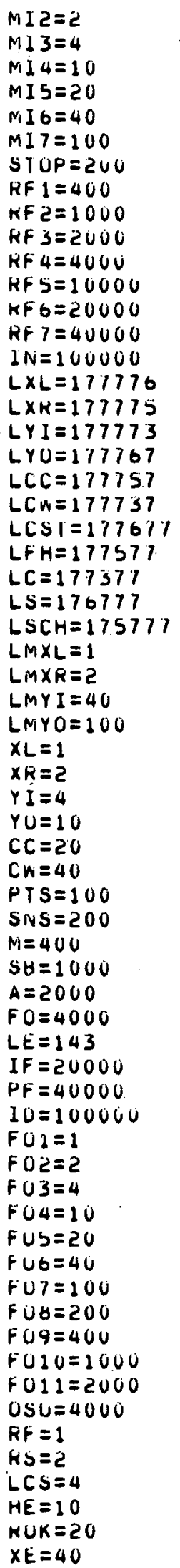




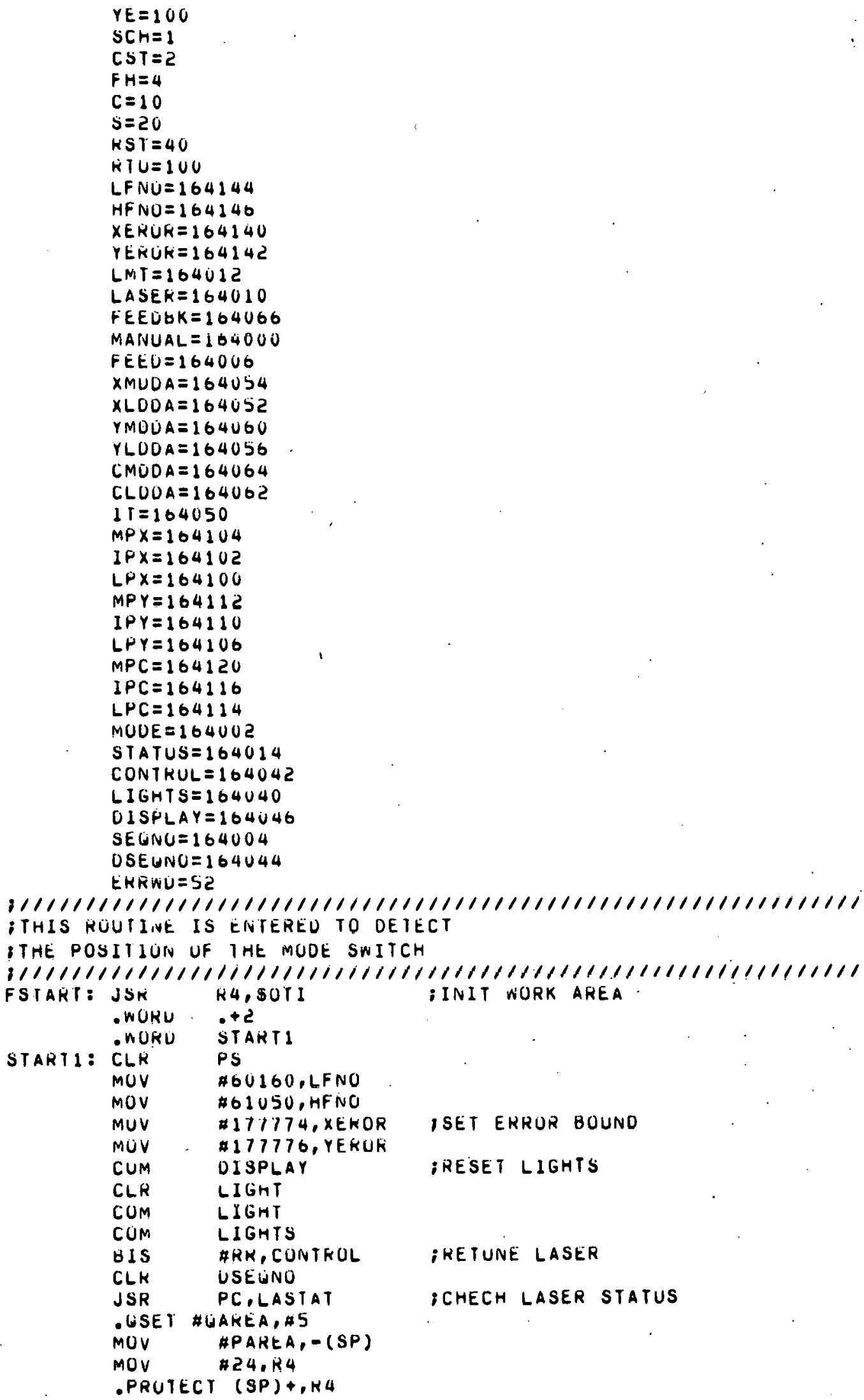

ISET ERRUR BOUNO

:RESET LIGHTS

ICHECH LASER STATUS 


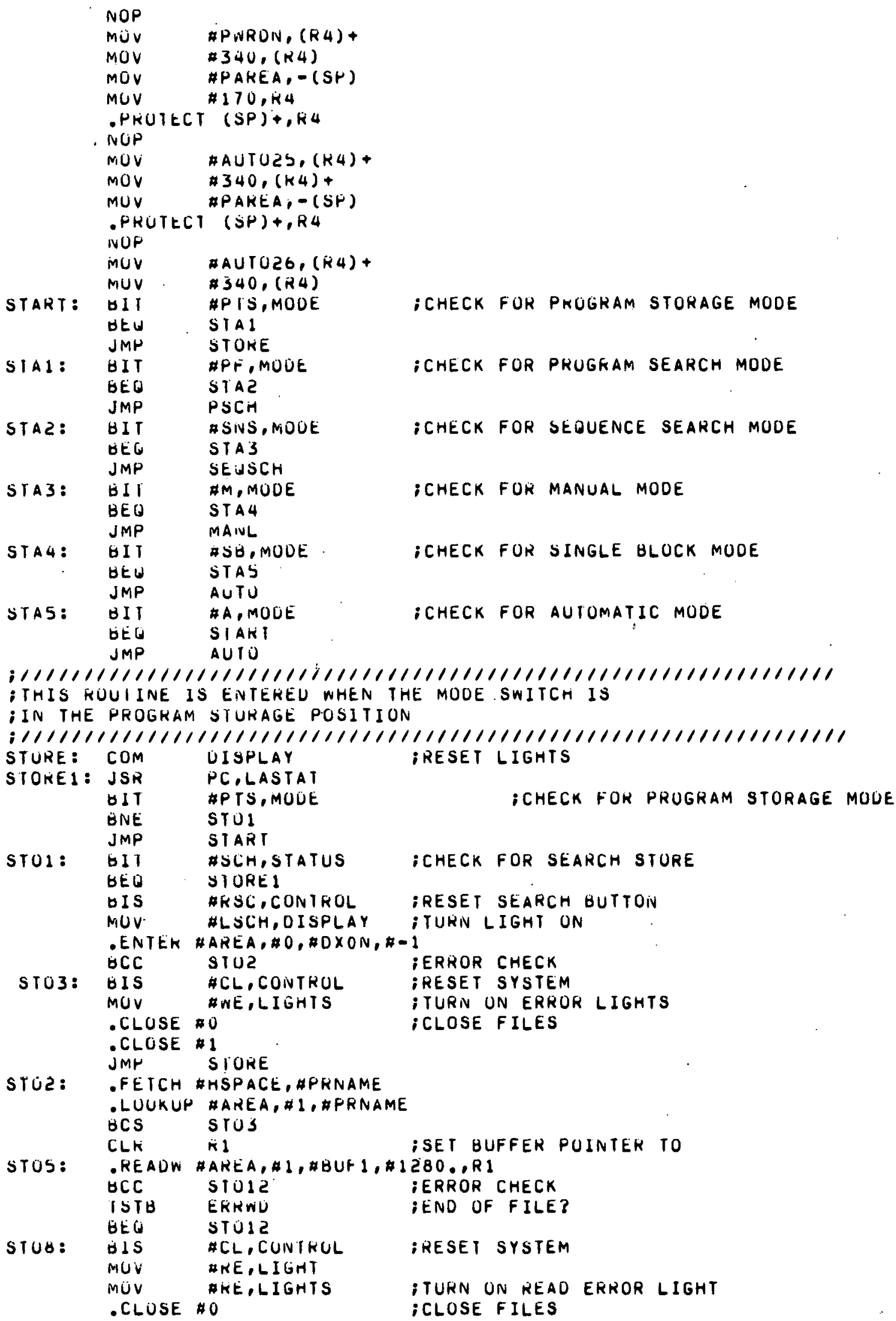




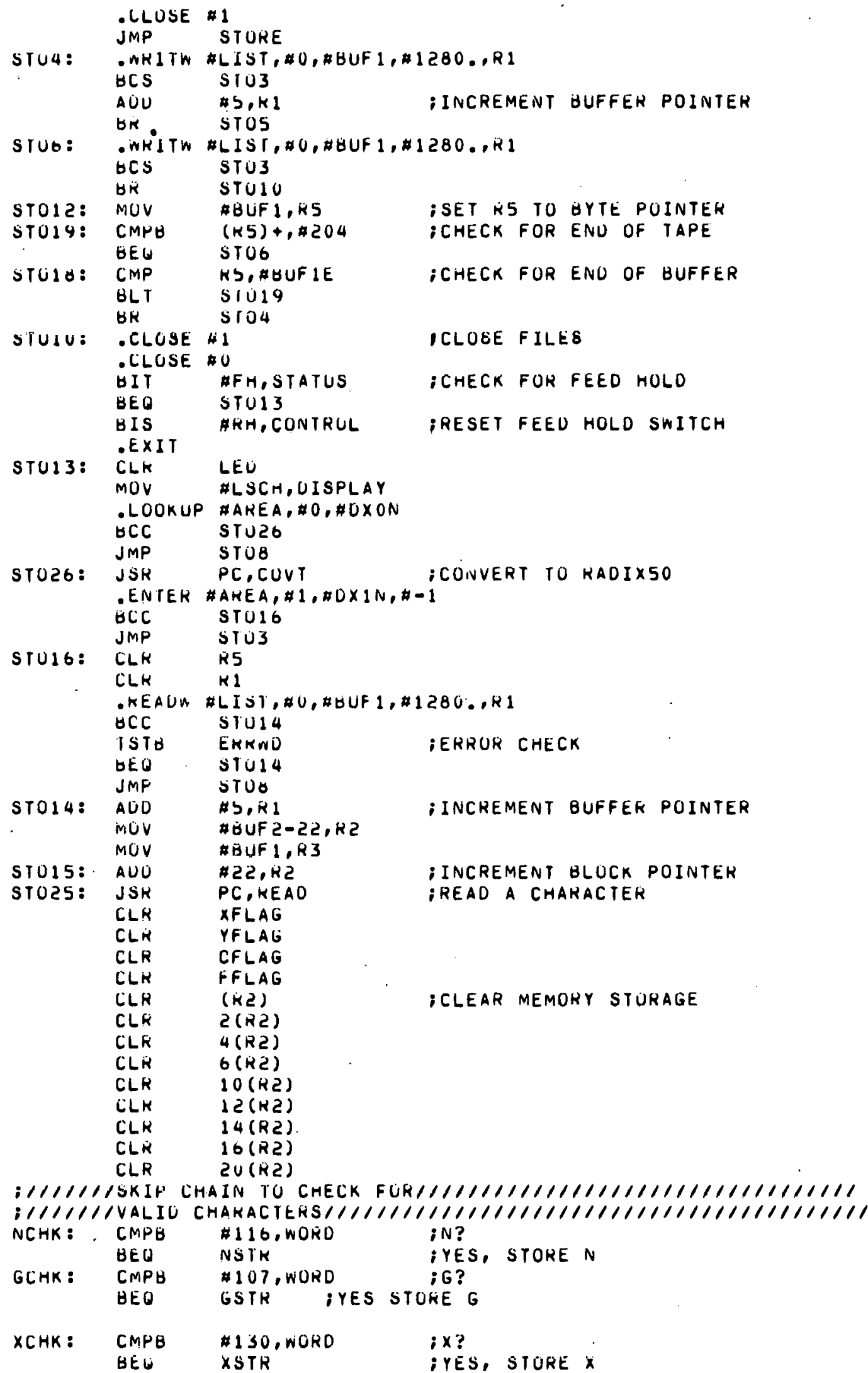




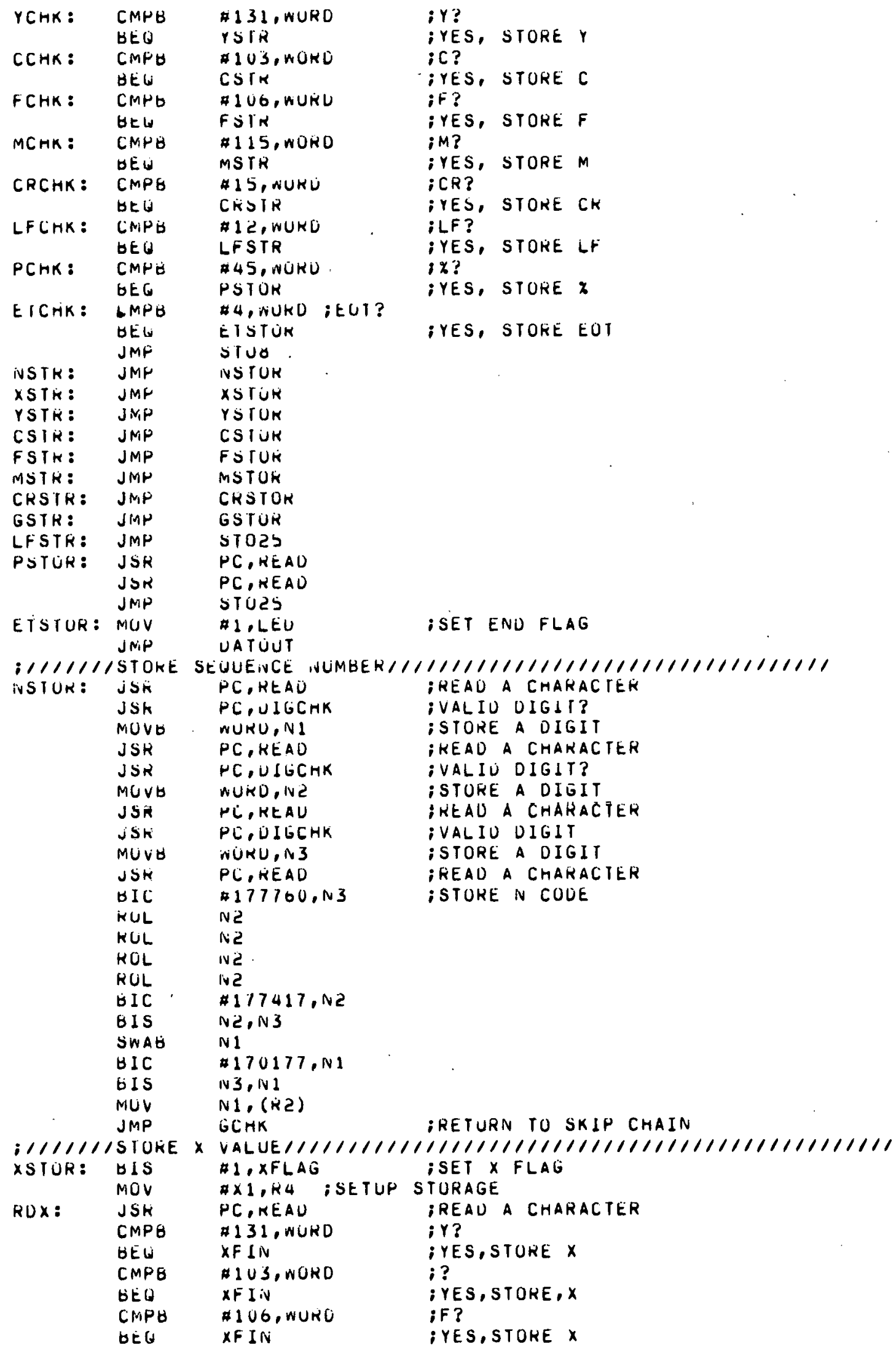




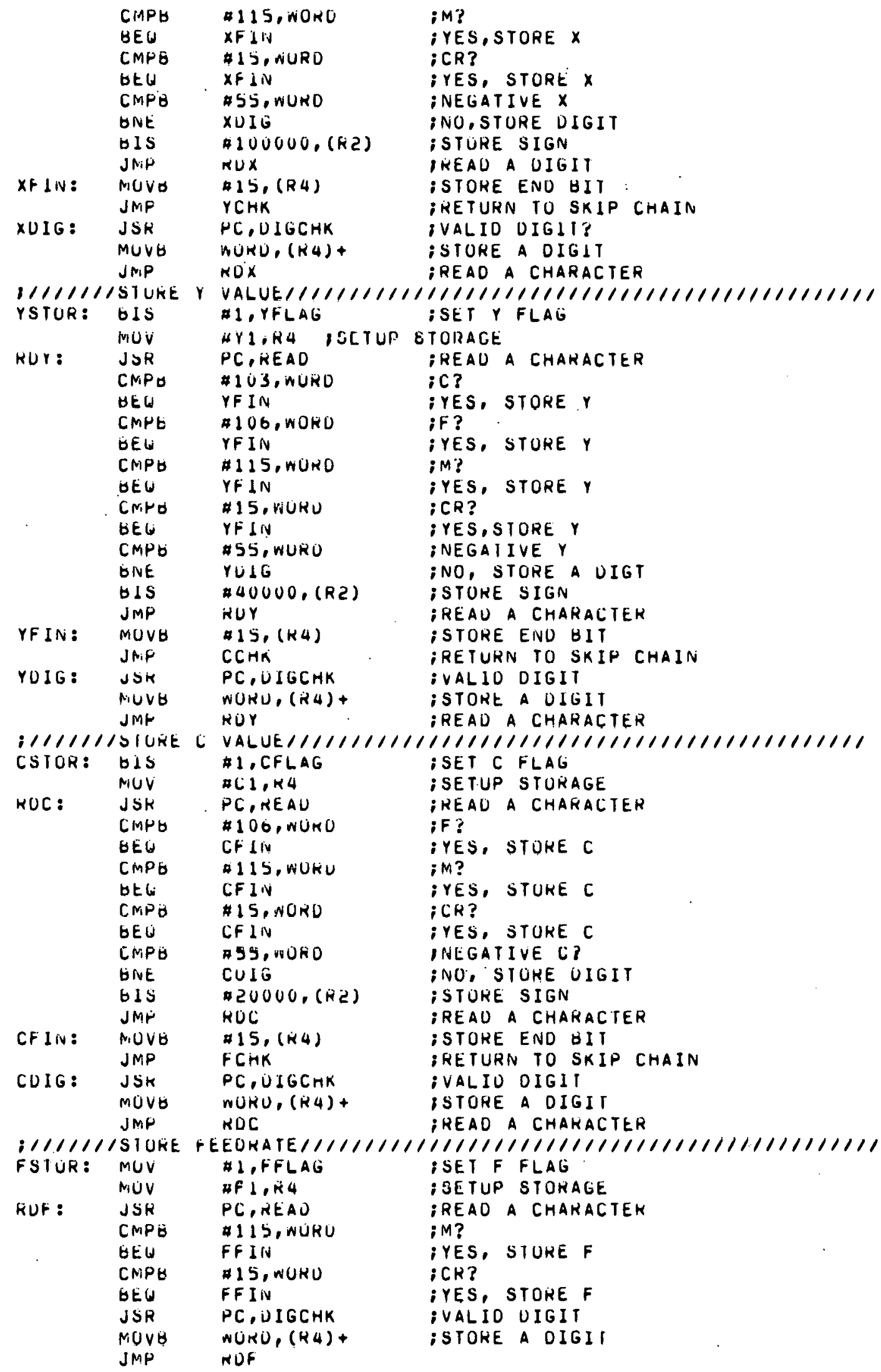




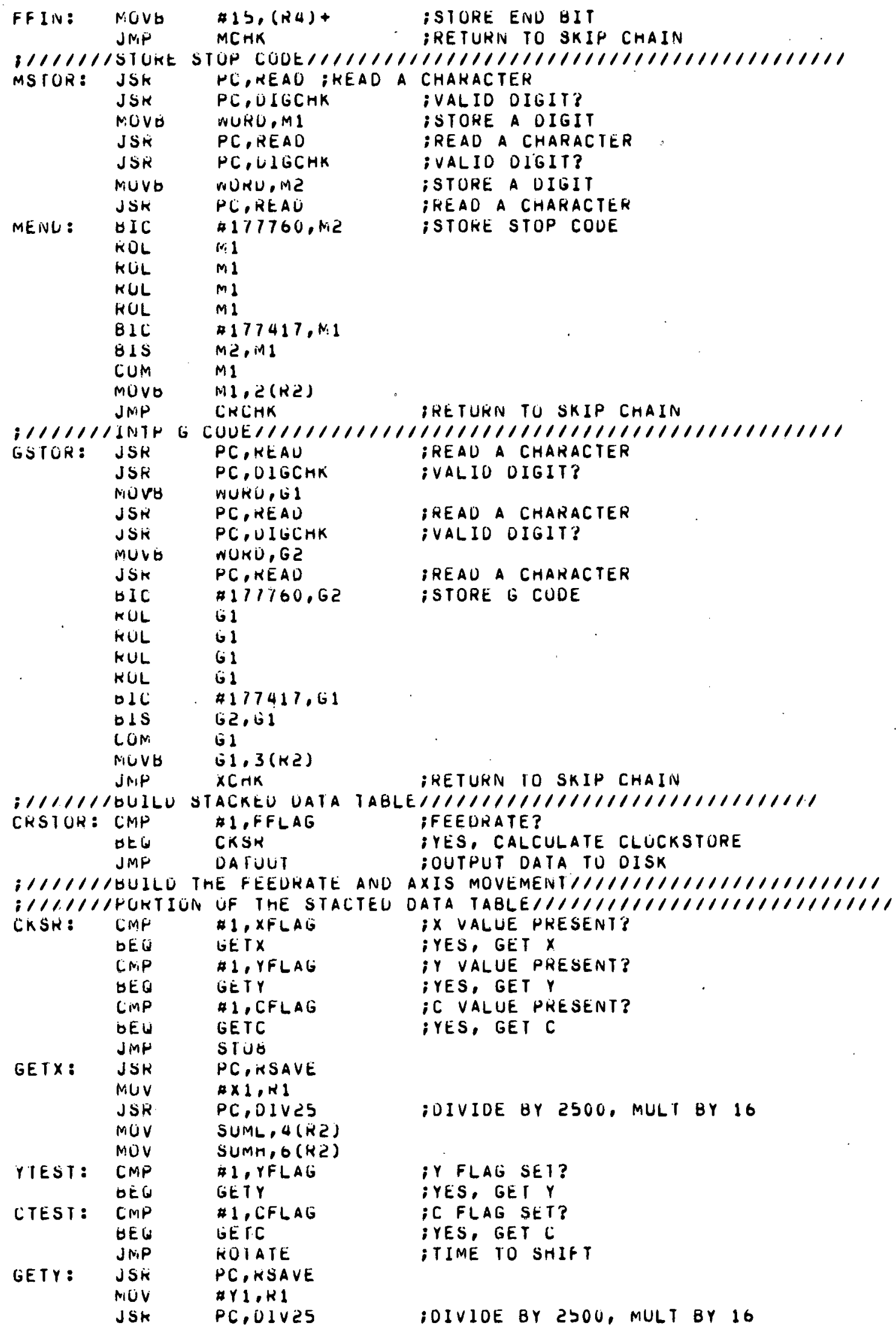




\begin{tabular}{|c|c|c|c|}
\hline & MUV & SUML, $1 \cup(R 2)$ & \\
\hline & MUUV & SUMH, $12(k 2)$ & \\
\hline JMP & CTES I & ;C FLAG & SET? \\
\hline GETC: & JSk & PC, K̈SAVE & \\
\hline & Múv & $\triangle C l, K l$ & \\
\hline & MOV & R2, RO & \\
\hline & ALO & $\$ 14,80$ & \\
\hline & JSK & PC,ATOI & IBCD TU OINARY CONVERSION \\
\hline & $\mathrm{JSH}$ & PC,RKET & 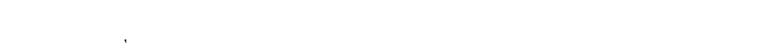 \\
\hline & HALI & & \\
\hline & JMP & RUTATE & \\
\hline DIV 25: & NiUV & ASUIML, KO & \\
\hline & JSX & $P C, A T U D$ & ;BCD TO BINARY \\
\hline & CLH & kO & \\
\hline & CLK. & $\kappa 1$ & \\
\hline & CLLK & K4 & \\
\hline & muv & $\$ 16.0 \mathrm{KS}$ & \\
\hline & JSK & $P C, M . D P I M$ & :MULT $\forall Y 16$ \\
\hline & CLK & K4 & \\
\hline & MOV & \#25, .155 & \\
\hline & JSR & $P C, M, O P I D$ & iOIV BY 2500 \\
\hline & MOV & HZ, SUMH & \\
\hline & MOV & K3. SUML & \\
\hline & $\begin{array}{l}\text { JSK } \\
\text { KTS }\end{array}$ & $\begin{array}{l}P C, K K E T \\
P C\end{array}$ & IRESTORE REGISTERS \\
\hline$: 11111$ & IKUTAIE & DATA ANU INSEKT & MARKER GIT/1/1/1/1/1/1/1/1/1/1/1 \\
\hline ROTATE: & MOV & $\# 100000$, NEUF 2 & \\
\hline & CLR & NBUF 1 & \\
\hline & $\begin{array}{l}\text { ASL } \\
K G L\end{array}$ & $\begin{array}{l}4(K 2) \\
6(k 2)\end{array}$ & ; COMBINED SHIFT LEFT ON $X$ \\
\hline & InC & $4(k 2)$ & ; SET MARKER BIT \\
\hline & $A S L$ & $1 \cup(R 2)$ & : COMBINED LEFT SHIFT ON $Y$ \\
\hline & $K U L$ & $12(K Z)$ & \\
\hline & $\operatorname{INC}$ & $10(R 2)$ & ISET MARKER BIT \\
\hline & ASL & $14(k 2)$ & ; COMBINED LEFT SHIFT UN $C$ \\
\hline & RUL & $16(R 2)$ & \\
\hline & $\operatorname{div} C$ & $14(k 2)$ & ISET MARKER GIT \\
\hline MMTT: & $6 I 1$ & $4100000,6(122)$ & : MAXIMIUM X? \\
\hline & DIVE & S1 UKXY & IYES, SE TUP TABLE \\
\hline & $6\rfloor 1$ & $1100000,12(k 2)$ & ; MAXIMIUM Y? \\
\hline & DIVE & SIUKXY & IYES, SETUP TAELE \\
\hline & BII & $\# 100000,16(R 2)$ & ;MAXIMIUM C? \\
\hline & bIVE & STURXY & i YES, SETUP TABLE \\
\hline MUKRUT: & $A S L$ & $4(k 2)$ & \\
\hline & KUL & $b(k 2)$ & \\
\hline & ASL & IU(K2) & \\
\hline & KUL & $12(k 2)$ & \\
\hline & $A S L$ & $14(k 2)$ & \\
\hline & HUL & $16(k 2)$ & \\
\hline & $\begin{array}{l}\text { LLC } \\
\text { KUK }\end{array}$ & ivOUF 2 & \\
\hline & KOK & NOUF 1 & \\
\hline & JMP & MMTI & ;CHECK FOK ENU OF SHIFT \\
\hline STORXY: & JSK & HC, RSAVE & \\
\hline & MUV & $\# F 1, R 1$ & \\
\hline & MiUV & $\triangle S U \operatorname{SinL}, K O$ & \\
\hline 1111111 & $\begin{array}{l}\text { JSR } \\
\text { CALCLLA }\end{array}$ & $\begin{array}{l}\text { PC, ATOI } \\
\text { TE CLOCKSTOKE/II }\end{array}$ & 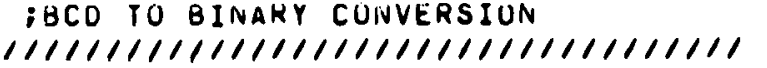 \\
\hline $\begin{array}{l}11111111 \\
1111111\end{array}$ & $\begin{array}{l}1600110 \\
\text { APUL } / C P\end{array}$ & $\begin{array}{l}\star \star 6) / F \star(10 \star \star-4)) \\
U L=(((U S / M I N) /(1)\end{array}$ & 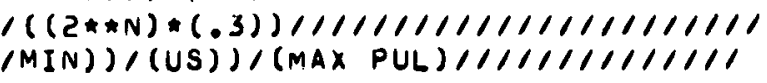 \\
\hline & MOV & SUML,R5 & \\
\hline & MuV & SUAH,RA & \\
\hline & CLK & Ko & \\
\hline & MOV & $\$ 677,61$ & \\
\hline
\end{tabular}




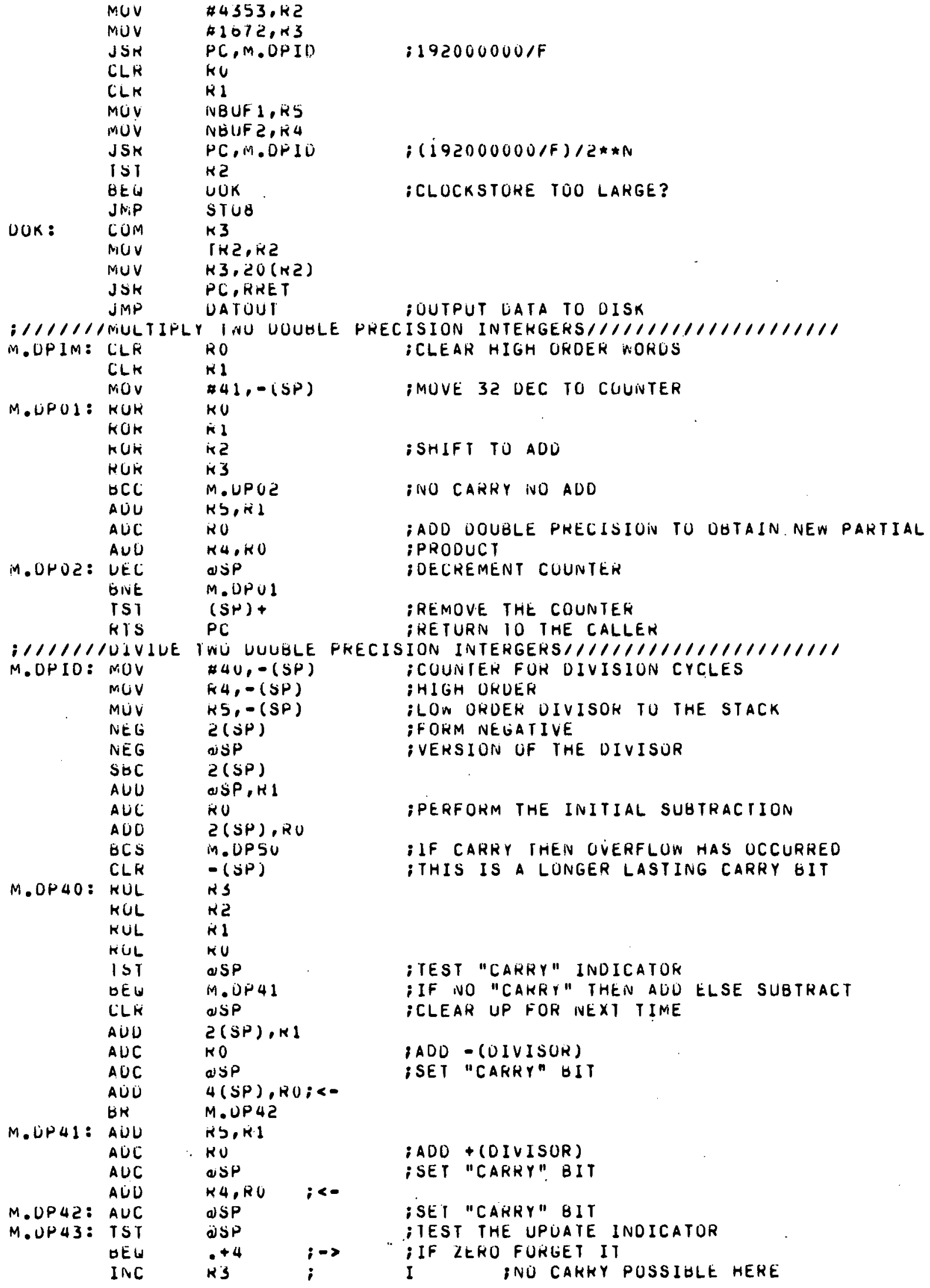




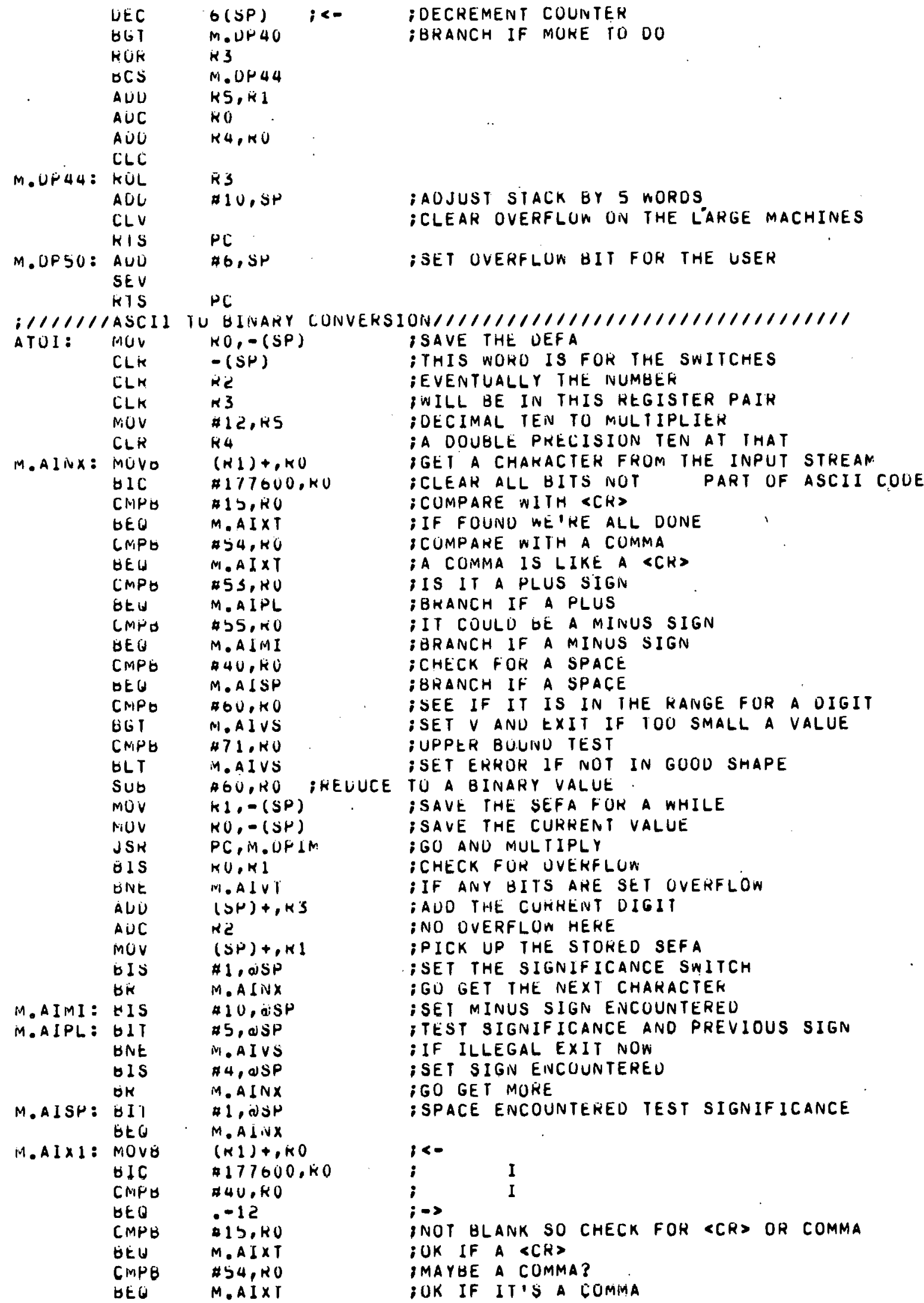




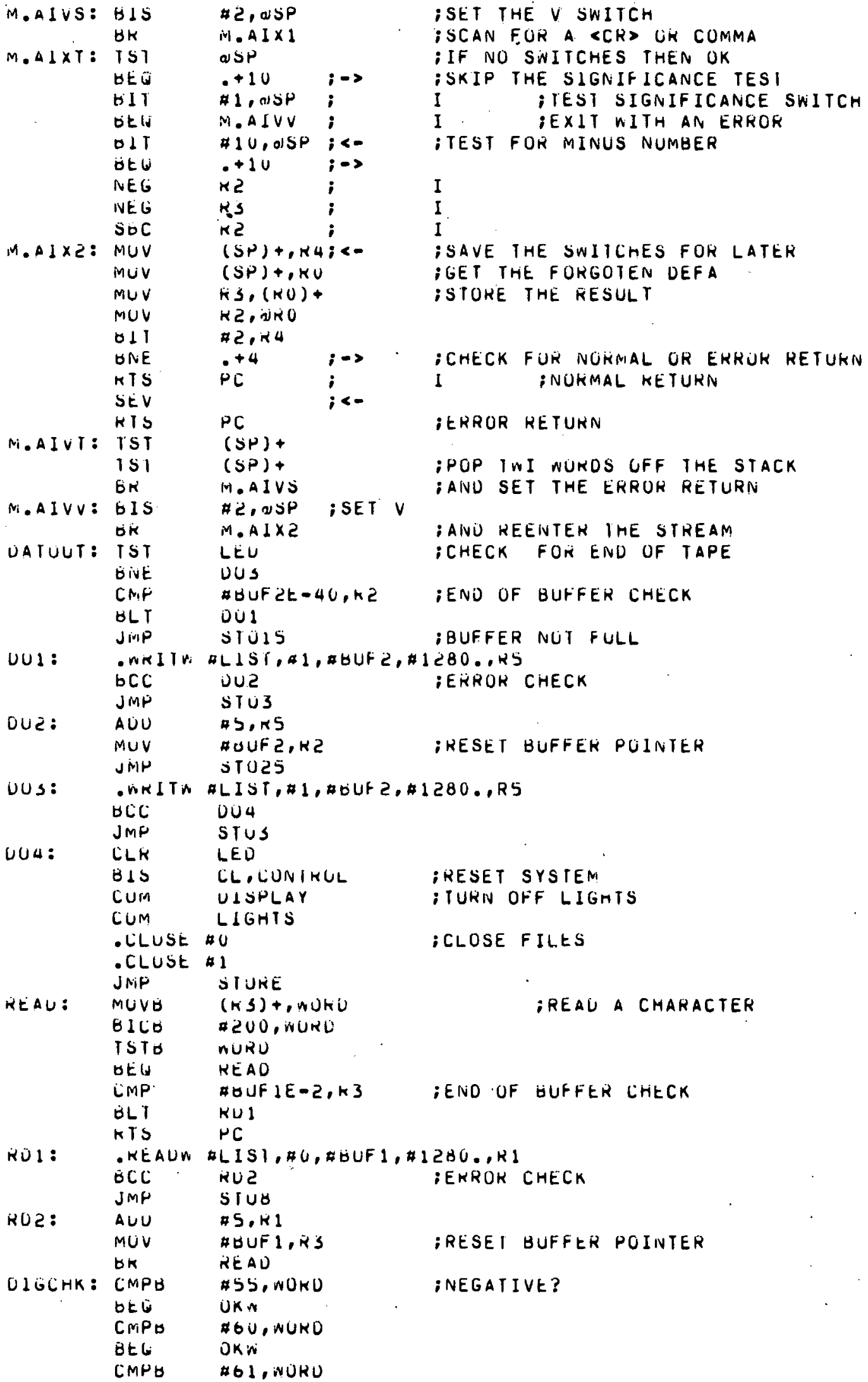




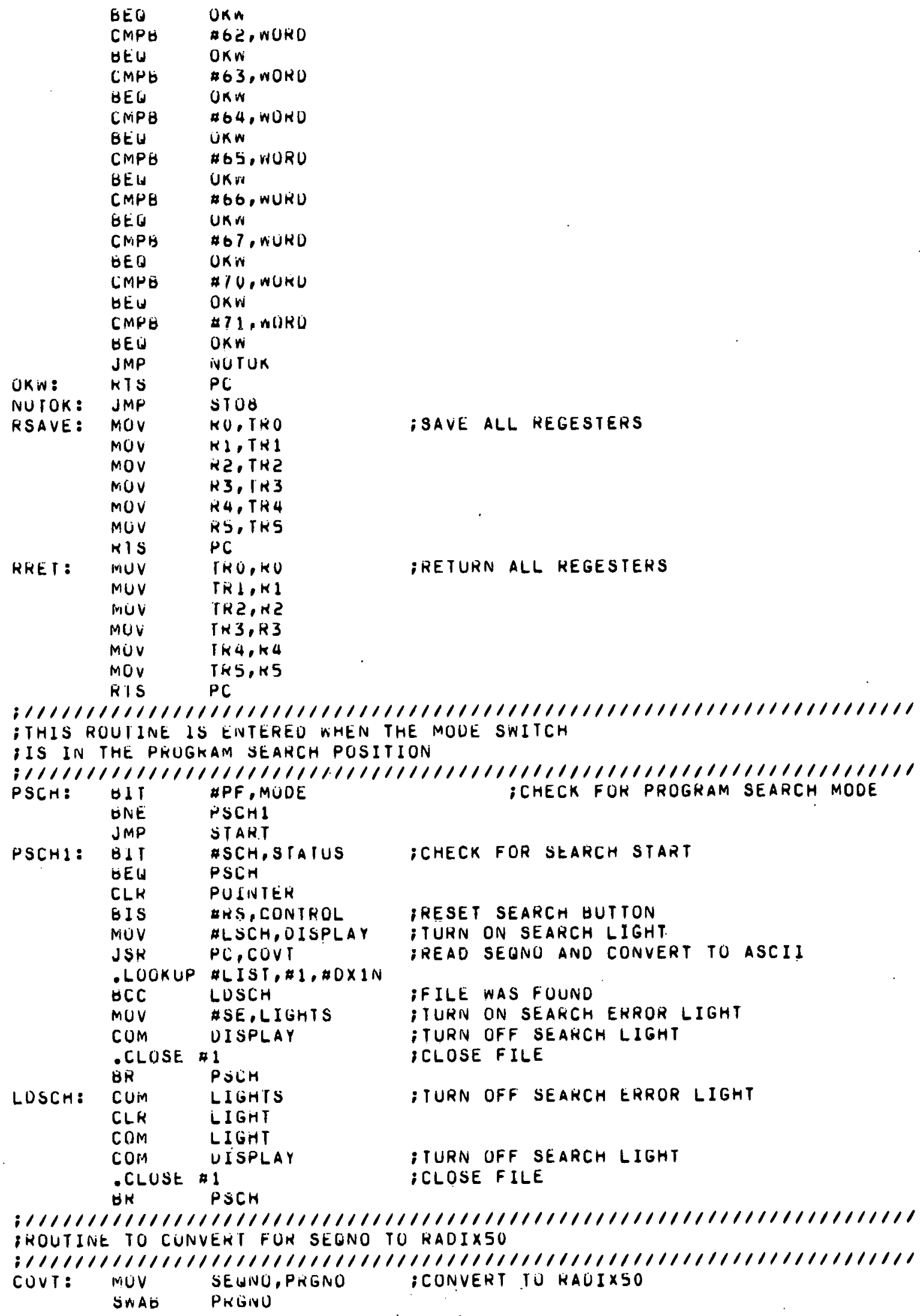




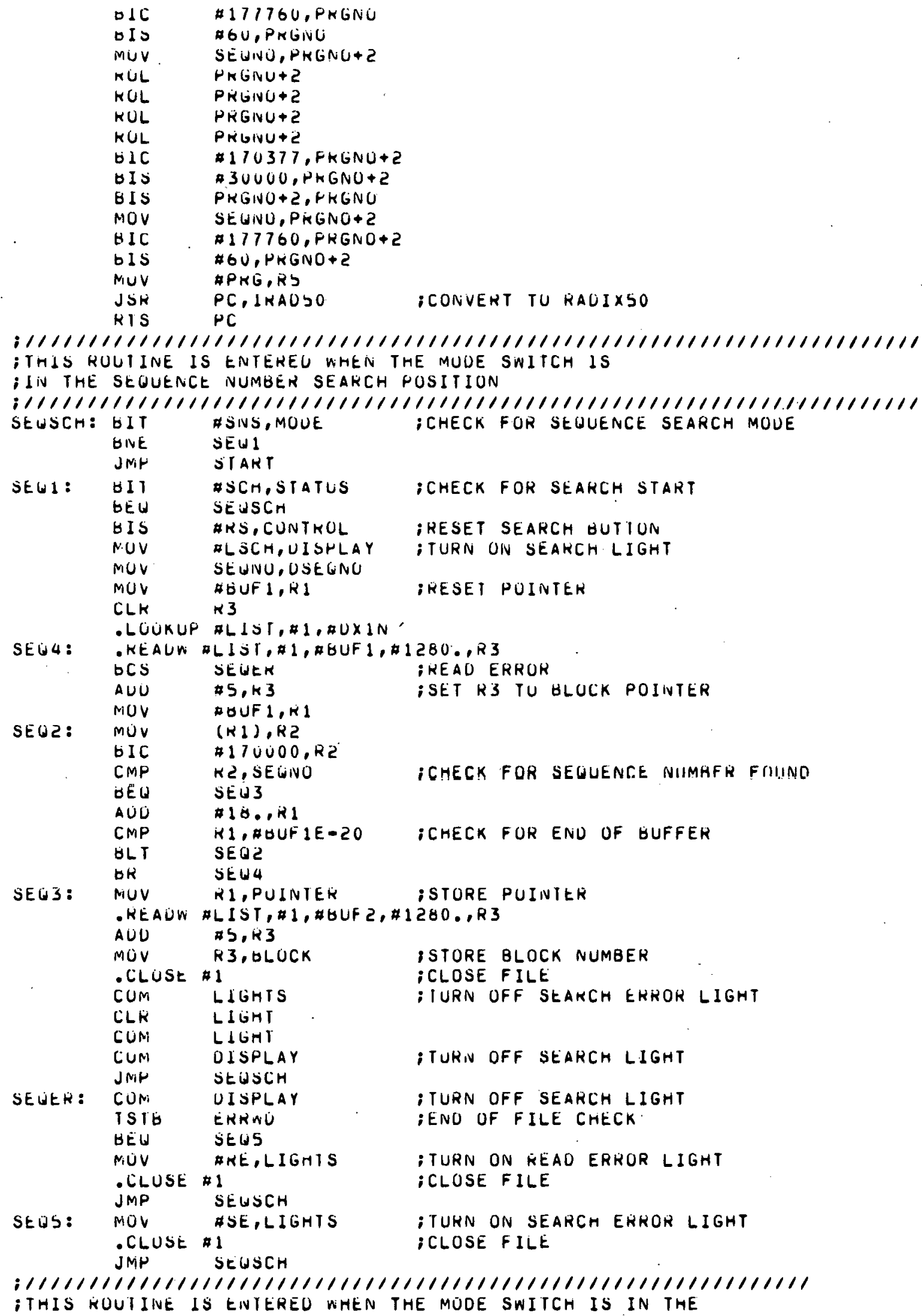


;AUTOMATIC UK SINGLE BLOCK POSITION

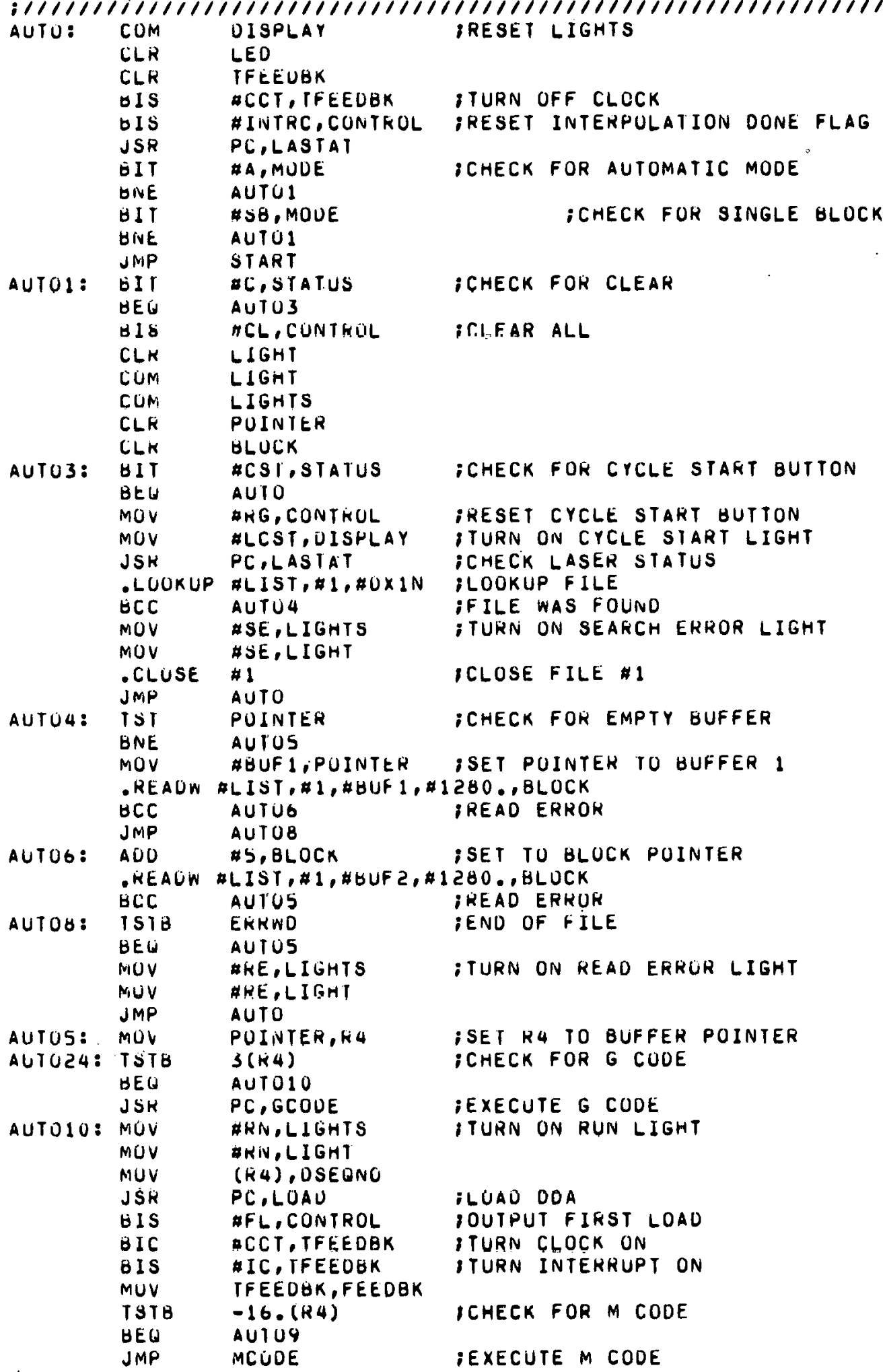




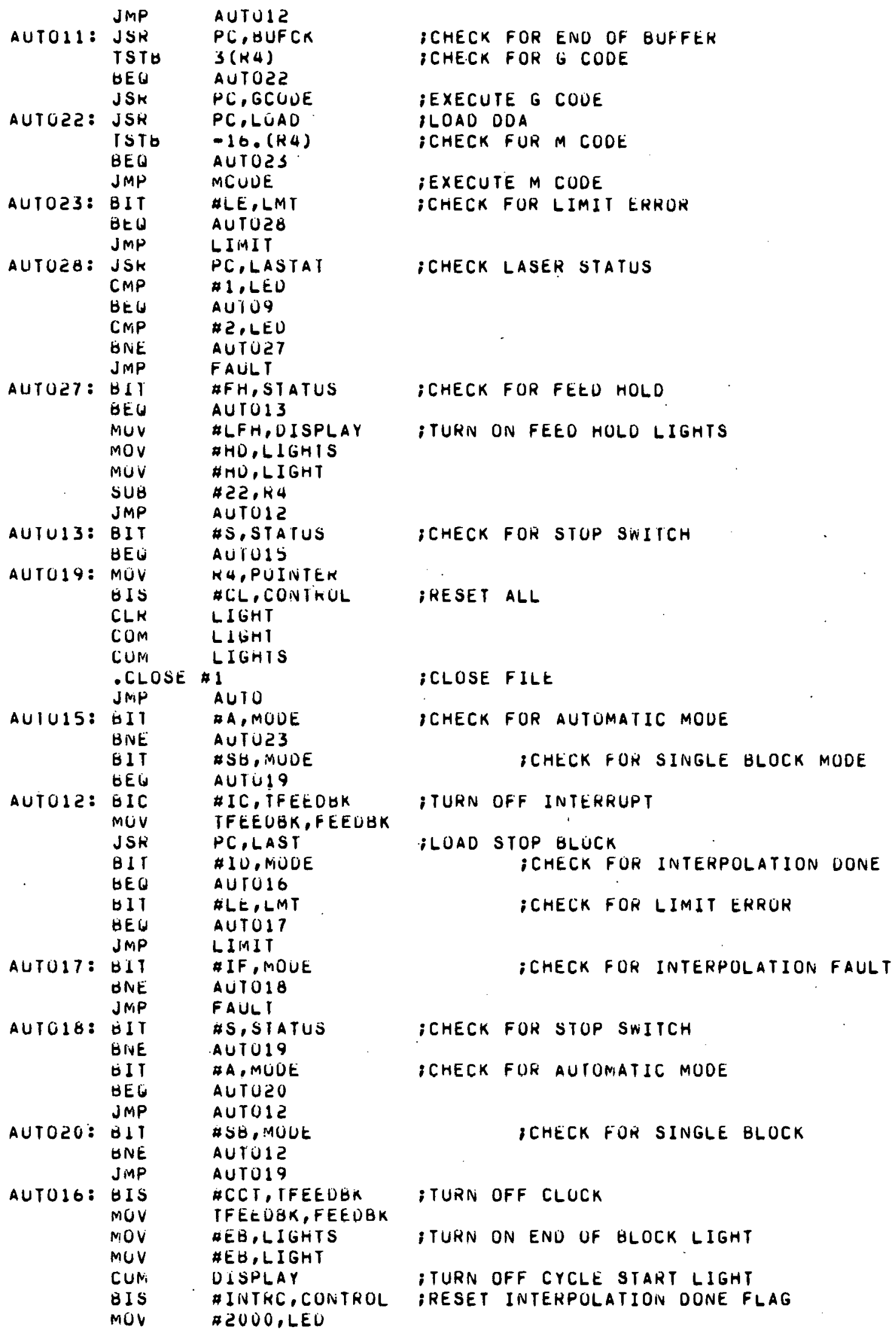




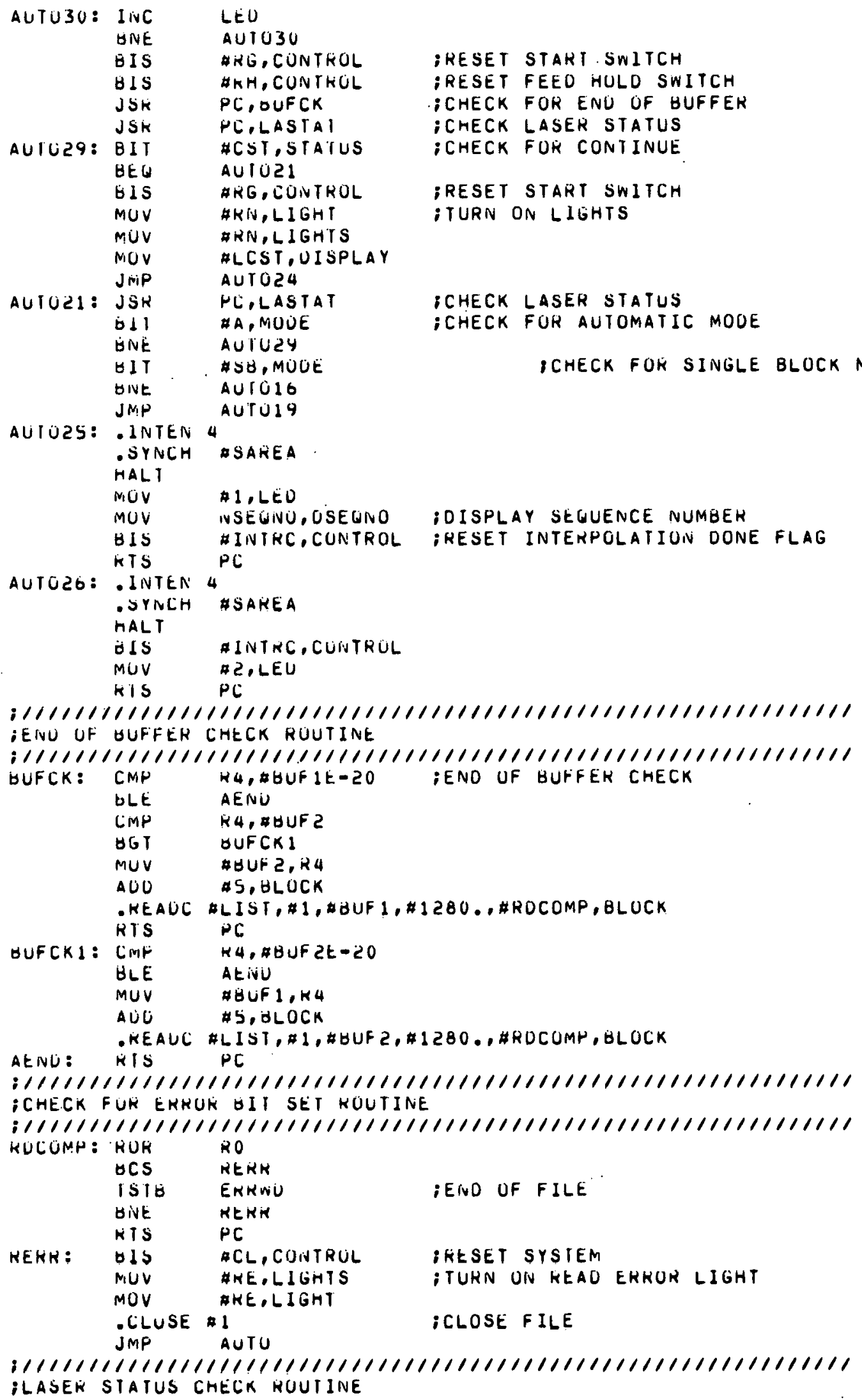




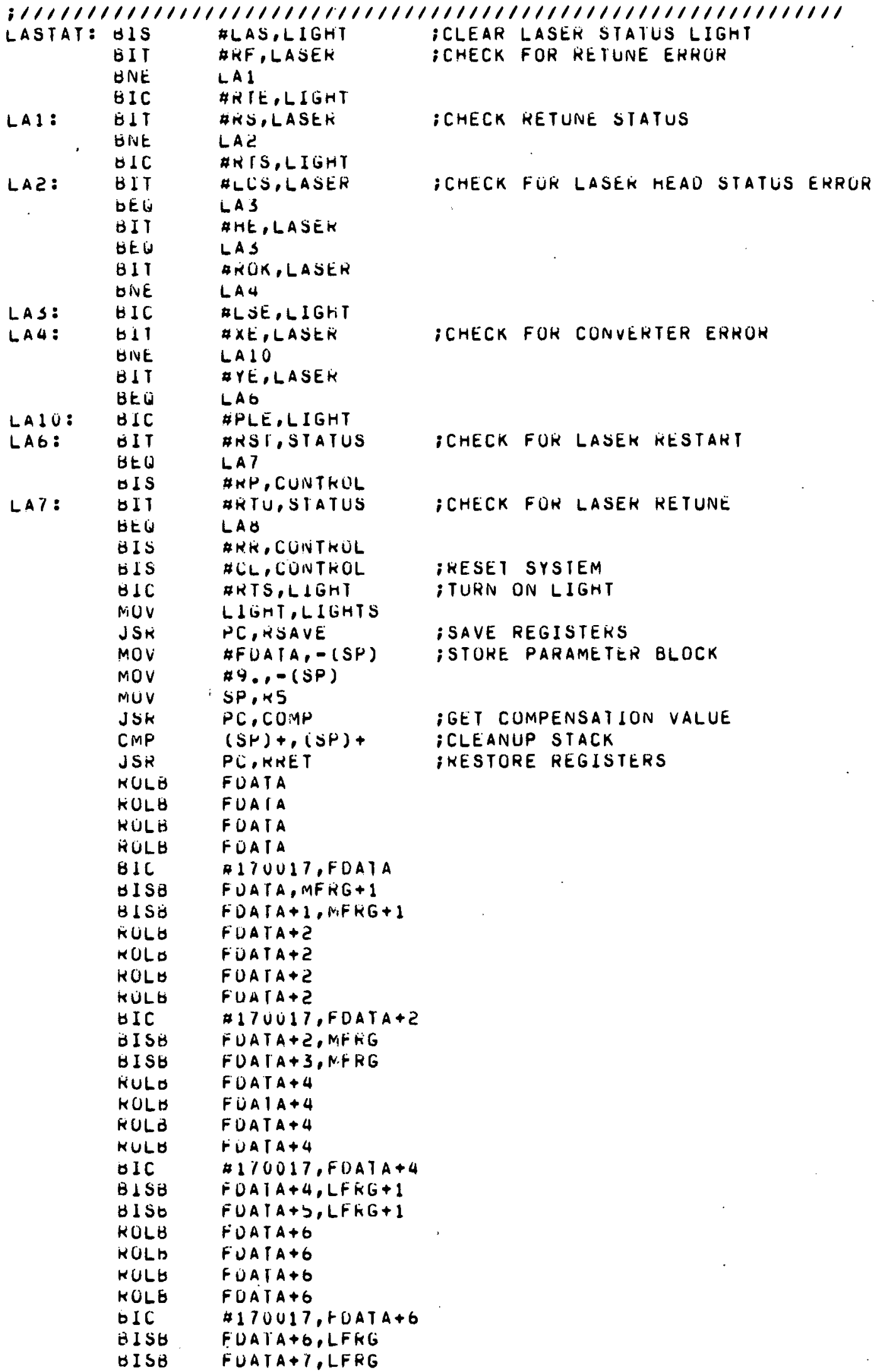




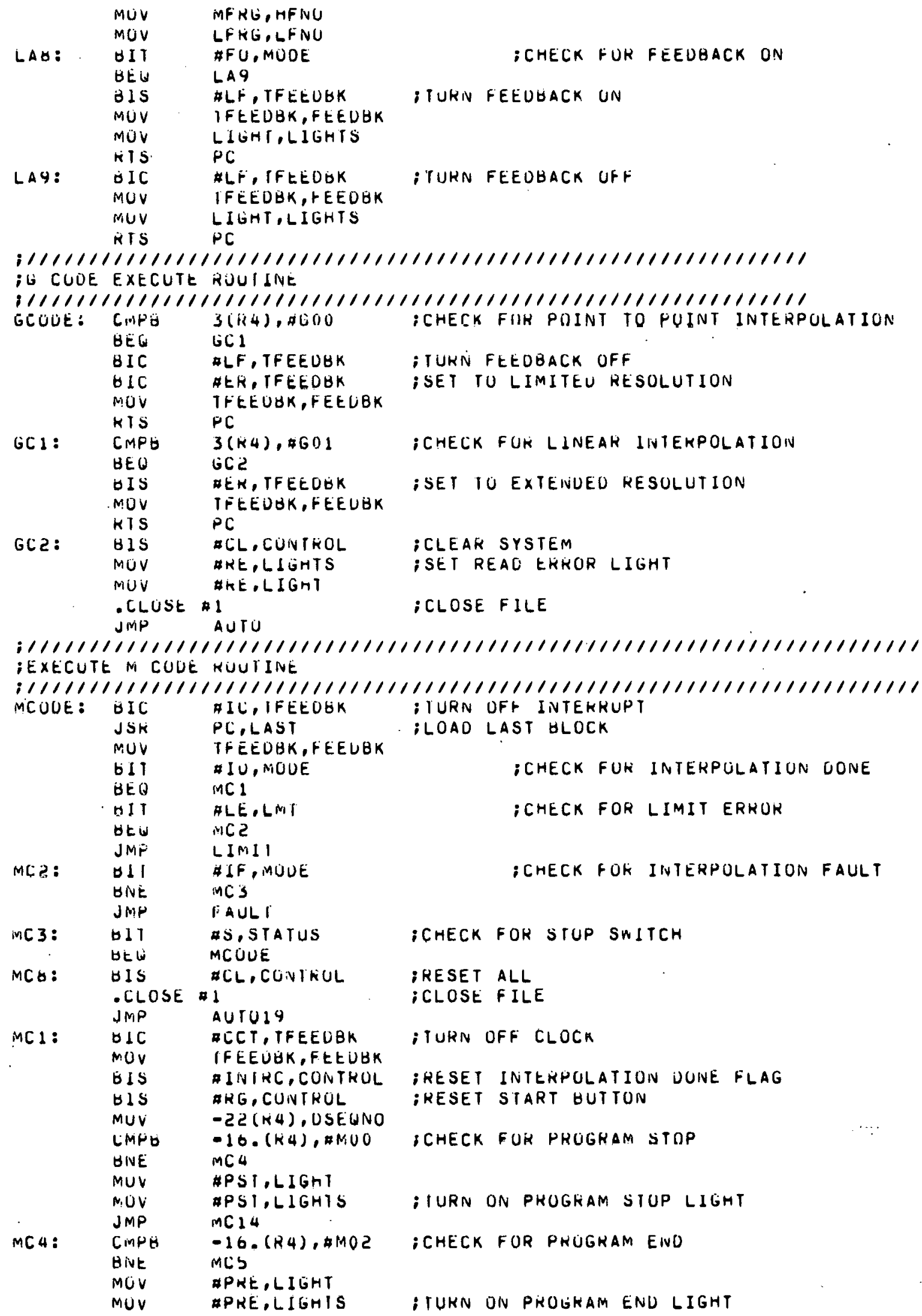




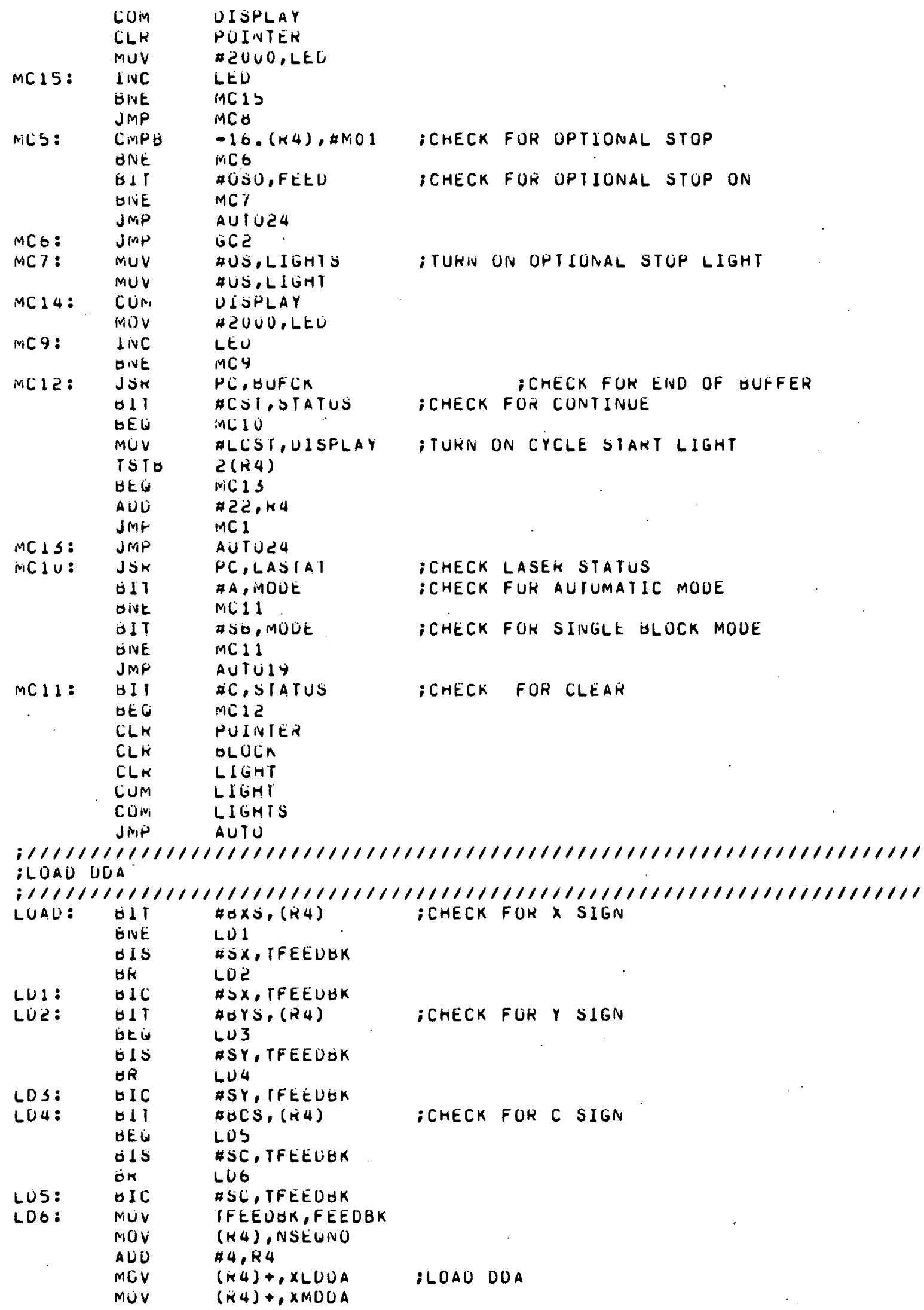




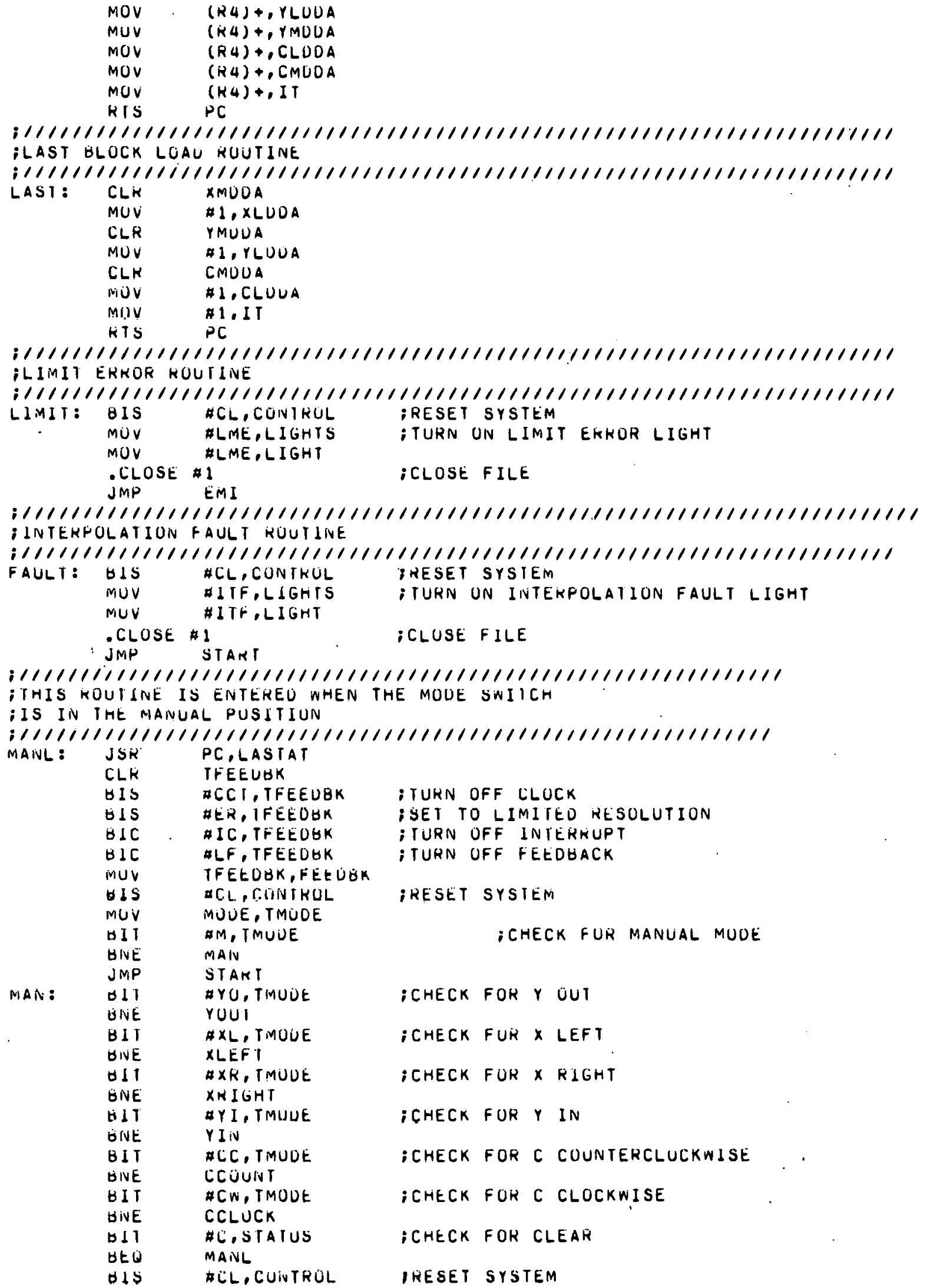




\begin{tabular}{|c|c|c|c|}
\hline & $\begin{array}{l}\text { CLK } \\
\text { CUNM } \\
\text { CUM }\end{array}$ & $\begin{array}{l}\text { LIGHT } \\
\text { LIGHT } \\
\text { LIGHTS }\end{array}$ & \\
\hline & JMIP & MAIVL & \\
\hline \multirow[t]{2}{*}{$X L E F$ I: } & $\begin{array}{l}\text { DIS } \\
\text { OIC }\end{array}$ & $\begin{array}{l}\text { \#LXL, UISPLAY } \\
\text { \#X, IFEEUUK }\end{array}$ & $\begin{array}{l}\text { : TUKN ON X LEFT LIGHT } \\
\text {; SET SIGN TU X LEFT }\end{array}$ \\
\hline & $b x$ & XURIVE & \\
\hline \multirow[t]{2}{*}{ XRIGHT: } & $\begin{array}{l}\text { BIS } \\
\text { BIS }\end{array}$ & $\begin{array}{l}\text { WLXK, OISPLAY } \\
\# S X, T F E E \cup B K\end{array}$ & $\begin{array}{l}\text { : TURIN ON X RIGHT LIGHT } \\
\text { :SET SIGN TU X RIGHT }\end{array}$ \\
\hline & $\Delta k$ & XUNIVE & \\
\hline YIIV: & $\begin{array}{l}B \perp 5 \\
\dot{B} \perp C \\
O K\end{array}$ & $\begin{array}{l}\text { RLYI, DISFLAY } \\
\text { RSY,IFEKUUK } \\
\text { YURIVE }\end{array}$ & $\begin{array}{l}\text { : TURN UN Y IN LIGHT } \\
\text { ISET SIGN TO Y IN }\end{array}$ \\
\hline YÕU: & $\begin{array}{l}\forall \llbracket S \\
\dot{D} I S \\
\forall K\end{array}$ & $\begin{array}{l}\text { ALYU, UISHLAY } \\
\text { ASY, TFEEDBK } \\
\text { YOKIVE }\end{array}$ & $\begin{array}{l}\text { : TUKN ON Y OUT LIGHT } \\
\text { ISET SIGN TU Y UUT. }\end{array}$ \\
\hline CCOUNI: & $\begin{array}{l}0 \perp S \\
\forall I S \\
\forall \dot{R}\end{array}$ & $\begin{array}{l}\text { OLCC, UISPLAY } \\
\text { ASC, IFEEOUK } \\
\text { CURIVE }\end{array}$ & $\begin{array}{l}\text { :TURN UN C COUNTER-CLOCKWISE LIGHT } \\
\text { ISET SIGN TO C COUNTEK-CLOCKWISE }\end{array}$ \\
\hline CCLUCK: & $\begin{array}{l}\text { DIS } \\
\Delta I C \\
\text { OK }\end{array}$ & $\begin{array}{l}\text { ALCW,UISPLAY } \\
\text { "SC, IFEEUEK } \\
\text { CURIVE }\end{array}$ & $\begin{array}{l}\text {; TURN ON C CLUCKWISE LIGHT } \\
\text {;SET SIGN TO C CLOCKWISE }\end{array}$ \\
\hline \multirow[t]{3}{*}{ XDKIVE: } & MuV & $\# X L \cup \cup A, R I$ & ISET X SLIUE TO MOVE \\
\hline & $\begin{array}{l}\text { MuV } \\
\text { MuY }\end{array}$ & $\begin{array}{l}\text { FLUUA,NC } \\
\text { \#LLUUA,RS }\end{array}$ & \\
\hline & $B K$ & URIVE & \\
\hline \multirow[t]{4}{*}{ YUKIVE: } & muv & FYLOUA,KI & ;SET Y SLIDE TO MOVE \\
\hline & MuV & $\# C L \cup D A, K 2$ & \\
\hline & MUV & $\triangle X L \cup \cup A, K 3$ & \\
\hline & $\Delta K$ & UKI VE & \\
\hline \multirow[t]{3}{*}{ CUKIVË: } & MUV & HCLUUA, KI & ISET C SLIUE TU MUVE \\
\hline & $N_{1} \cup \bar{V}$ & $\triangle X L O D A, K 2$ & \\
\hline & MuV & \#LLDUA, KS & $\cdot$ \\
\hline \multirow[t]{30}{*}{ UKLVt: } & MOV & TREEOUK,FEEUBK & \\
\hline & MOV & MANUAL, IMANLIAL & :CHECK WHICH MANUAL INCKEMENT \\
\hline & $\begin{array}{ll}\text { BIT } \\
\text { BNE }\end{array}$ & $\begin{array}{l}\text { \#MI I, IMANUAL } \\
\text { SMII }\end{array}$ & IUR RAPID FEED SELECTED \\
\hline & 011 & \#MIZ, TMANUAL & \\
\hline & UIVL & ن们在 & \\
\hline & BIT & \#MI 3, IMANUAL & \\
\hline & Bive & $3 M I 3$ & \\
\hline & $\forall \perp T$ & DMI 4 , IMANLAL & \\
\hline & ÖNE & $\sin 14$ & \\
\hline & BII & AMIS, TMANUAL & \\
\hline & BNE & SMIS & \\
\hline & $81 T$ & AMIO, TMANUAL & \\
\hline & BIVE & $\operatorname{SiM} I 6$ & \\
\hline & $\dot{\Delta} 11$ & -MI7, TMANLIAL & \\
\hline & BNE & SMI 7 & \\
\hline & BI I & WRF I. TMATUAL & \\
\hline & BIVE & SifF 1 & \\
\hline & bIT & AKF 2, TMANUAL & \\
\hline & BNE & SNF 2 & \\
\hline & BI T & \#RF $3, T$ TMANUAL & . \\
\hline & BIVE & SkF $S$ & \\
\hline & $B \perp T$ & ARF 4 , TMANUAL & \\
\hline & GNE & SNF 4 & \\
\hline & $B I T$ & HKF 5, TMANUAL & \\
\hline & BIVE & SKFS & . \\
\hline & 011 & AHF G, TMAIVUAL & \\
\hline & BINE & SKFO & \\
\hline & BIT & \#KF 7 , TMANUAL & \\
\hline & bivt & SKF I & \\
\hline & $\Delta R$ & DNIVE & \\
\hline
\end{tabular}




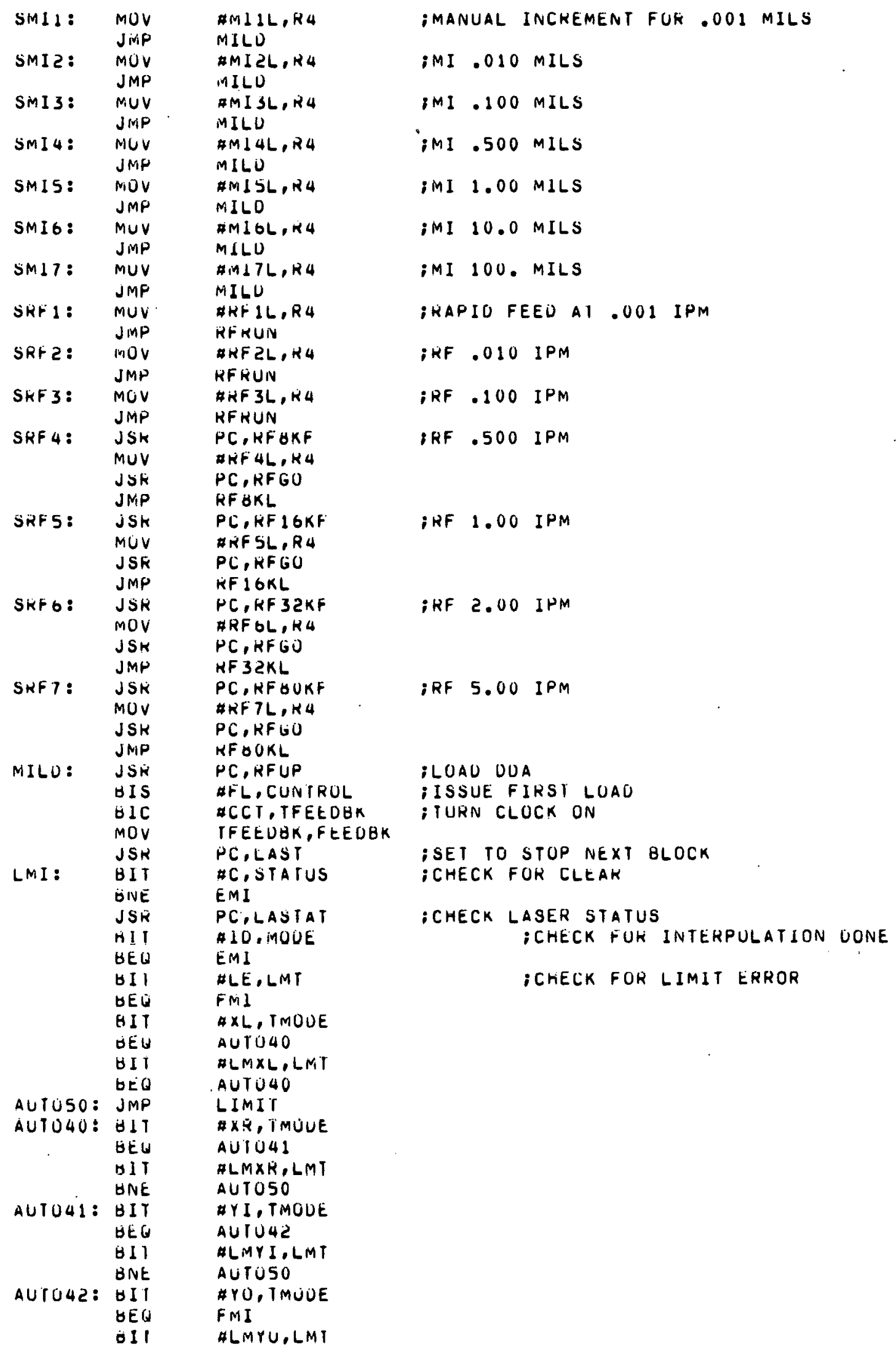




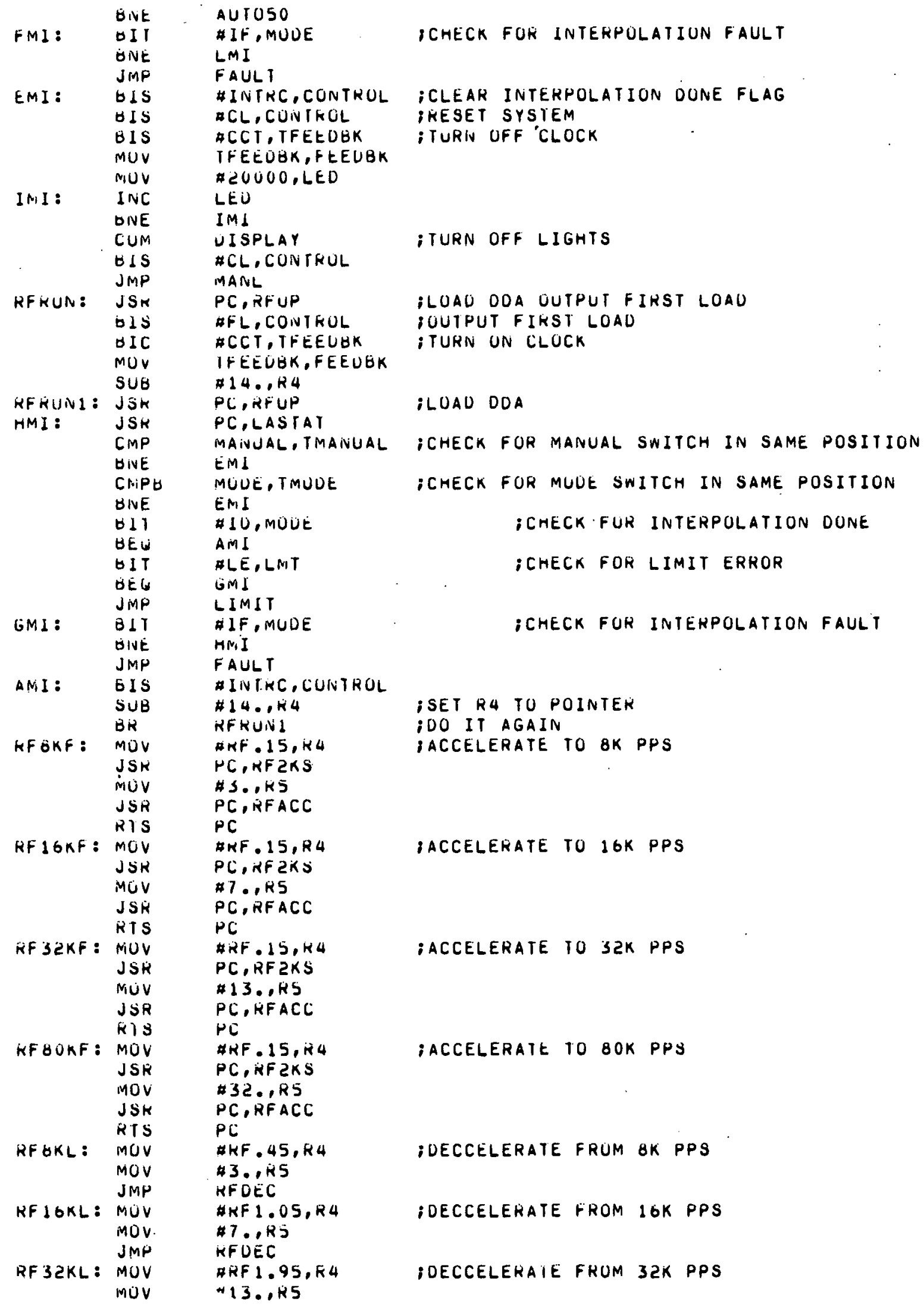




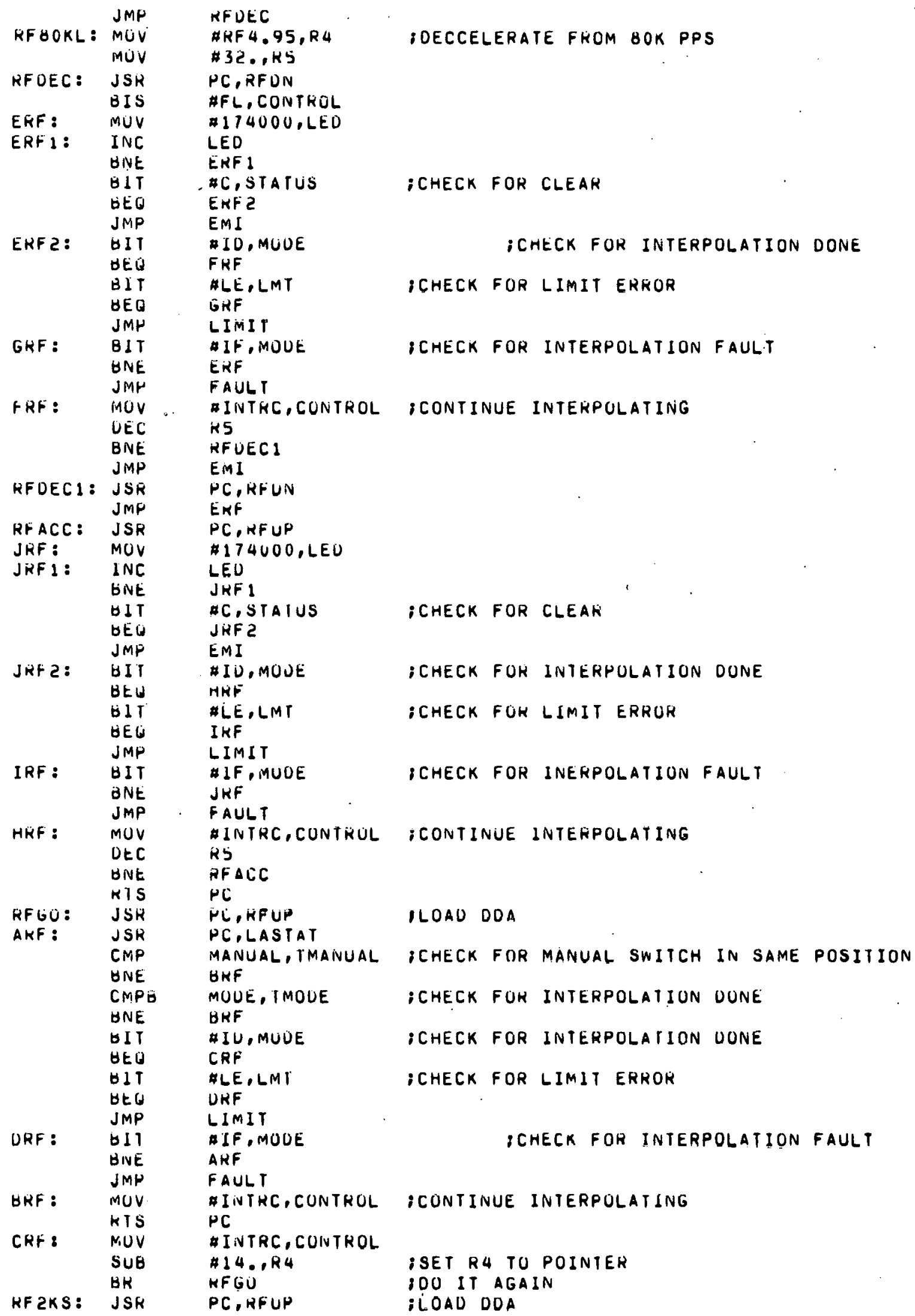




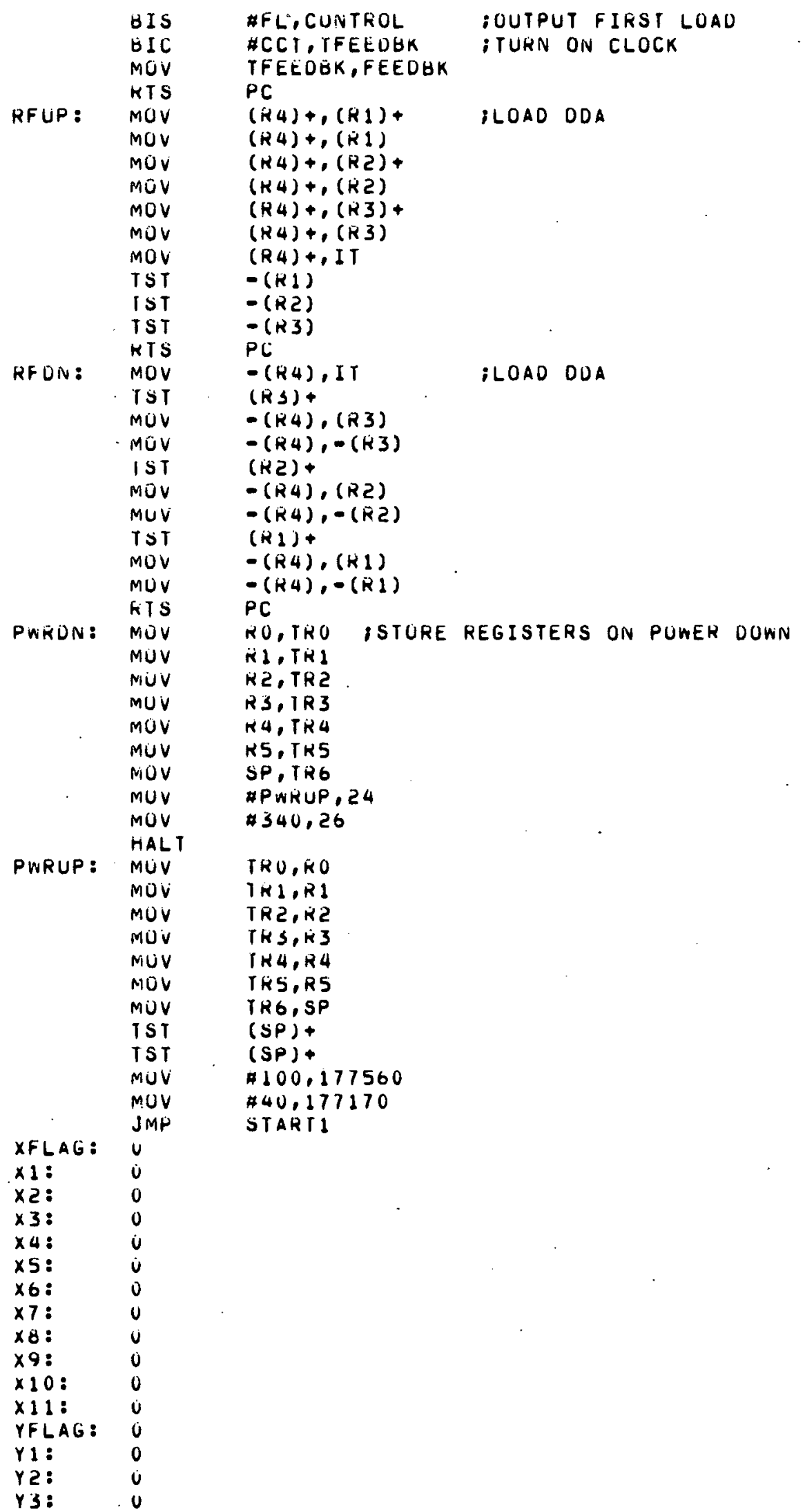




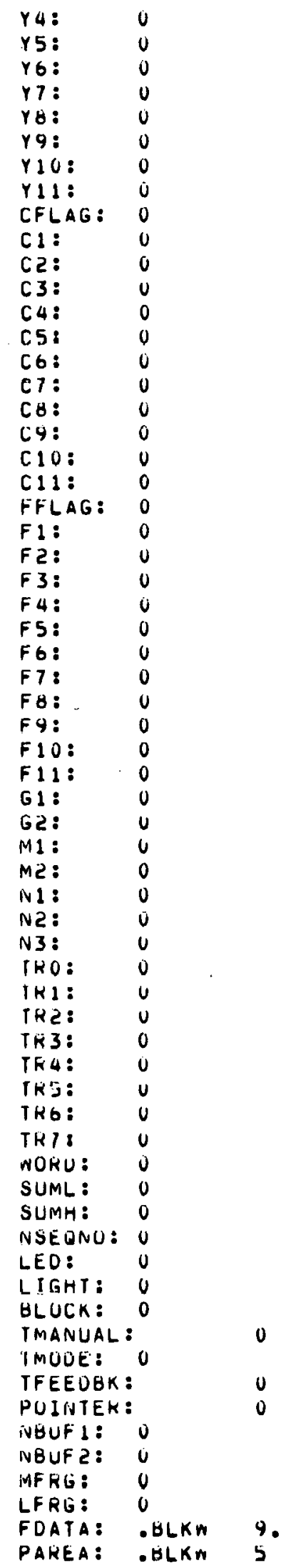




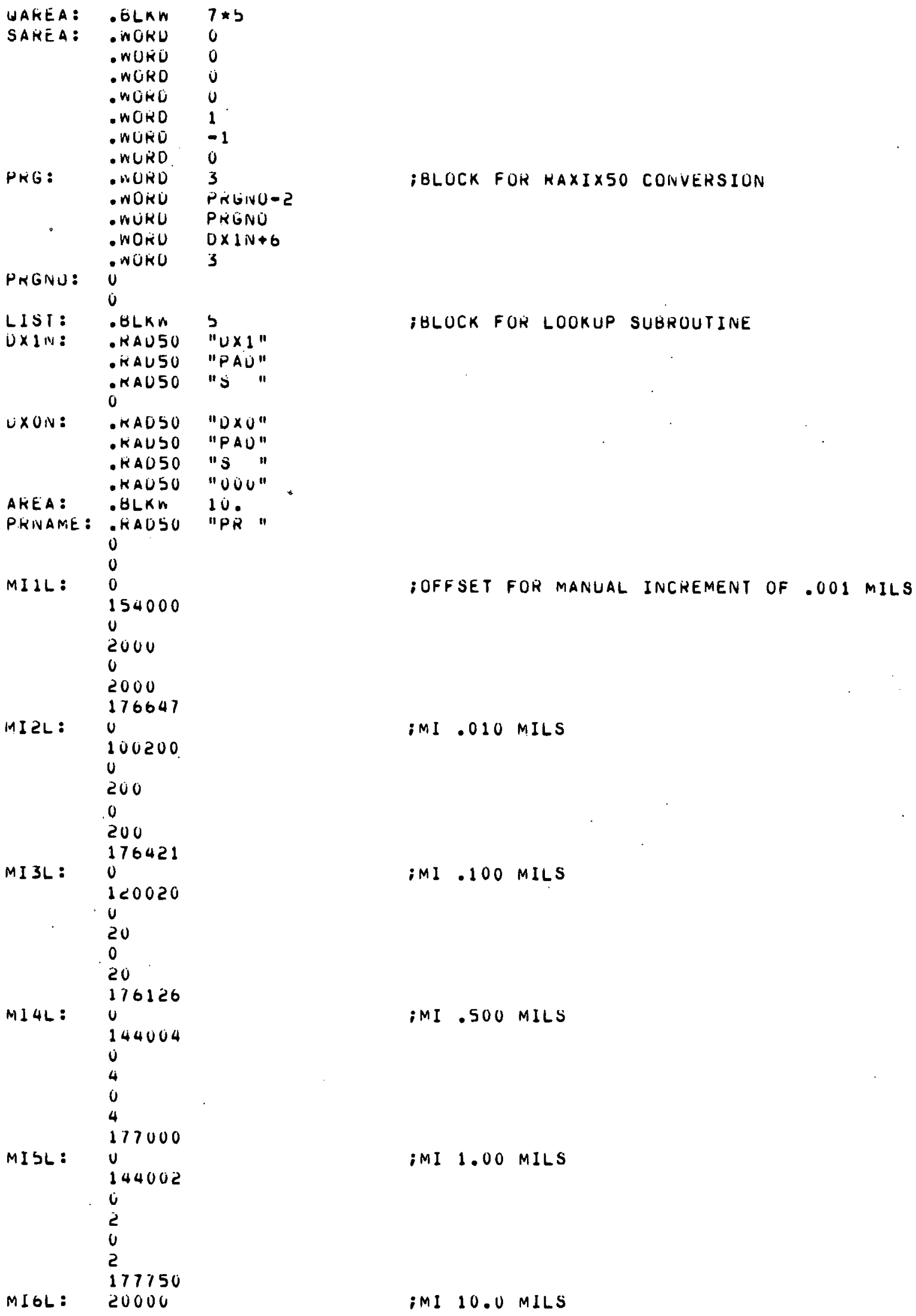




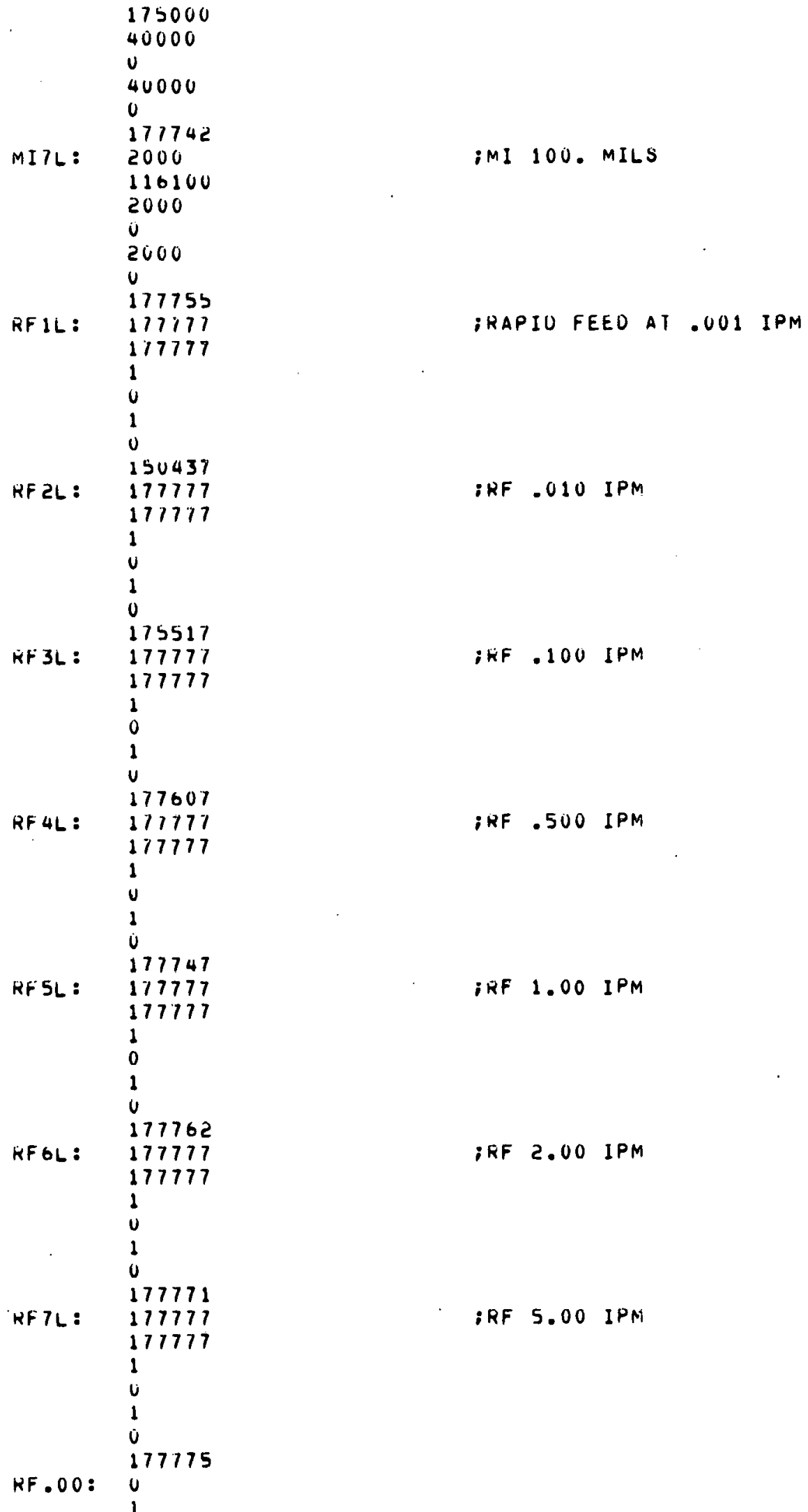




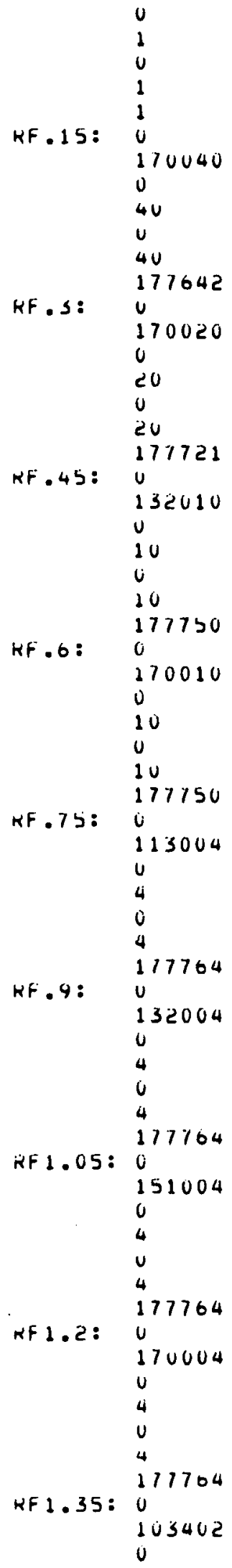




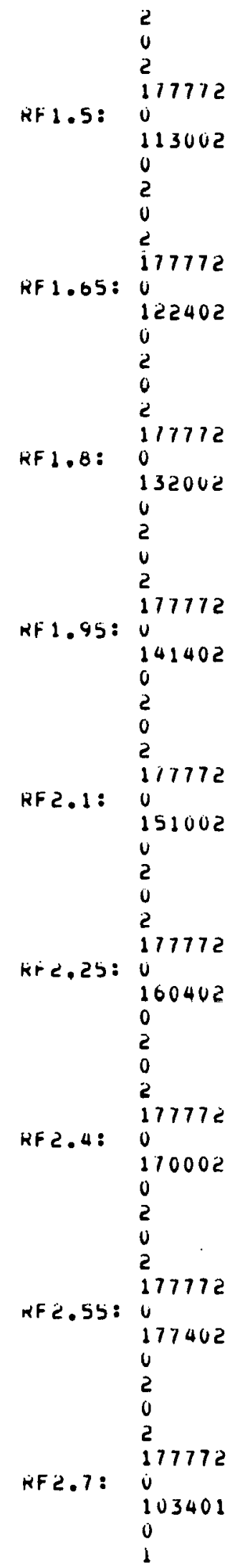




$$
\text { Kf 2.65: } \begin{gathered}
u \\
1 \\
177775 \\
0 \\
107201 \\
u \\
1 \\
0 \\
1 \\
177775
\end{gathered}
$$




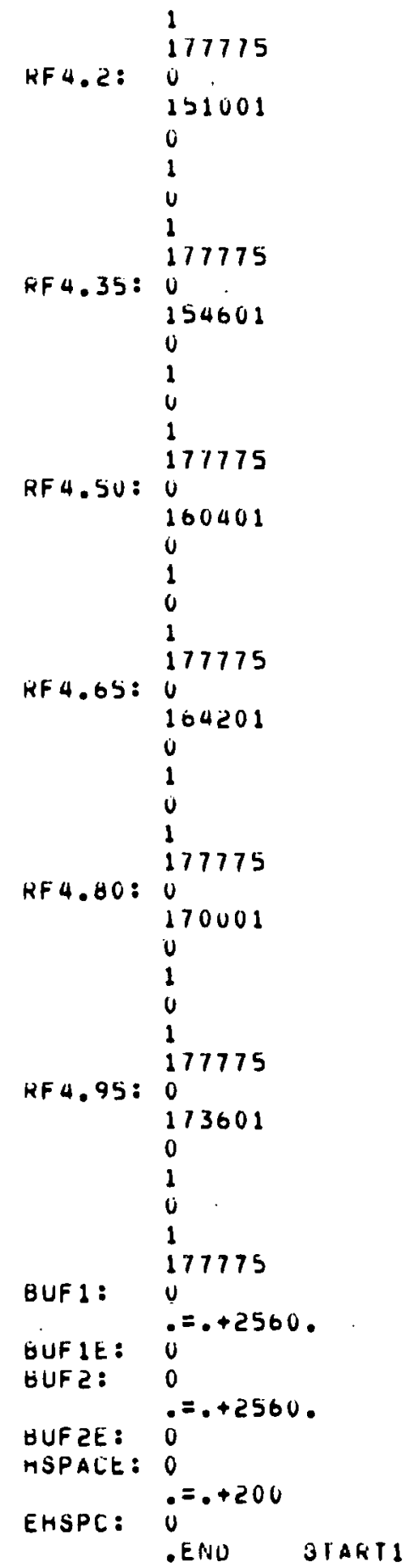




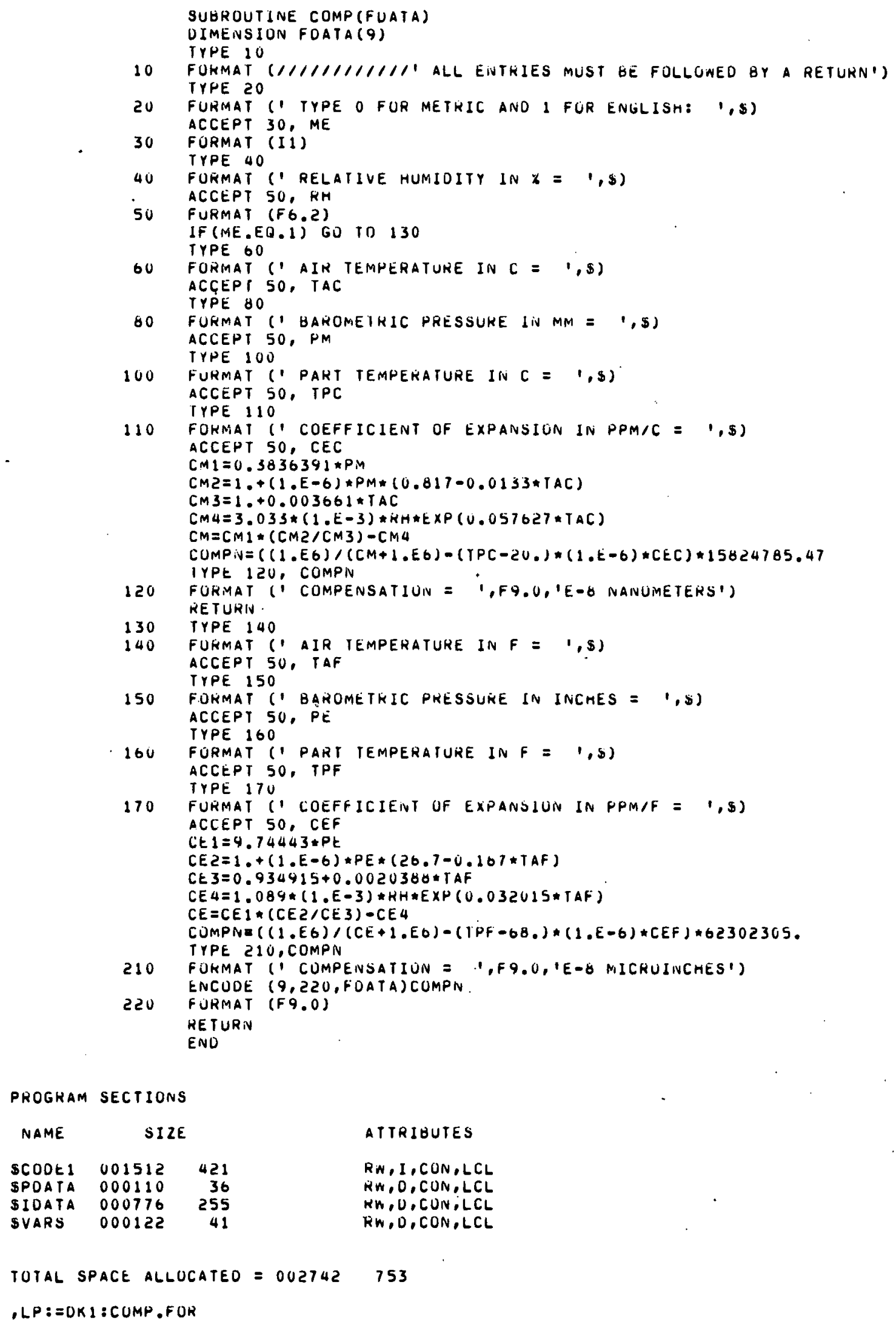


APPENDIX F

HARDWARE DRAWINGS 


\section{THIS PAGE ,}

WAS INTENTIONALLY

LEFT BLANK 

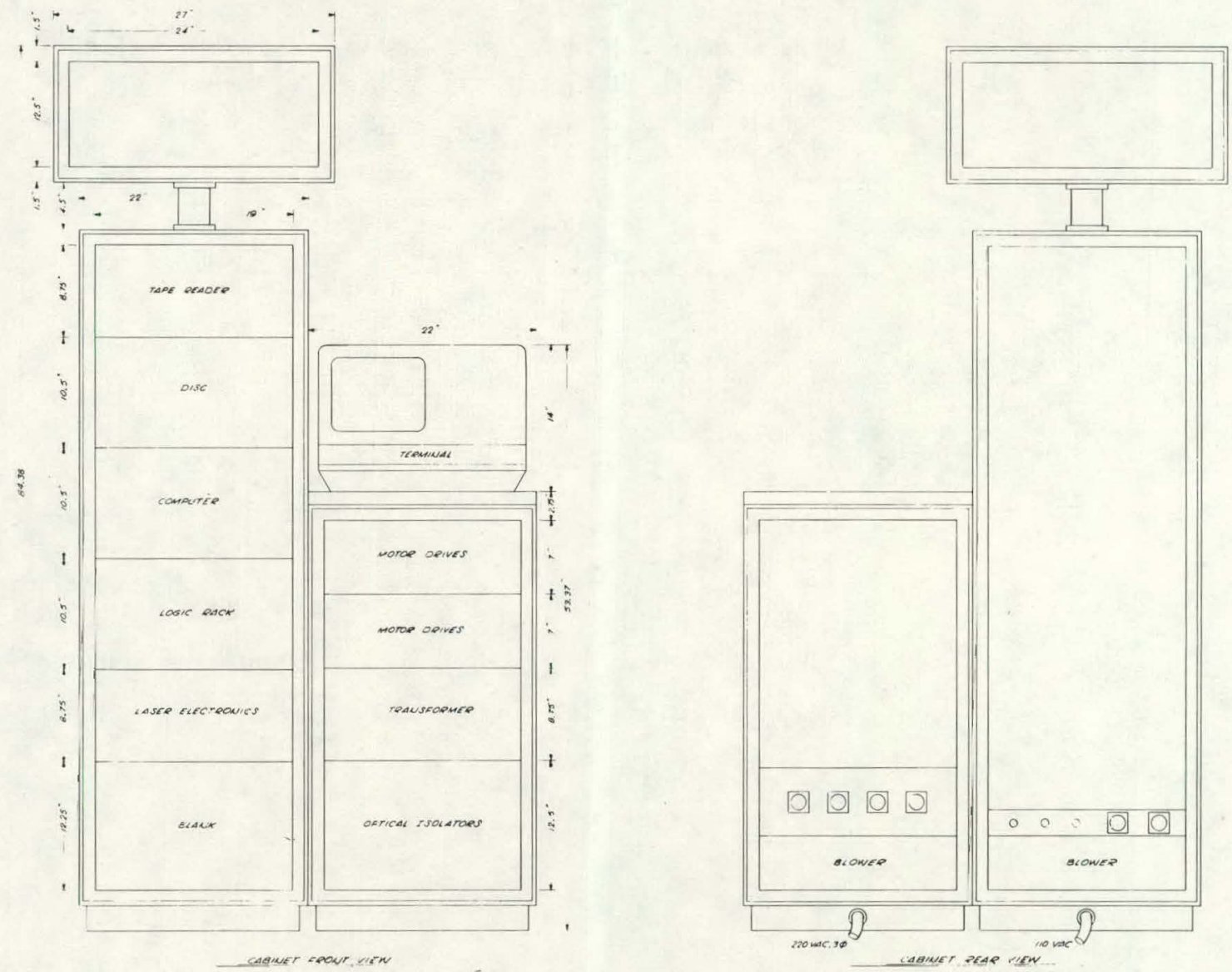

Figure F-1. LASER ERROR CORRECTION. (Cabinet Assembly) 


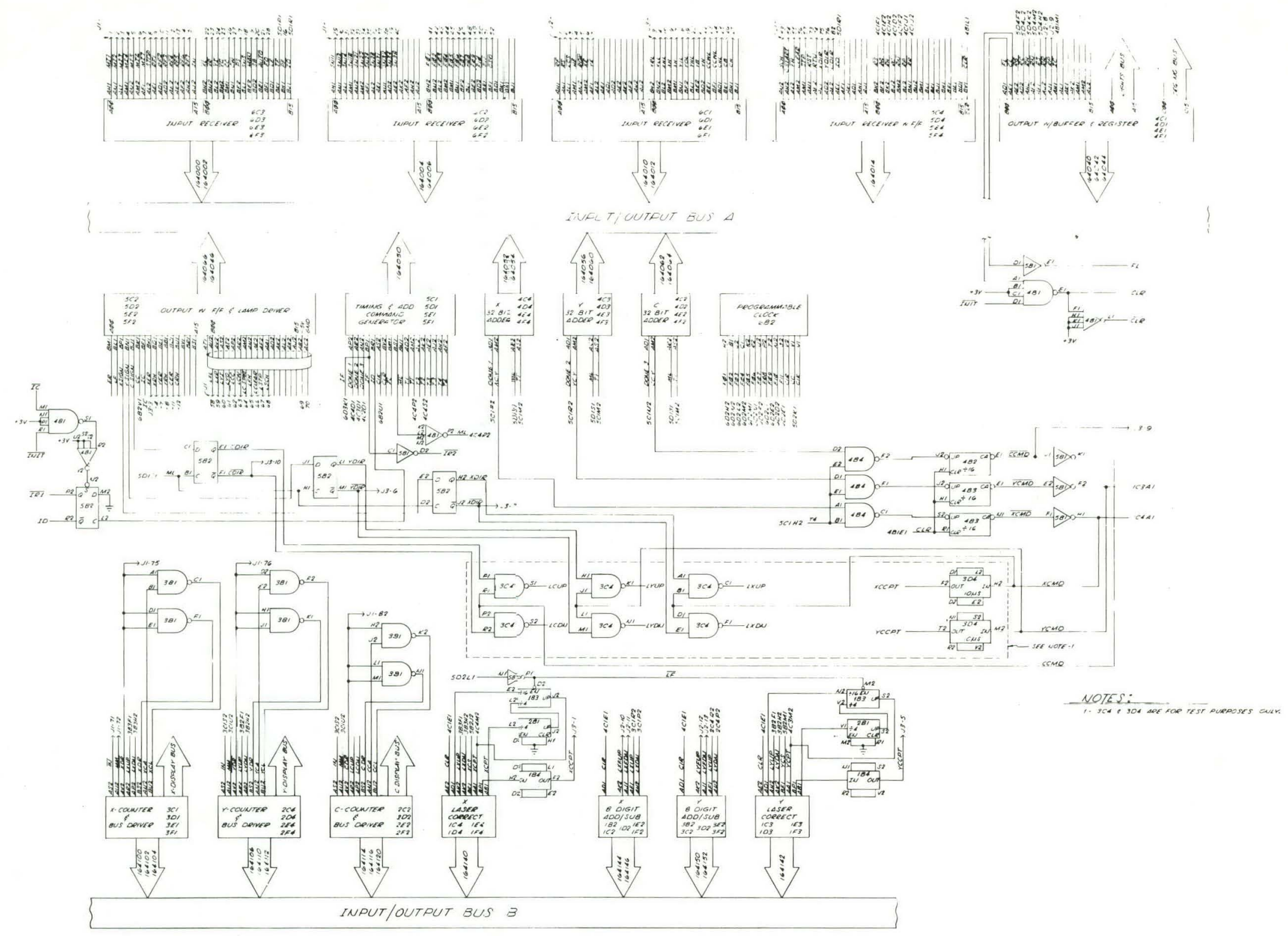

Figure F-2. LASER ERROR CORRECTION. (System Block Diagram) 


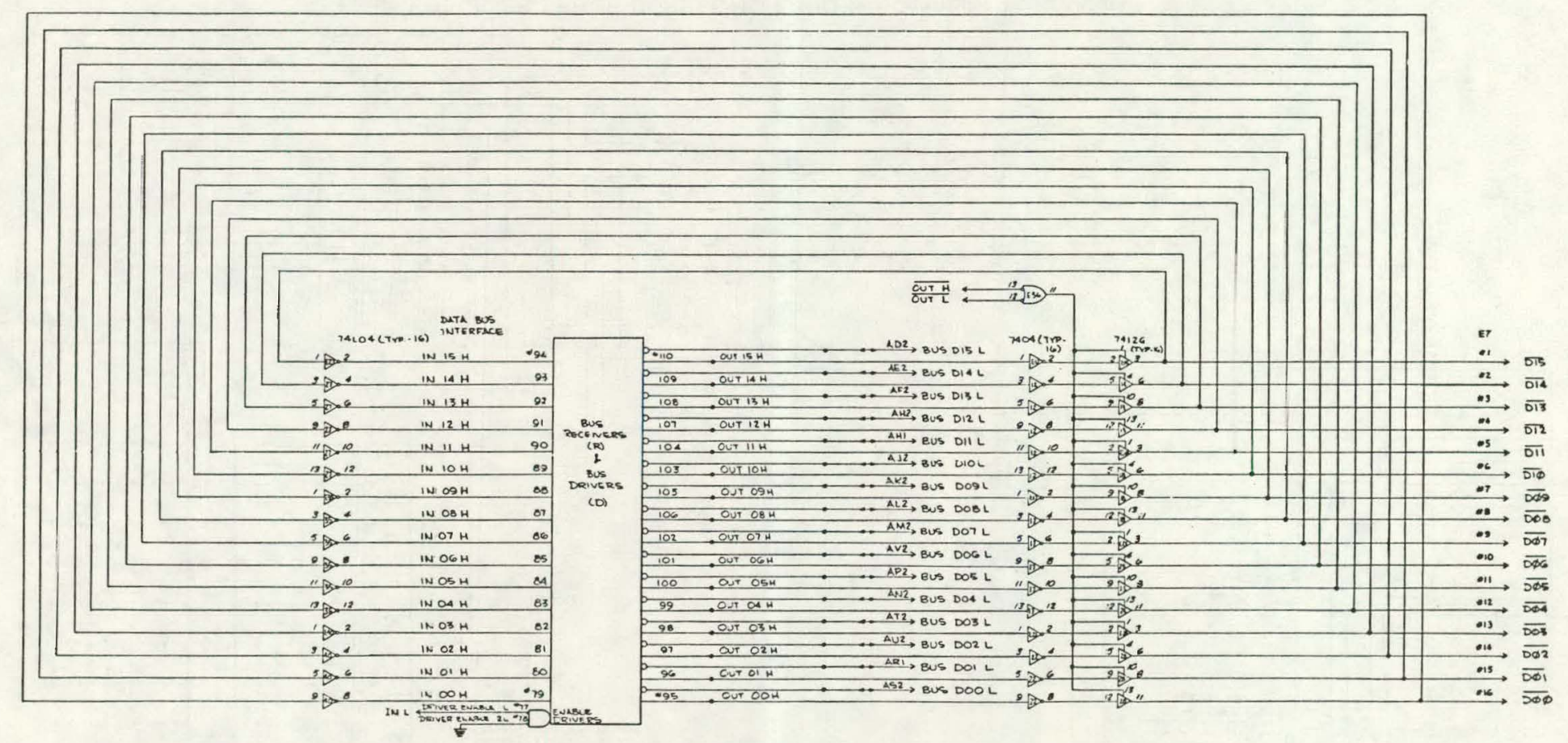

Figure F-3. LASER ERROR CORRECTION. (I/O Bus Controller Logic Diagram, Sheet ") 

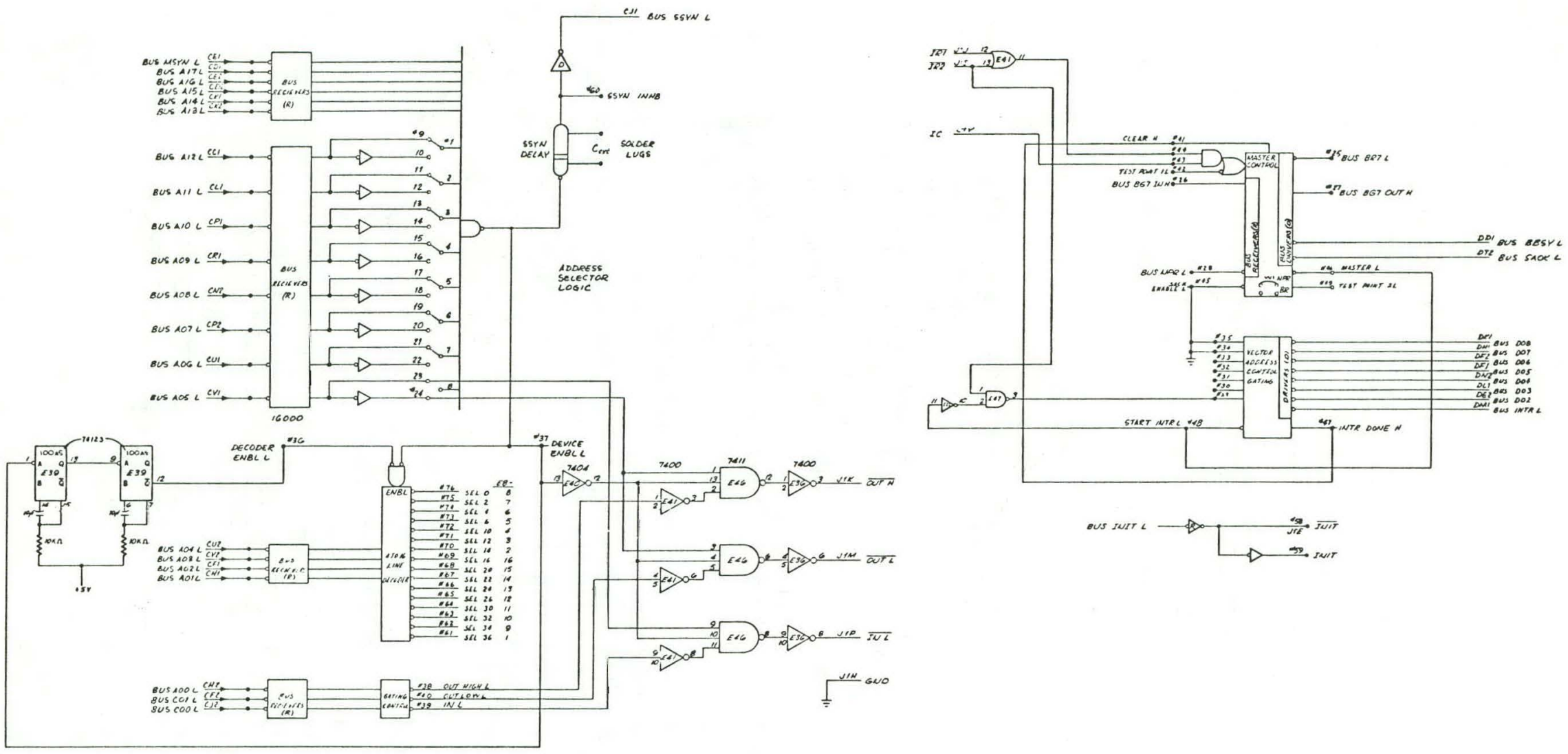

Figure F-4. LASER ERROR CORRECTION. (I/O Bus Controller Logic Diagram, Sheet 2) 


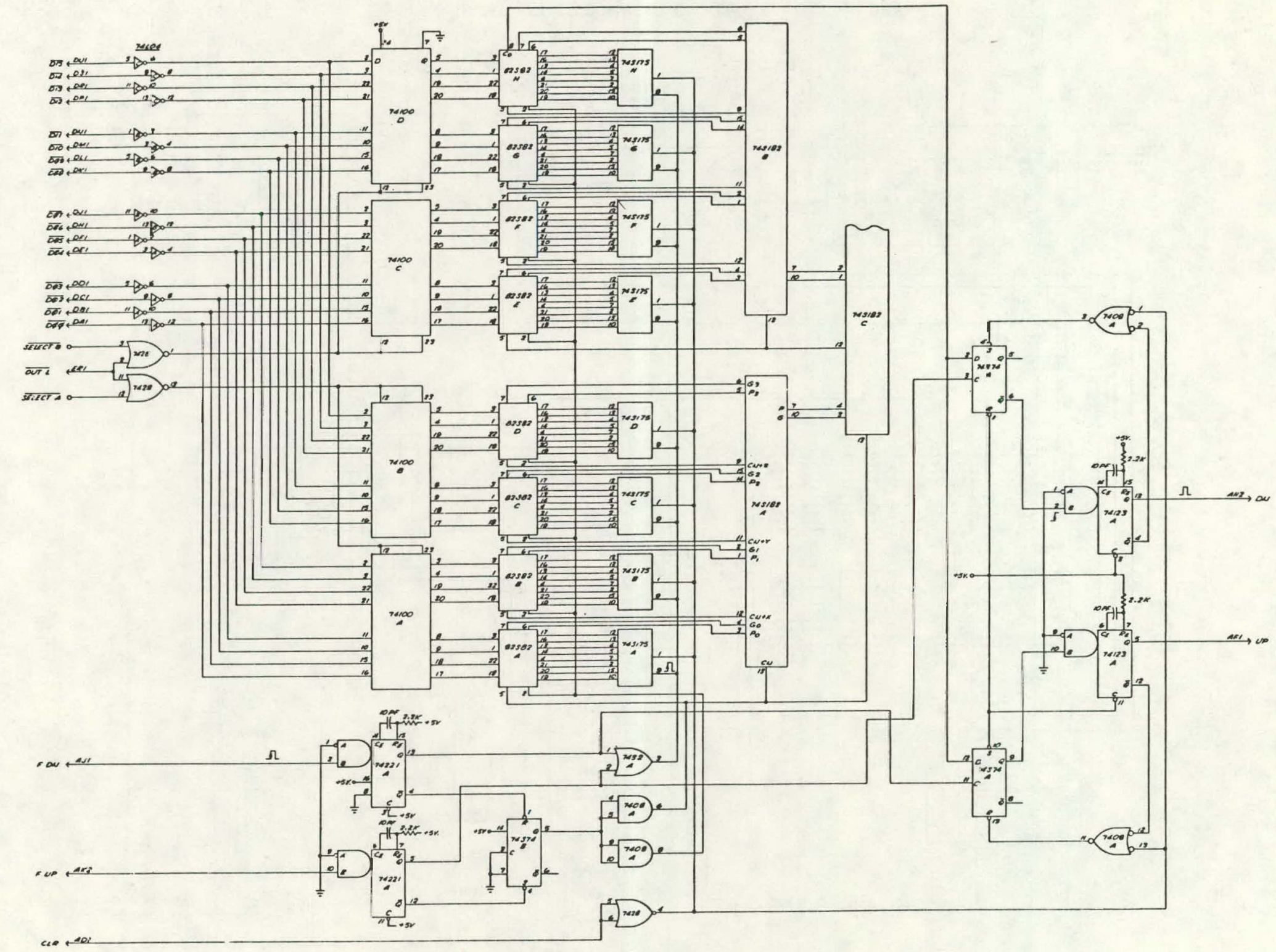

Figure F-5. LASER ERROR CORRECTION. (8-Digit Add/Sub Logic Diagram) 


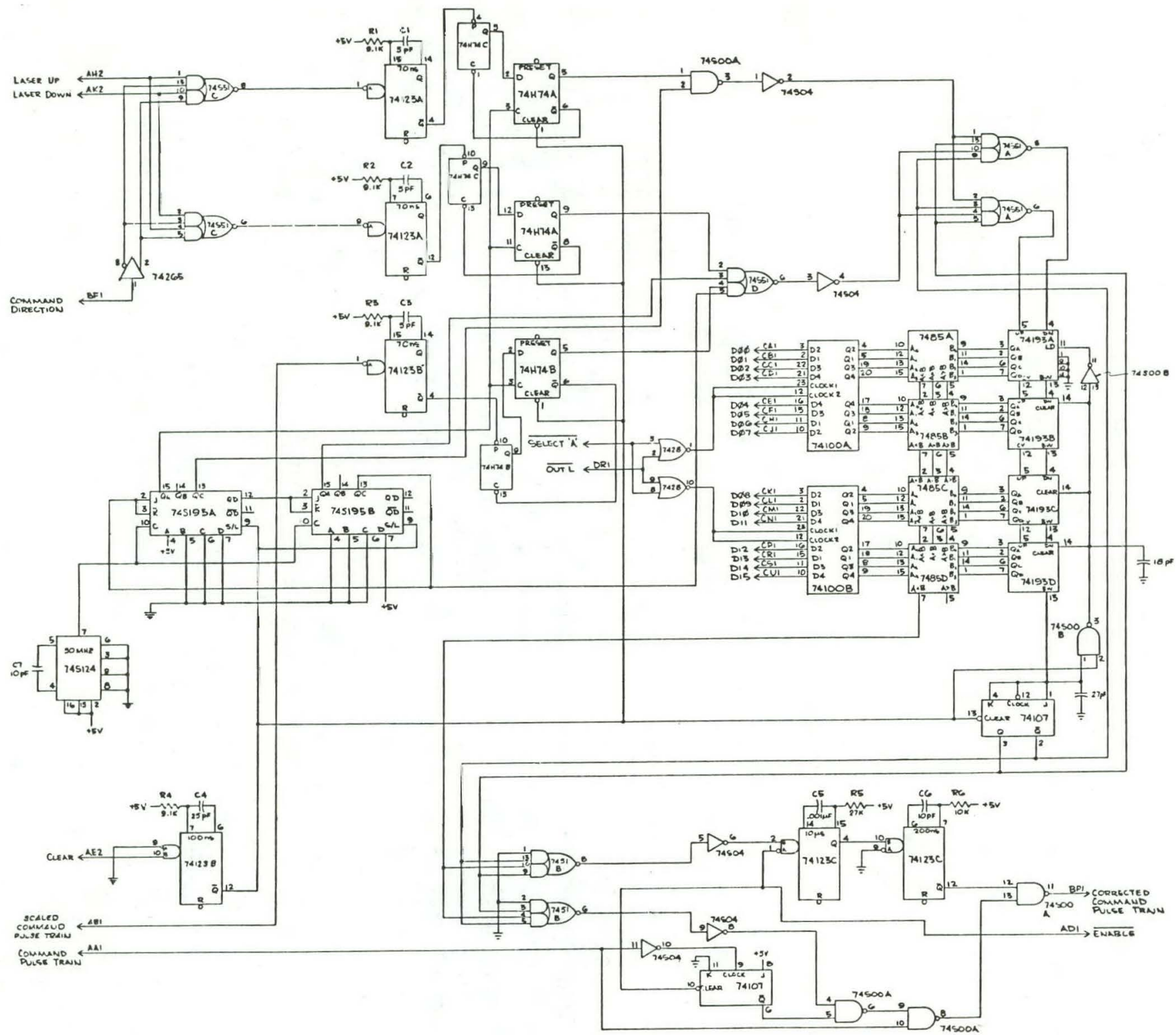

Figure F-6. LASER ERROR CORRECTION. (Laser Correct Logic Diagram) 


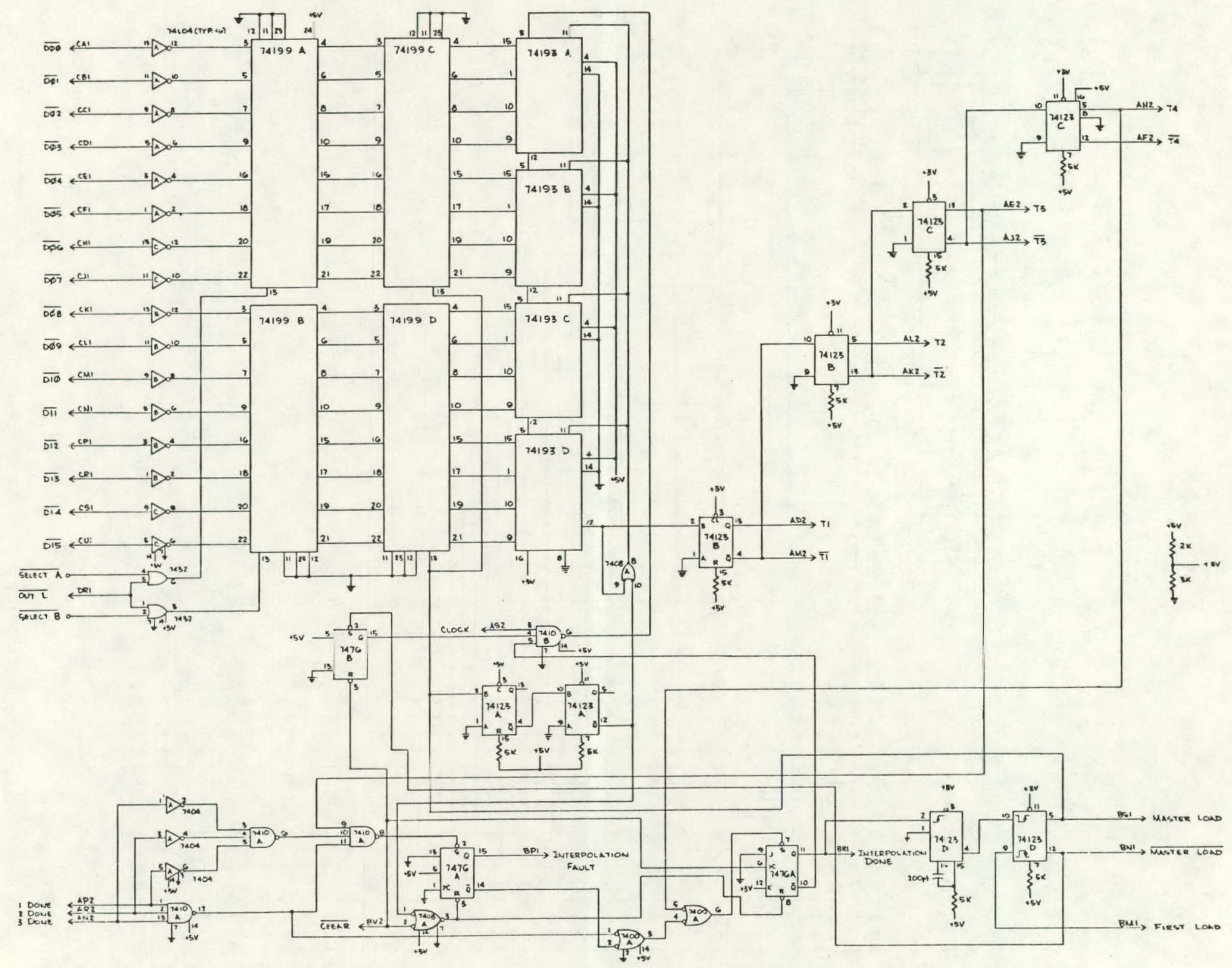

Figure F-7. LASER ERROR CORRECTION. (Timing and Add Command Generator Logic Diagram) 


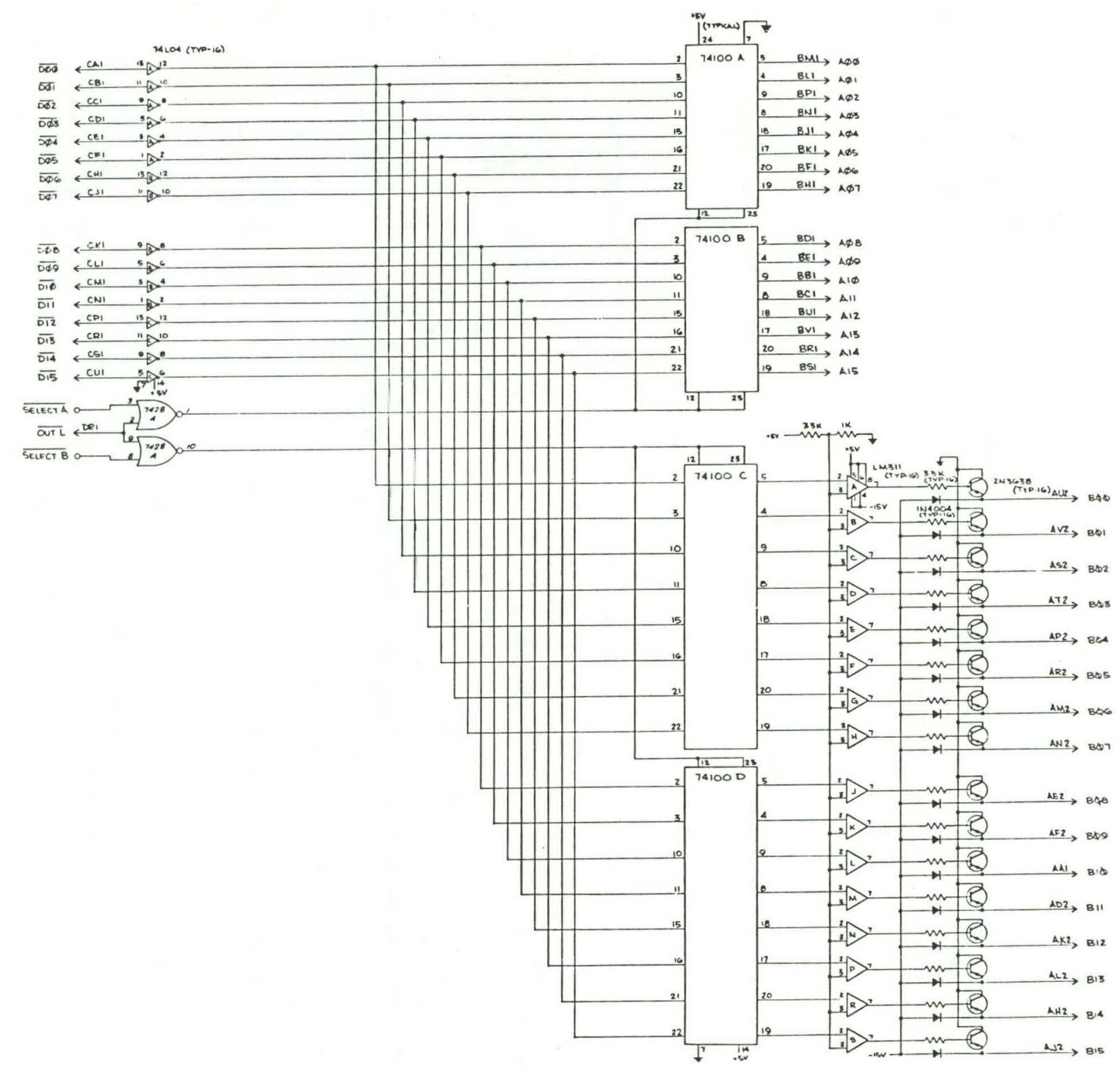

Figure F-8. LASER ERROR CORRECTION. (32-Bit Adder Logic Diagram) 


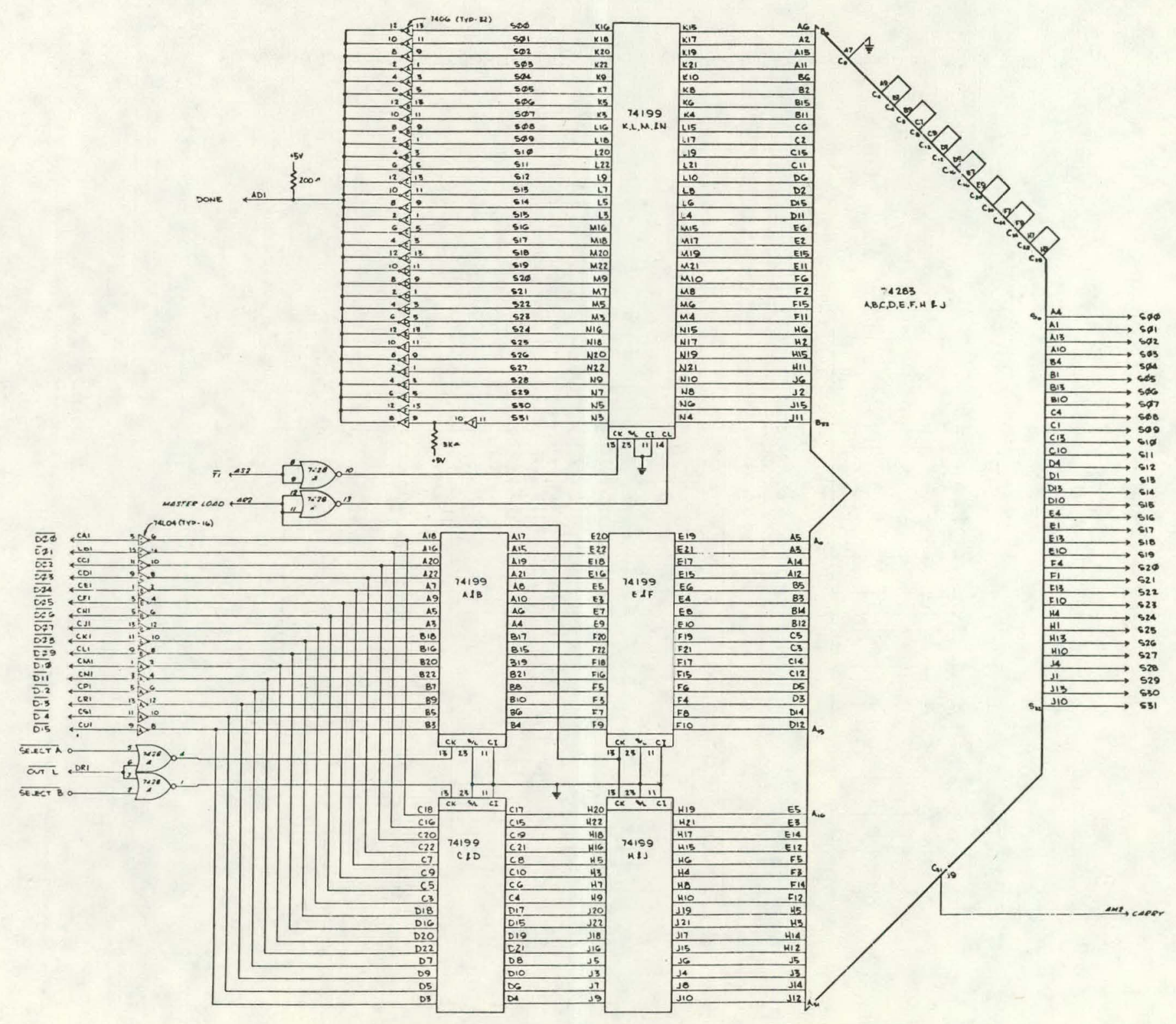

Figure F-9. LASER ERROR CORRECTION. (Output W F/F and Lamp Driver's Logic Diagram 


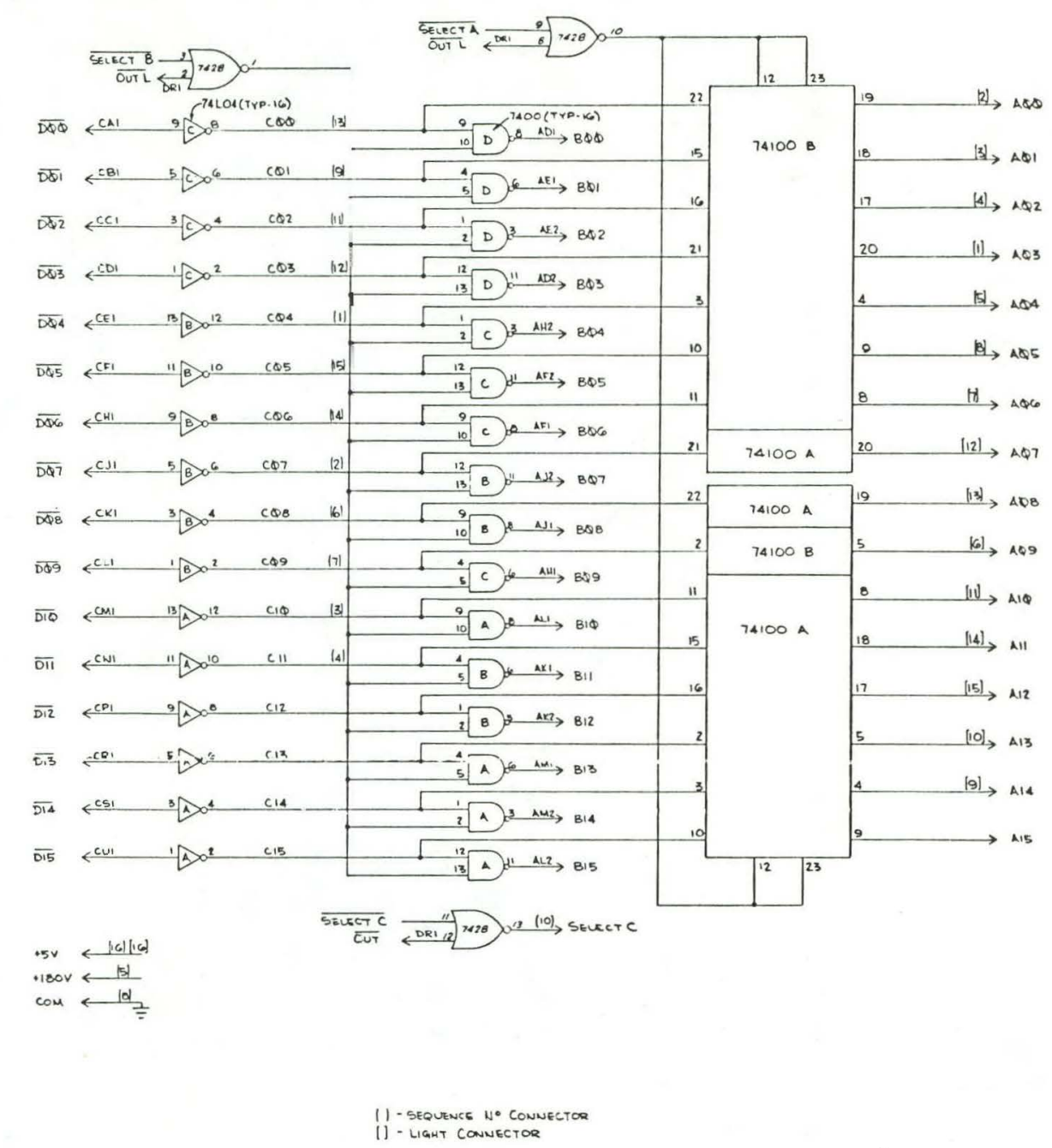

Figure F-10. LASER ERROR CORRECTION. (Output W/Buffer and Register Logic Diagram) 


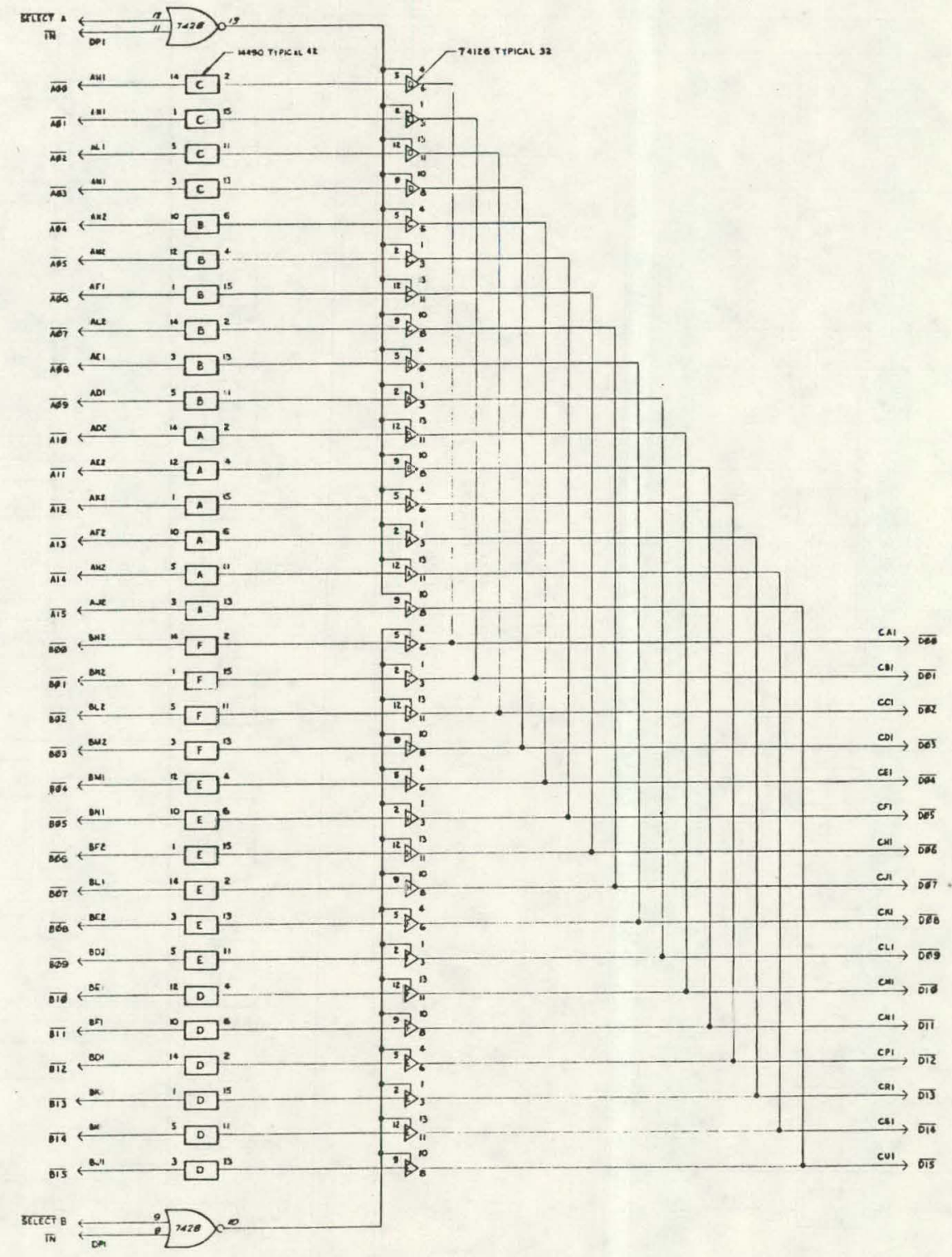

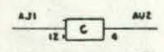

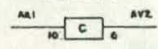

ax $=0.02$

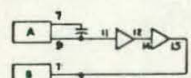

(c)

C.

6

(4) 

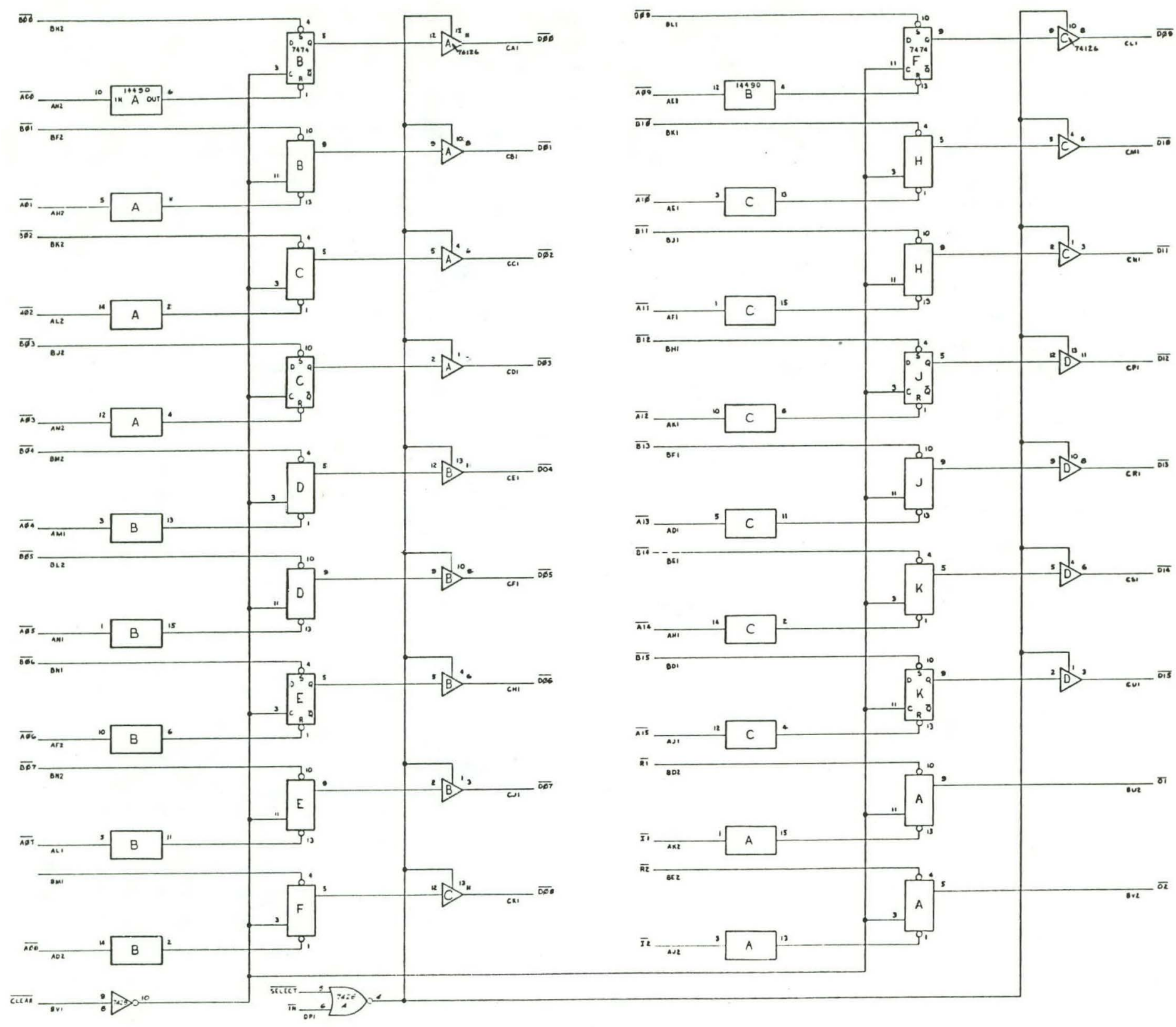

Figure F-12. LASER ERR.JR CORRECTION. (Input Receiver W F/F Logic Diagram) 


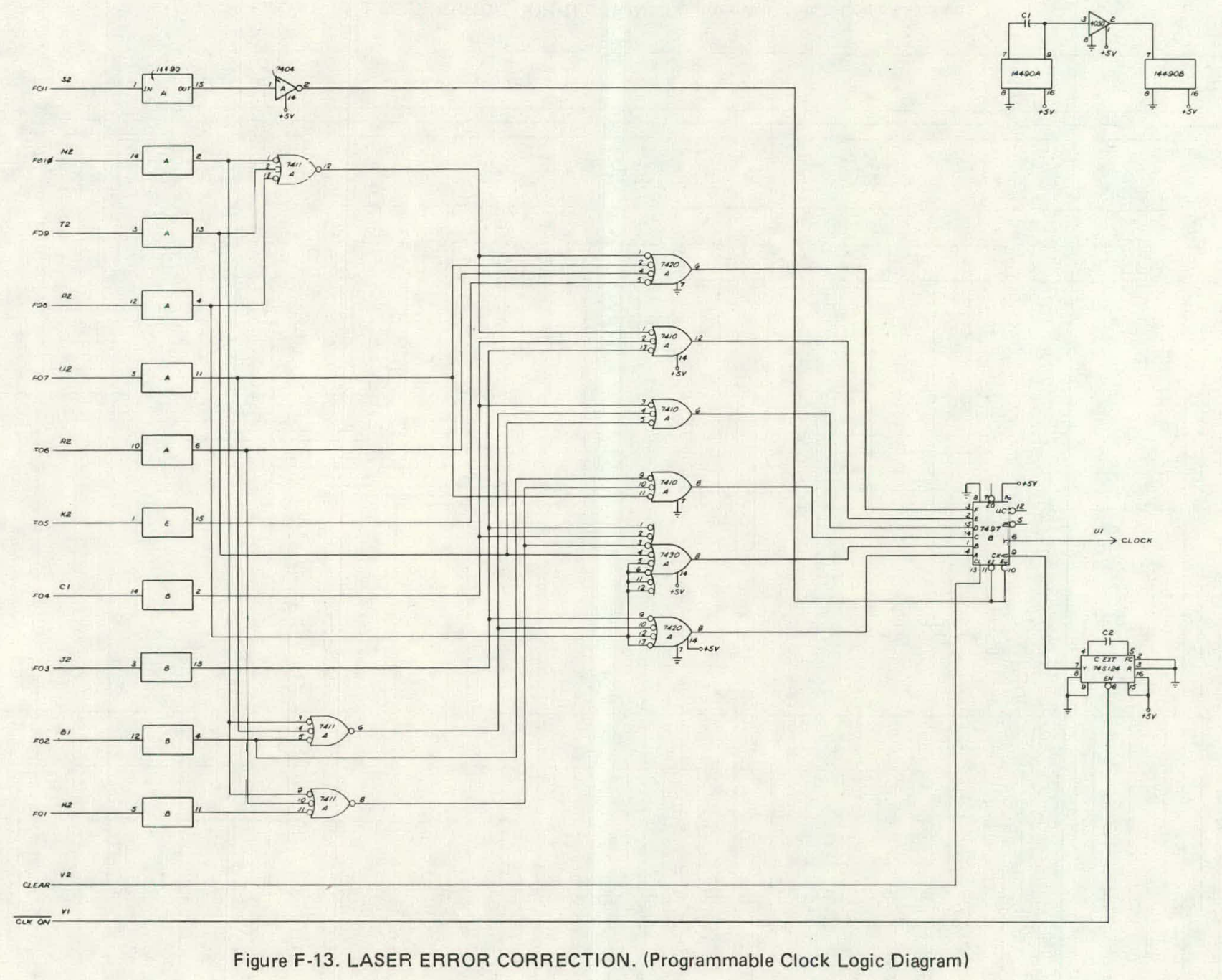




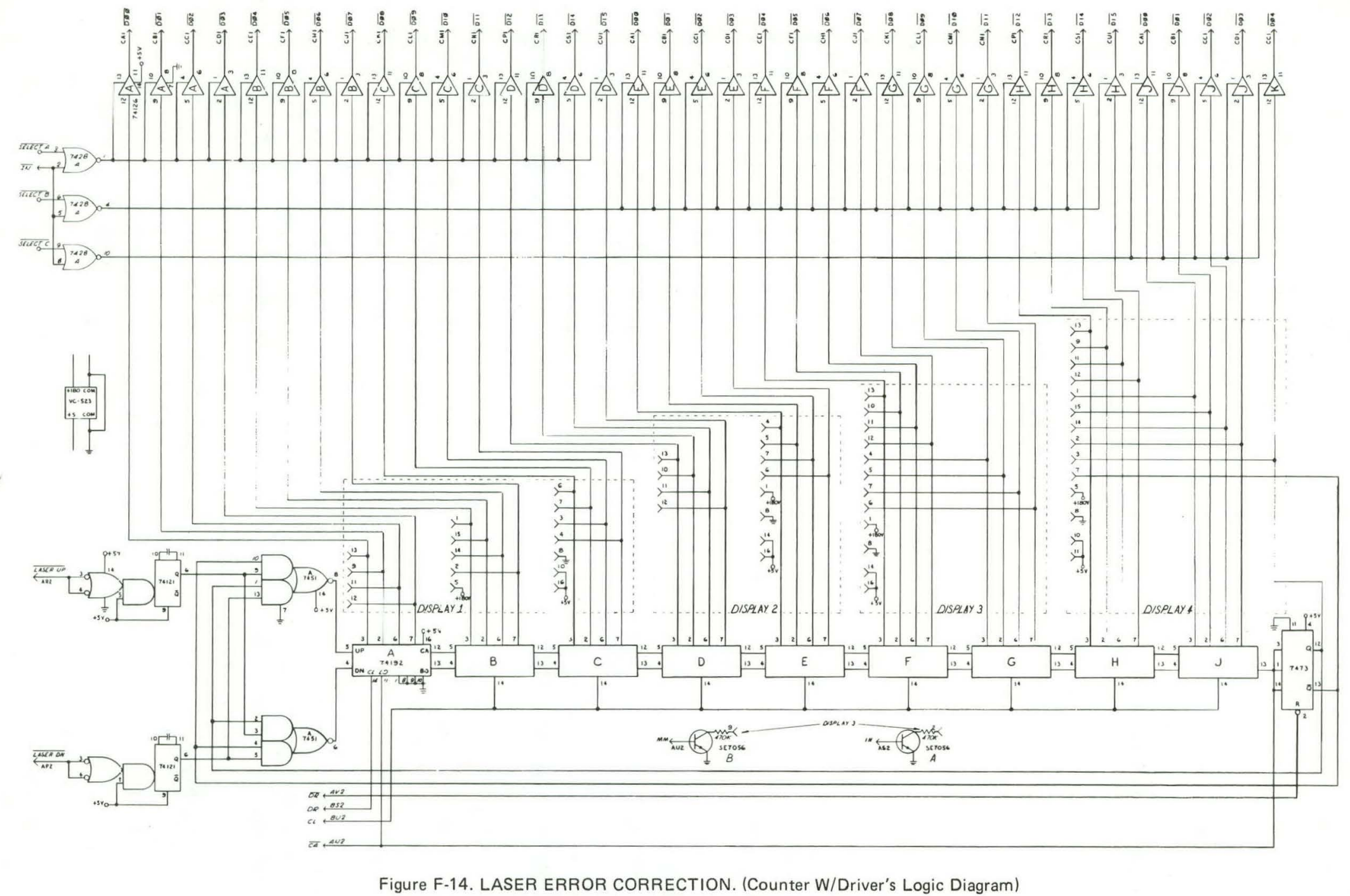



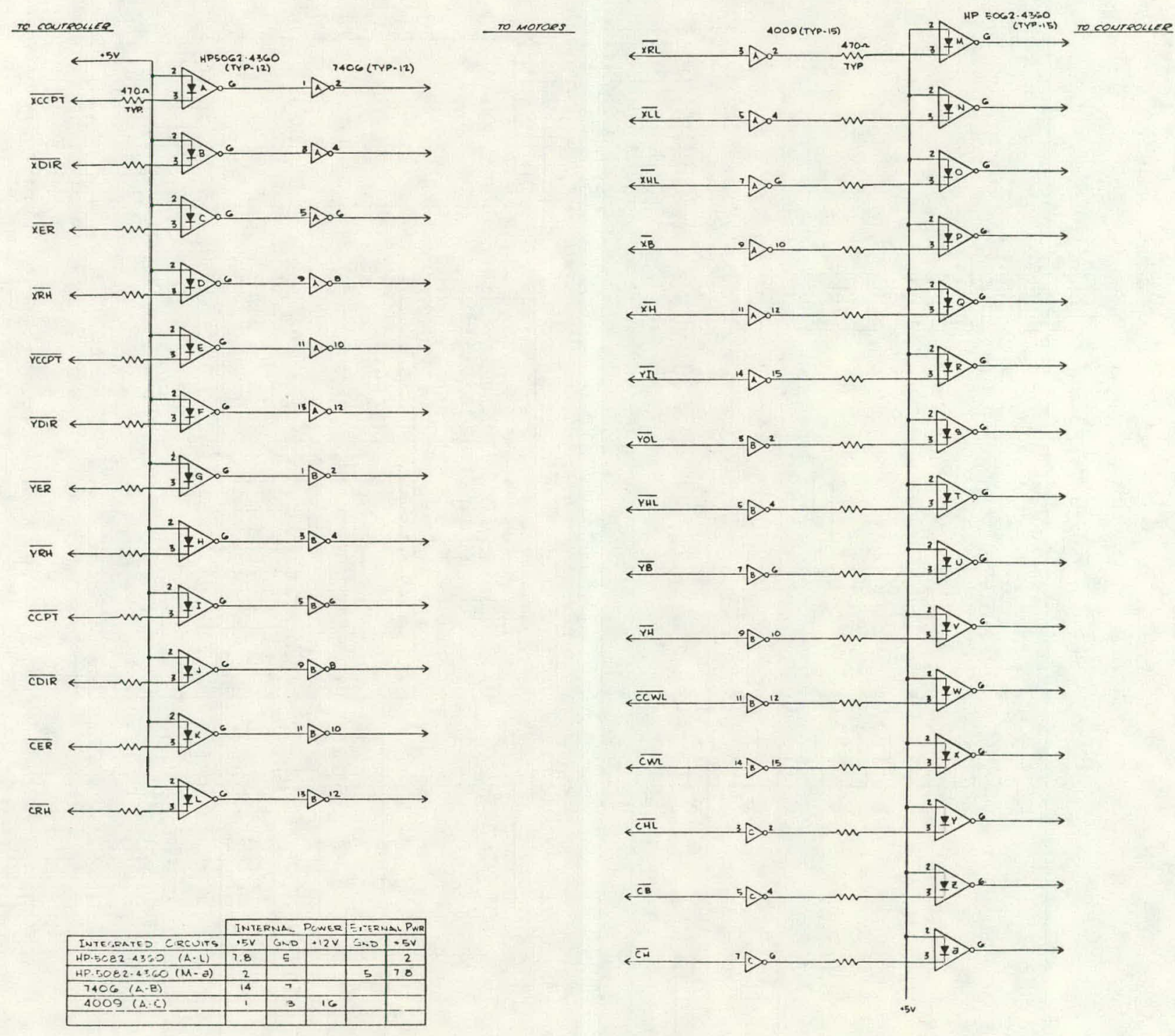

Fiçure F-15. LASER ERROR CORRECTION. (Optical Isolator Logic Diagram) 


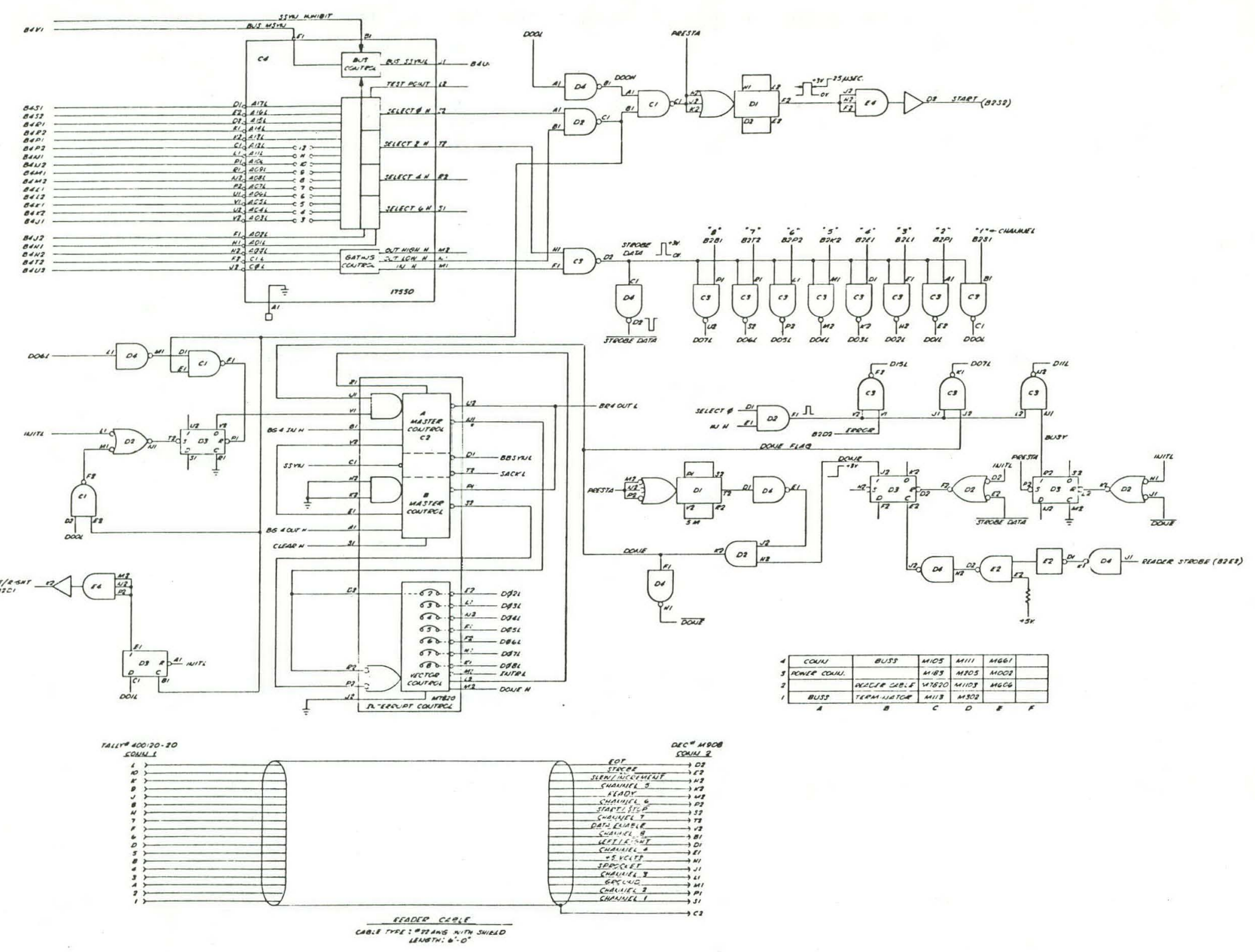

Figure F-16. LASER ERROR CORRECTION. (Reader Interface Schematic) 


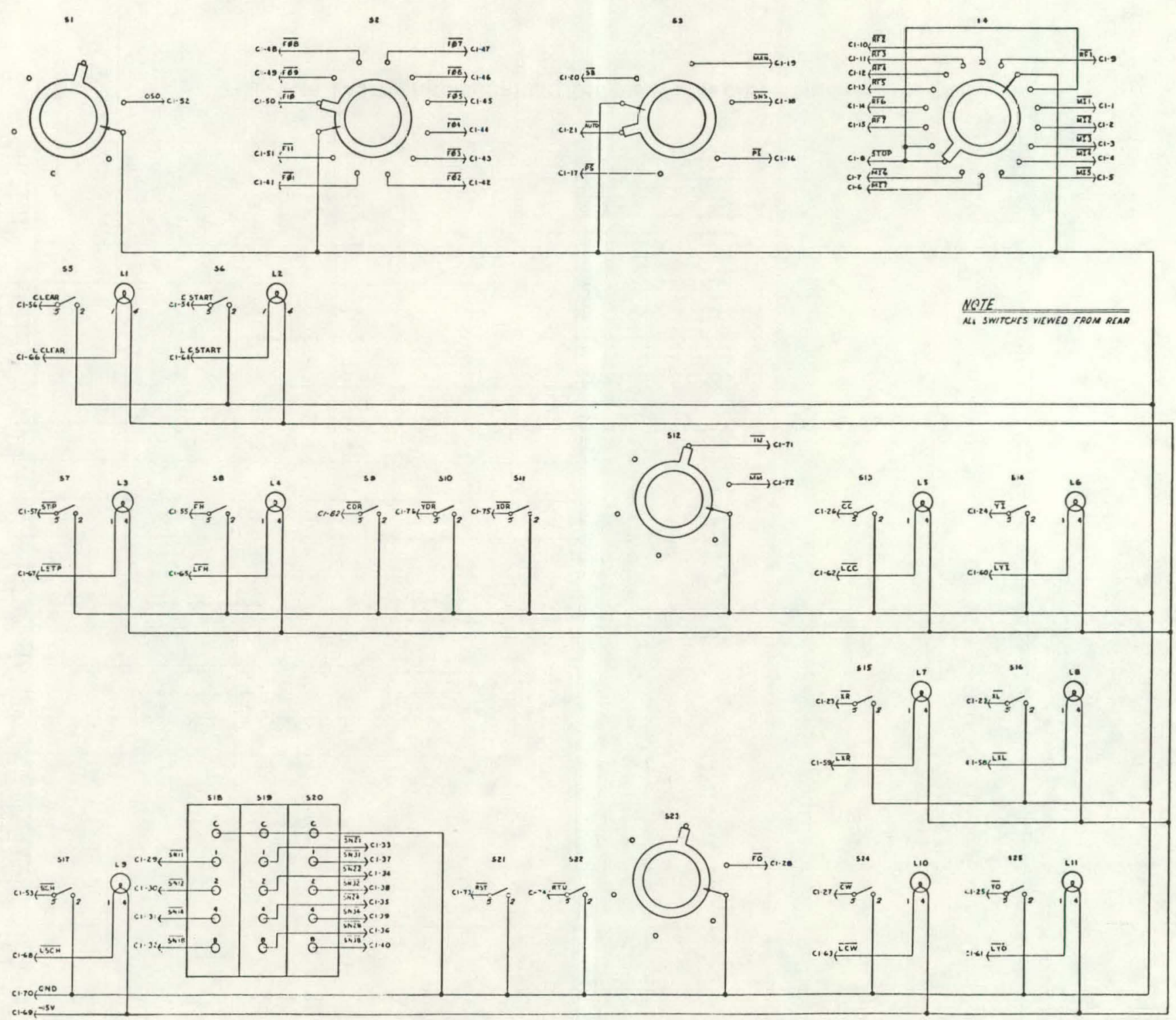

Figure F-17. LASER ERROR CORRECTION. (Control Panel Wiring Diagram) 

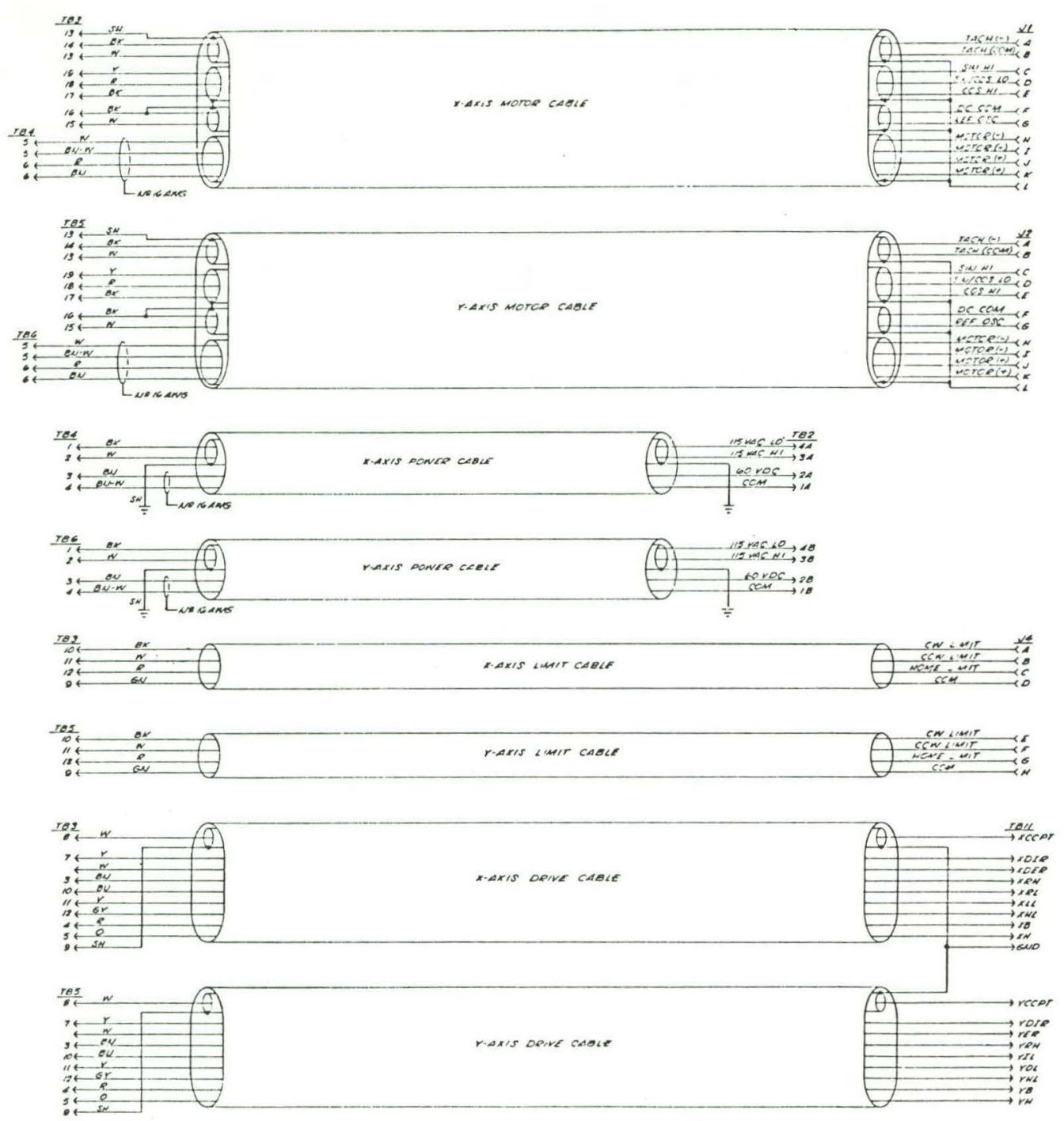

Figure F-18. LASER ERROR CORRECTION. (Motor Drive Cabinet Interconnecting Cables) 

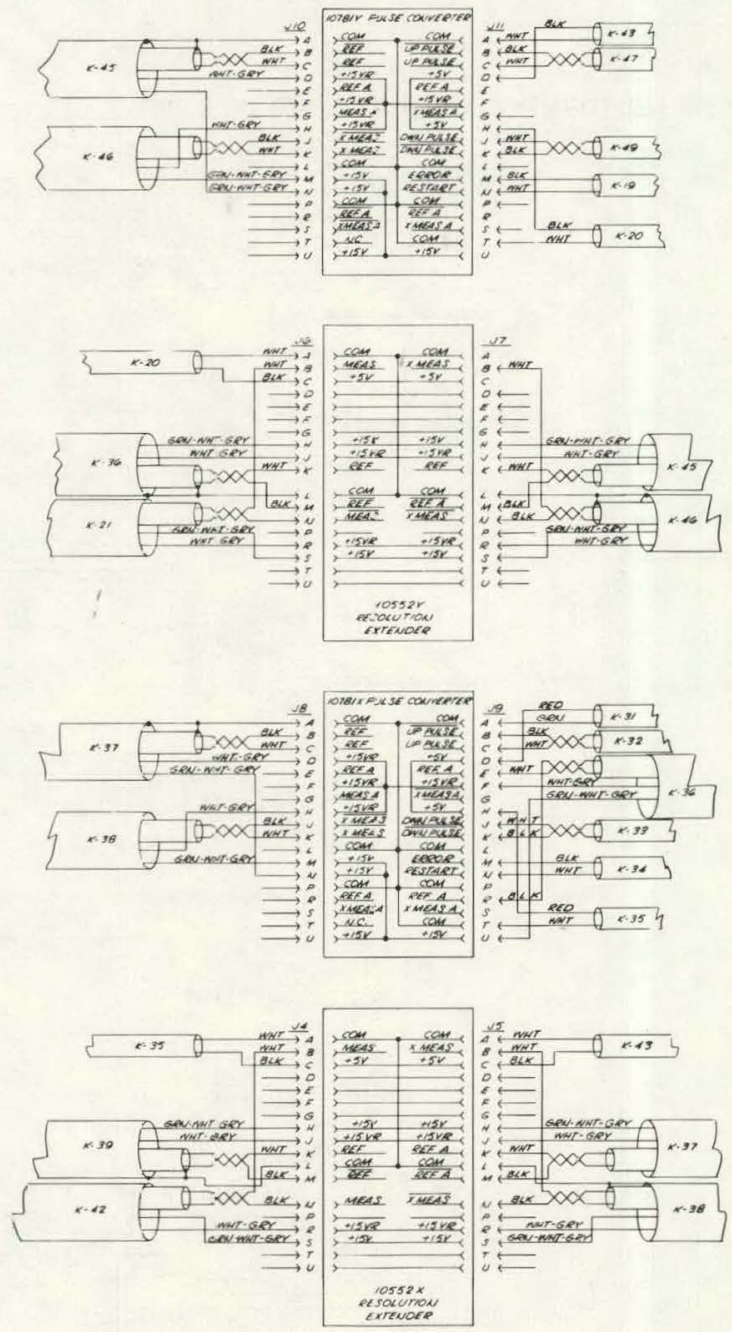

Figure F-19. LASER ERROR CORRECTION. (Control Cabinet Interconnecting Cables)

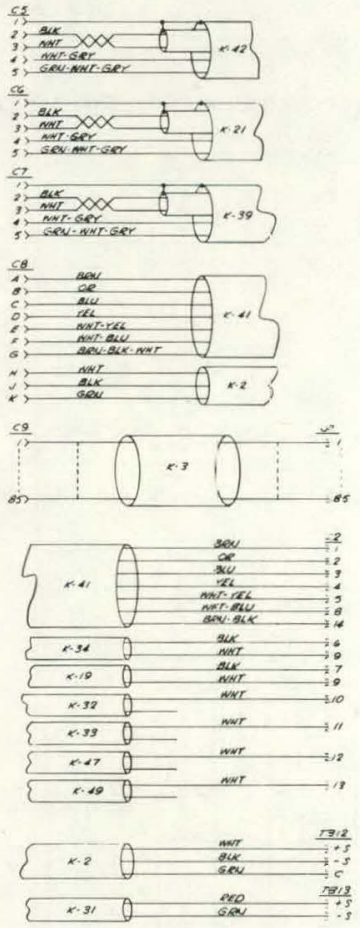




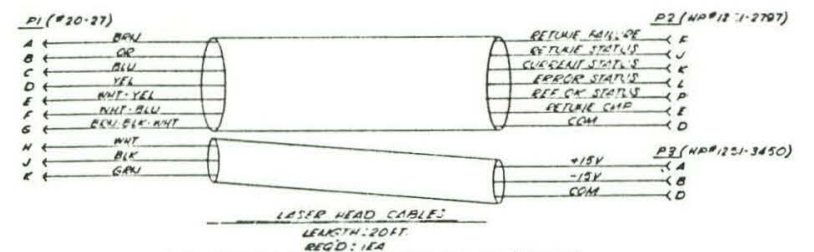

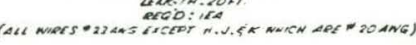
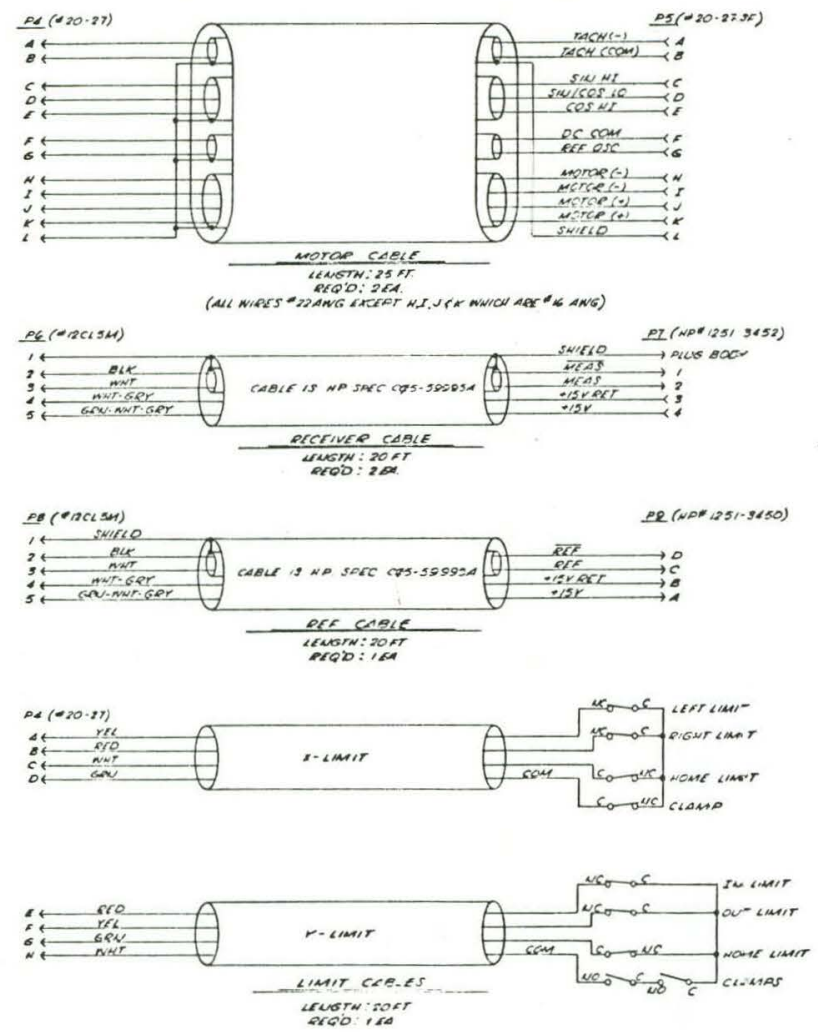

Figure F-20. LASER ERROR CORRECTION. (Miscellaneous Cable and Module Utilization)

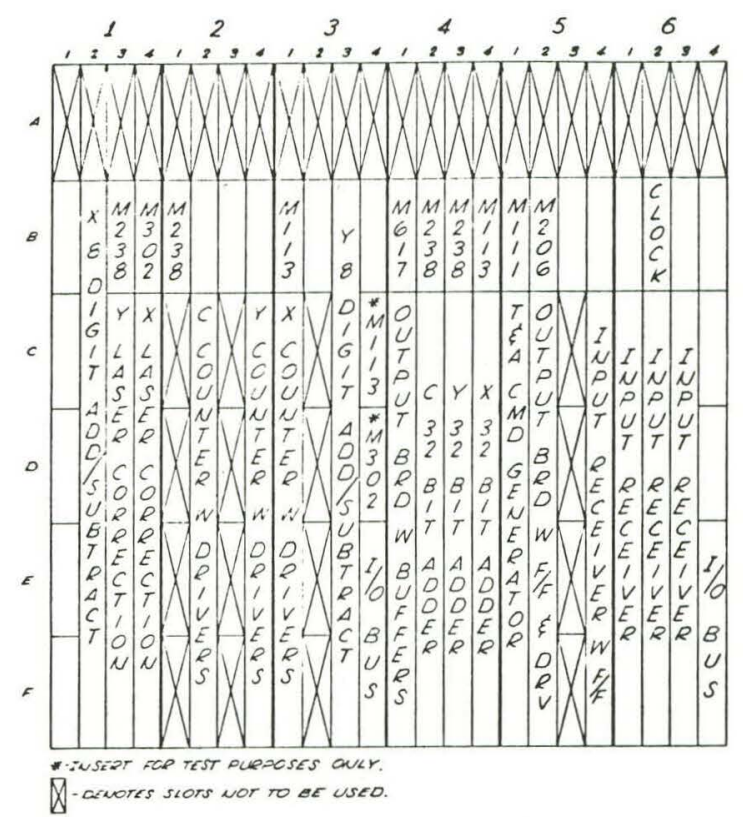

LOGIS PACK MODULE UTILIZATION 

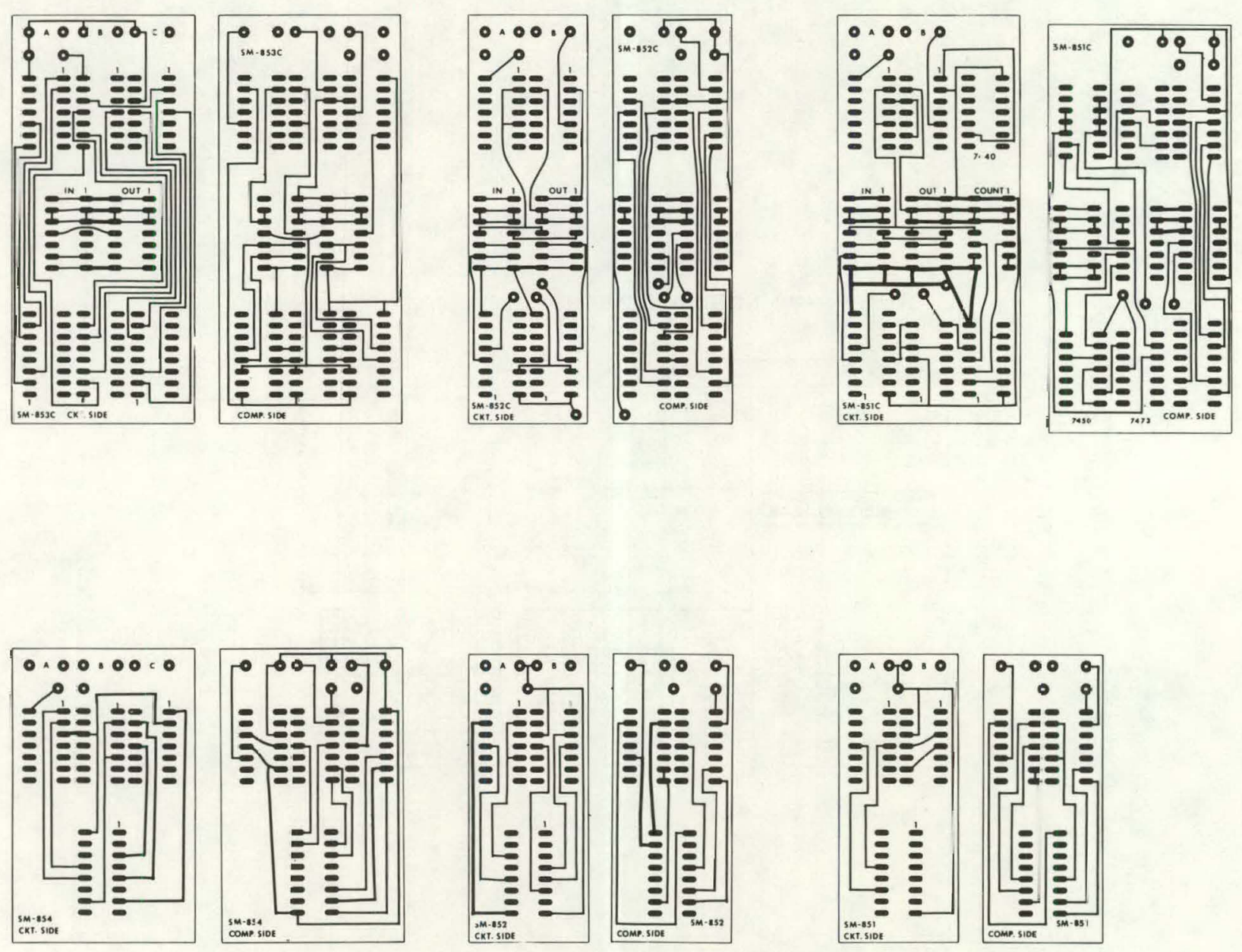

Figure $=-21$. LASER ERROR CORRECTION. (Display PC/Boardi 


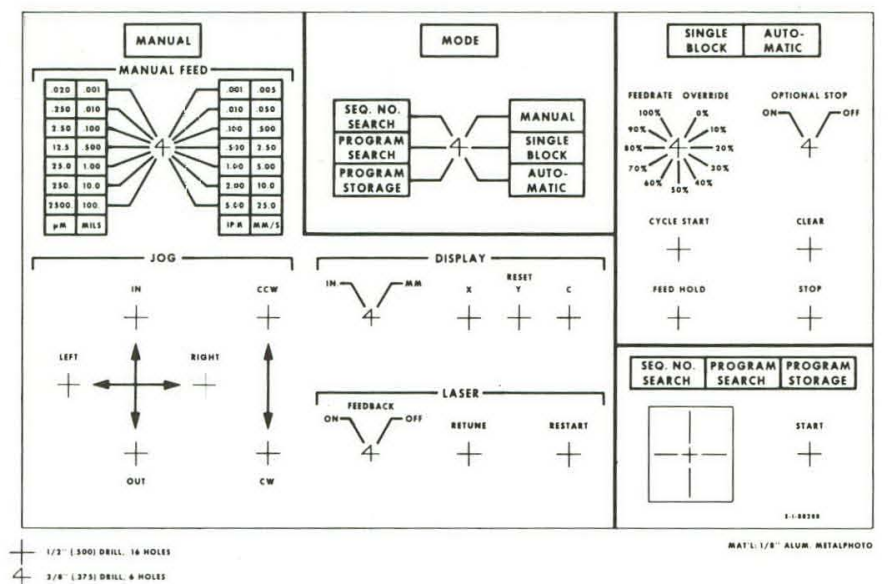

Figure F-22. LASER ERROR CORRECTION. (Control Panel) 
ree

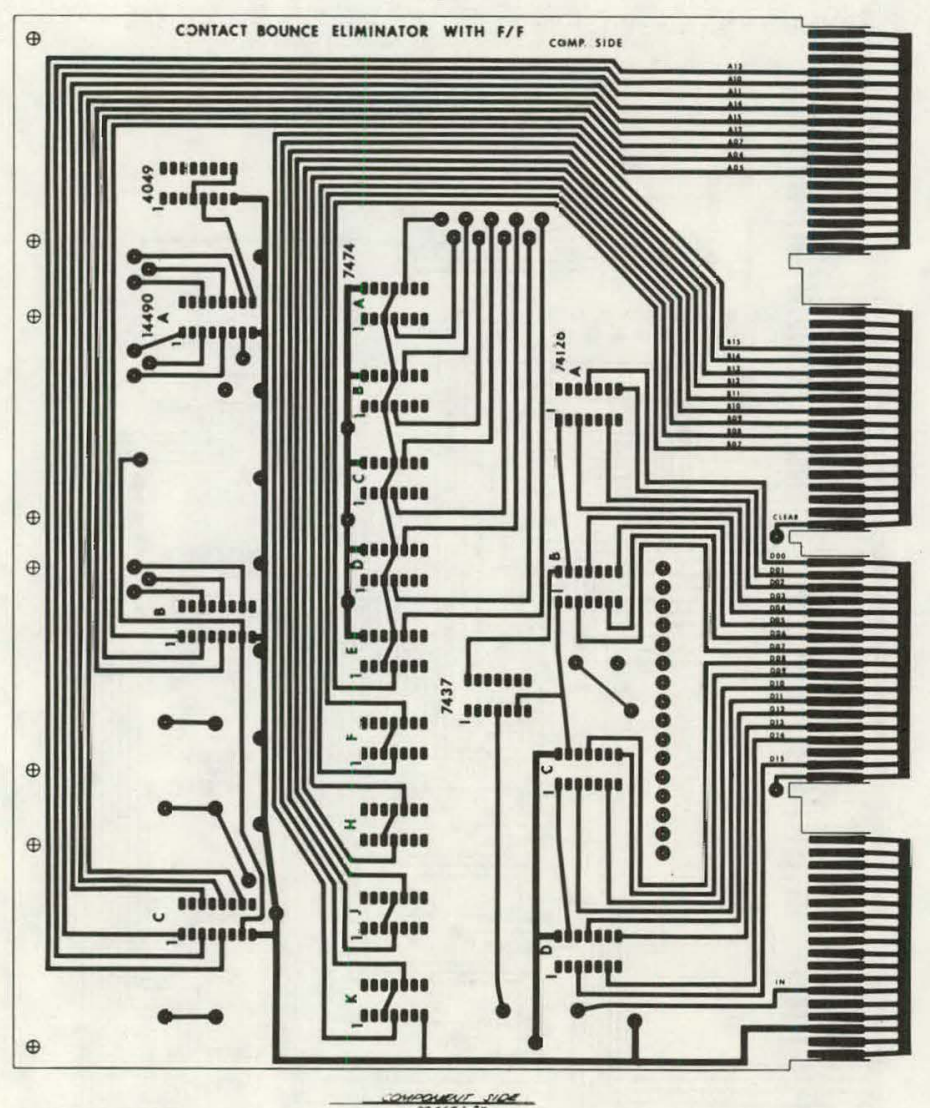

roe

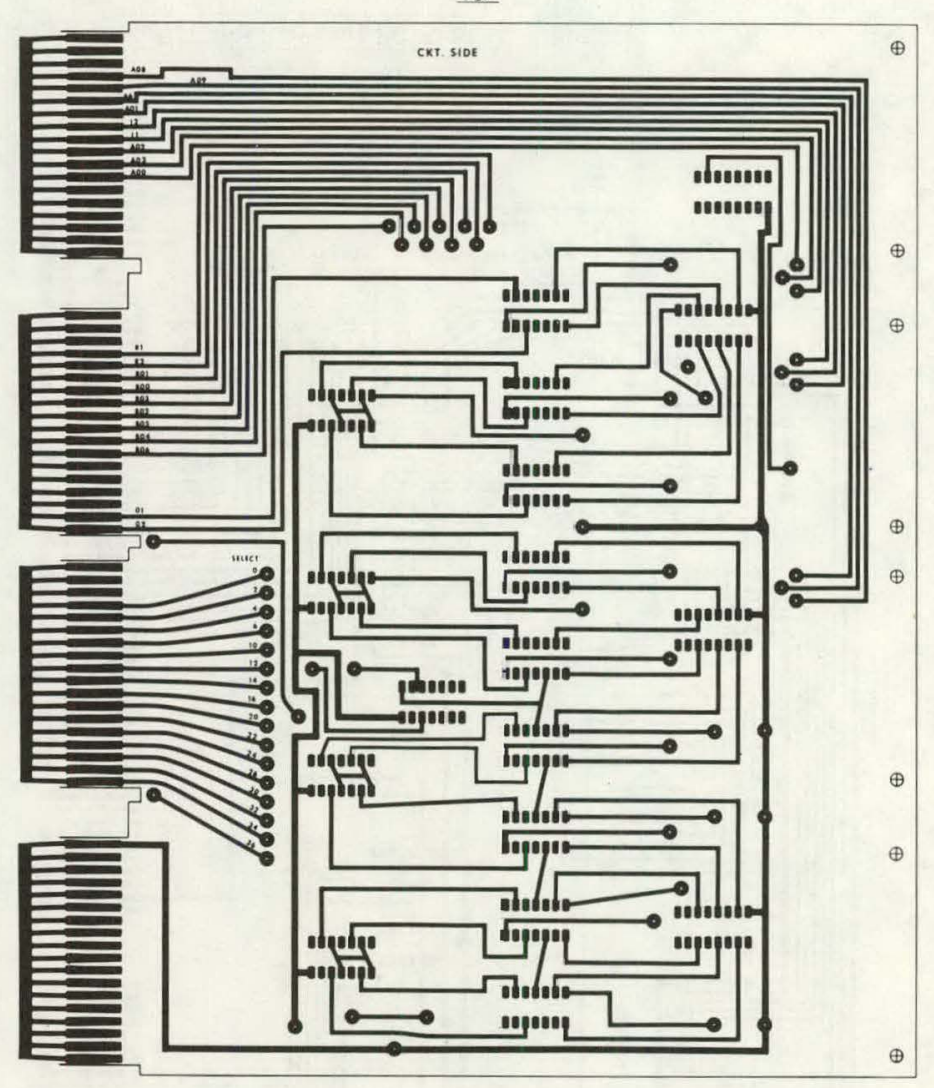

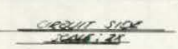

Figure F-23. LASER ERROR CORRECTION. (Input Receiver W F/F PC/Board) 
res
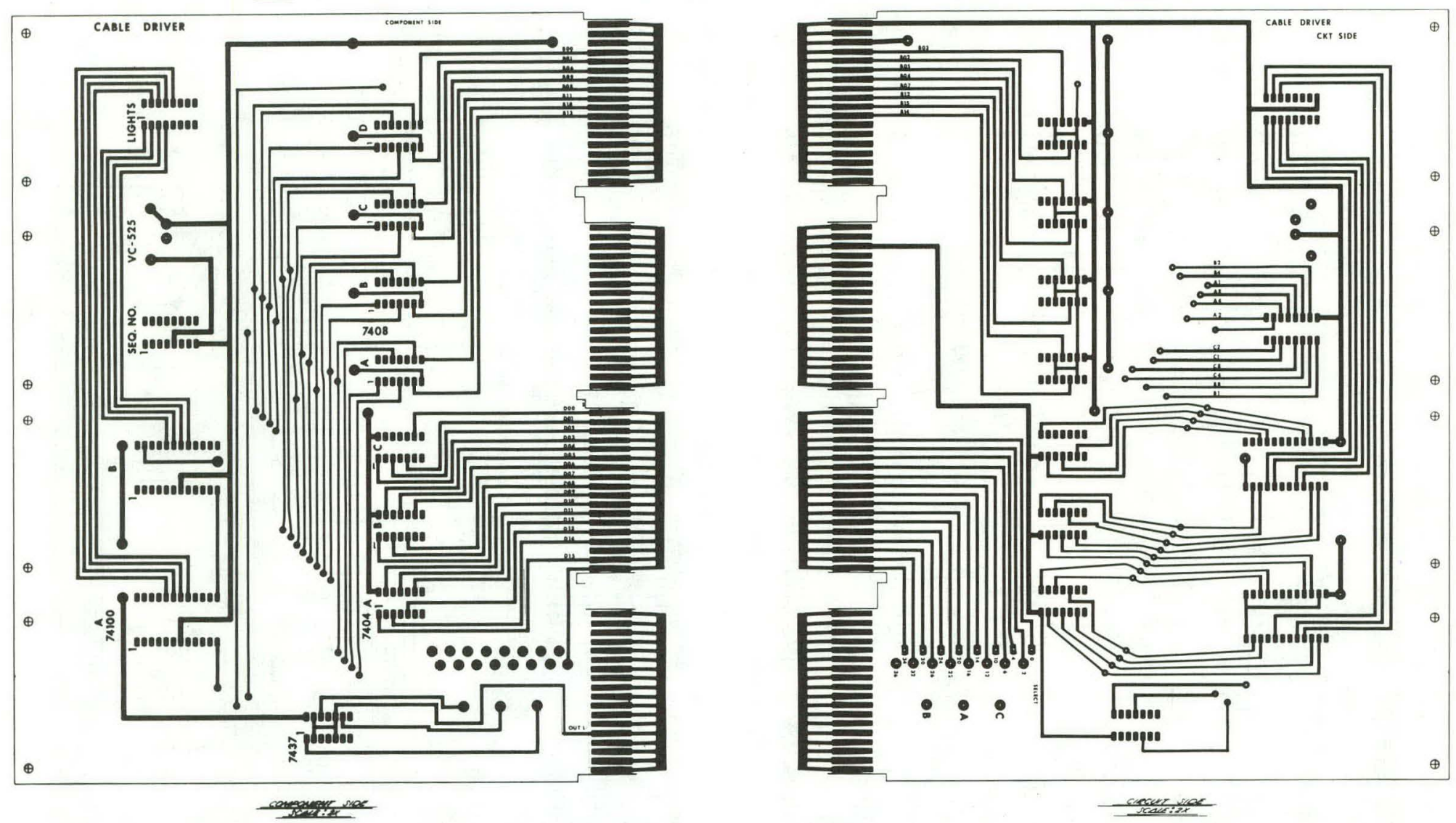

Figure F-24. LASER ERRO₹ CORRECTION. (Output W Buffer and Registers PC/Board) 


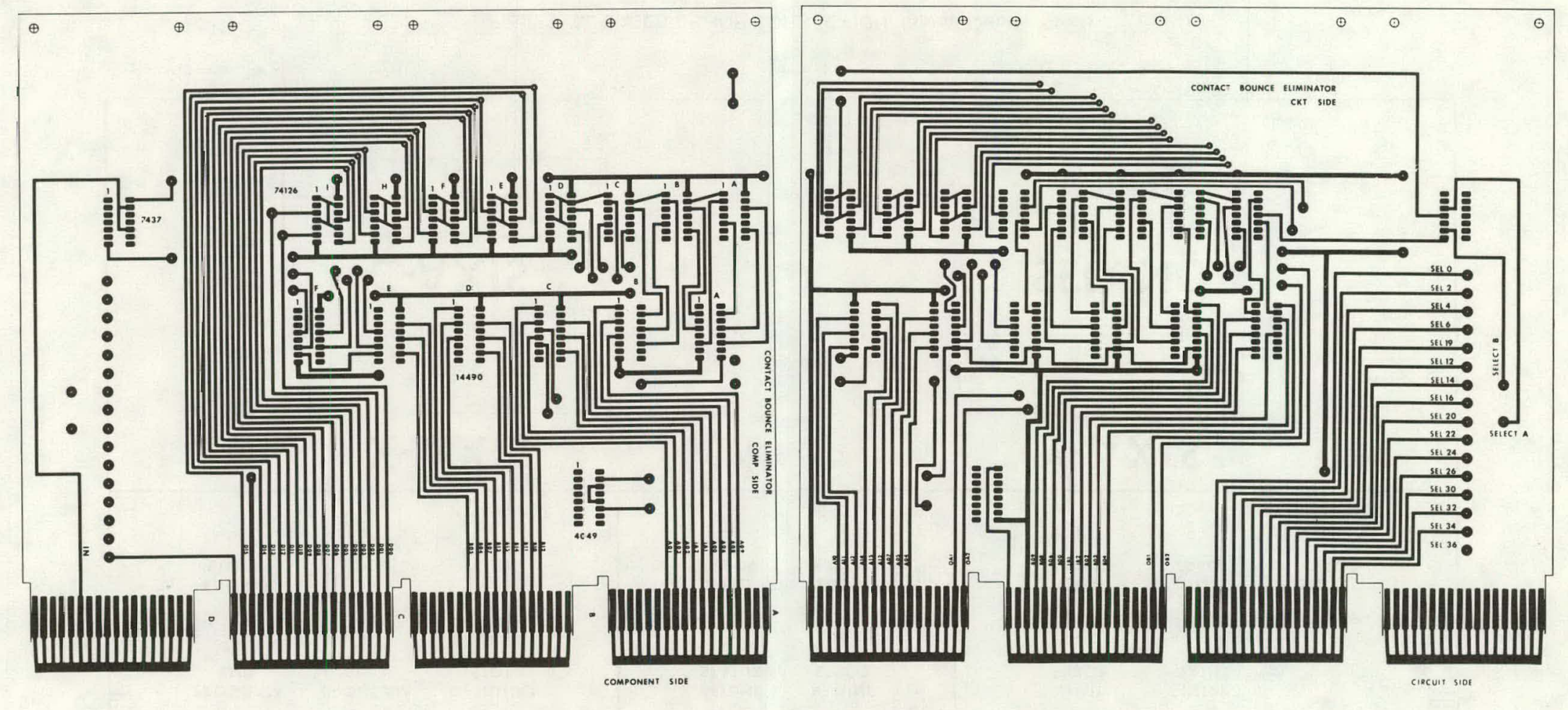

Figure F-25. LASER ERROR CORRECTION. (Input Receiver PC/Board) 


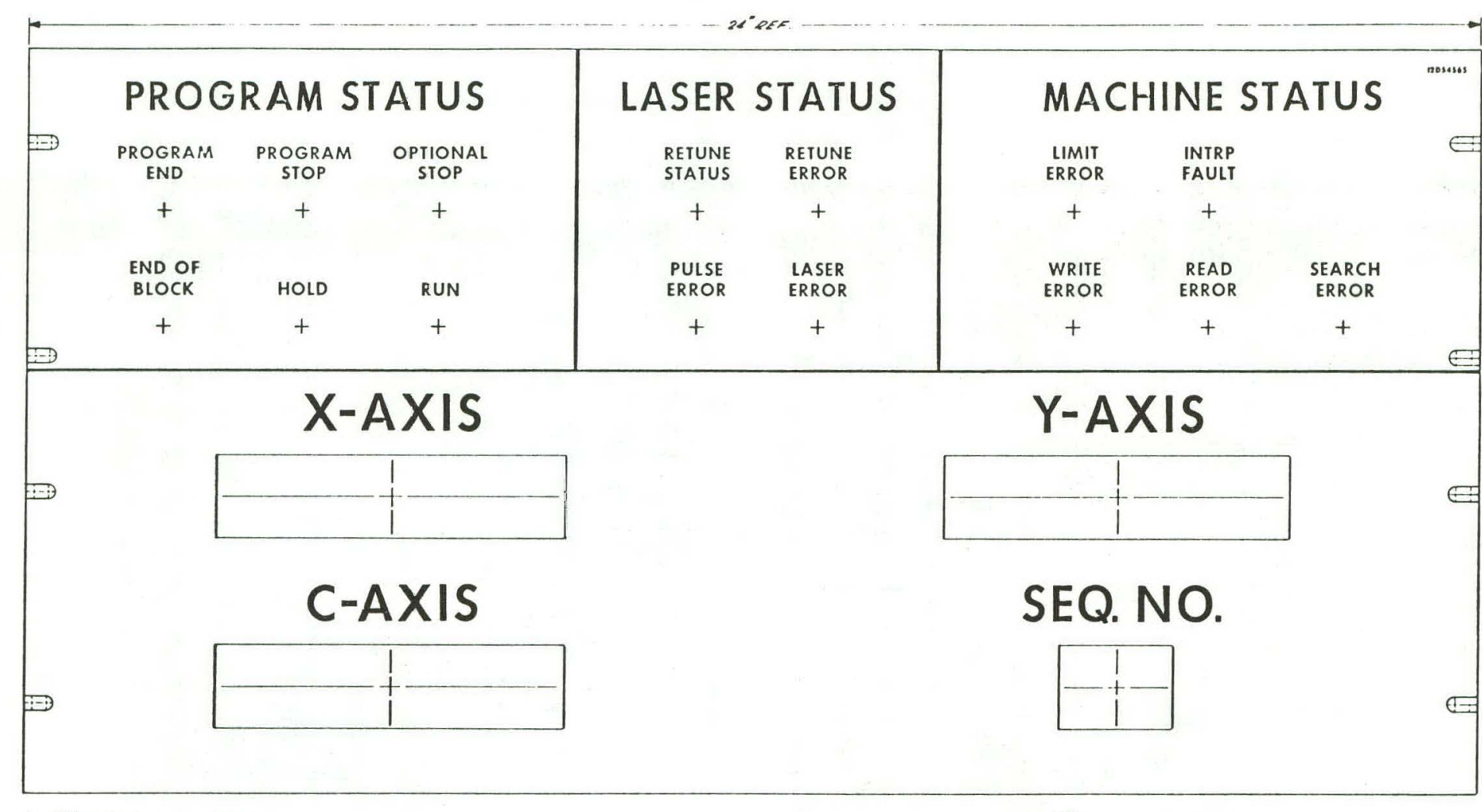

$+\frac{1}{8}(.250)$ De114, 16 wOLS

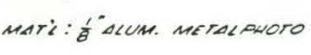

Figure F-26. LASER ERROR CORRECTION. (Status Display Panel) 


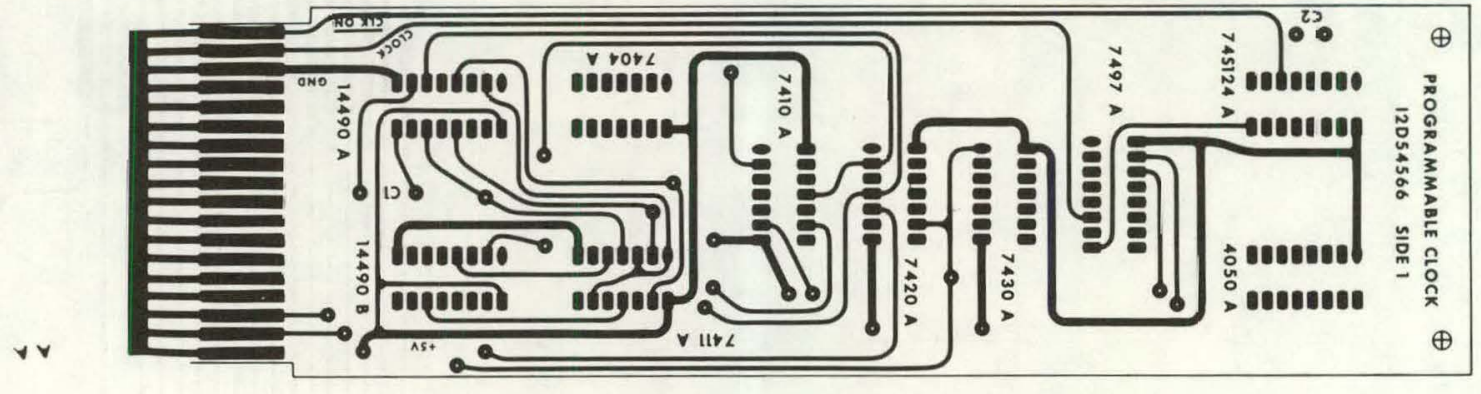

6

C

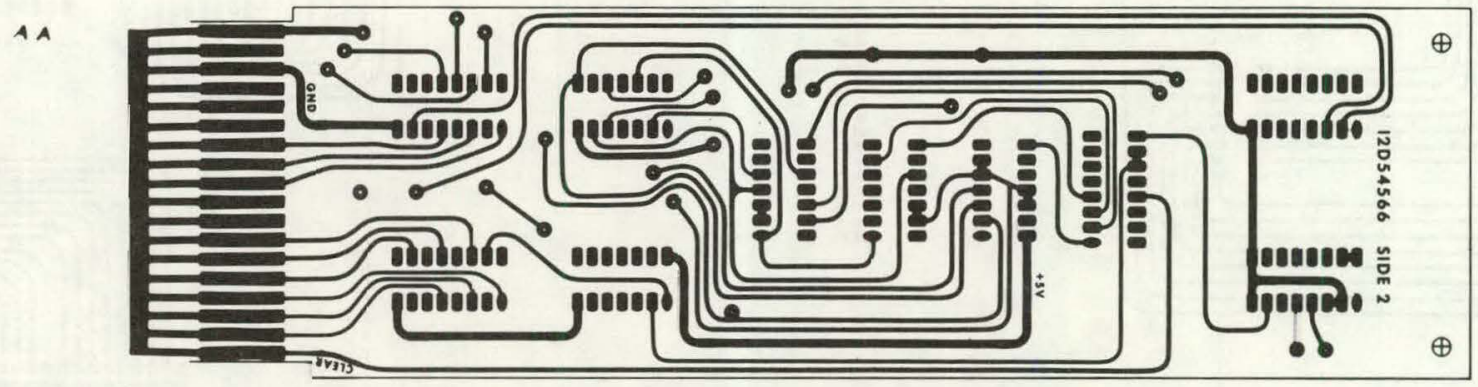

Figure F-27. LASER ERROR CORRECTION. (Programmable Clock PC/Board) 


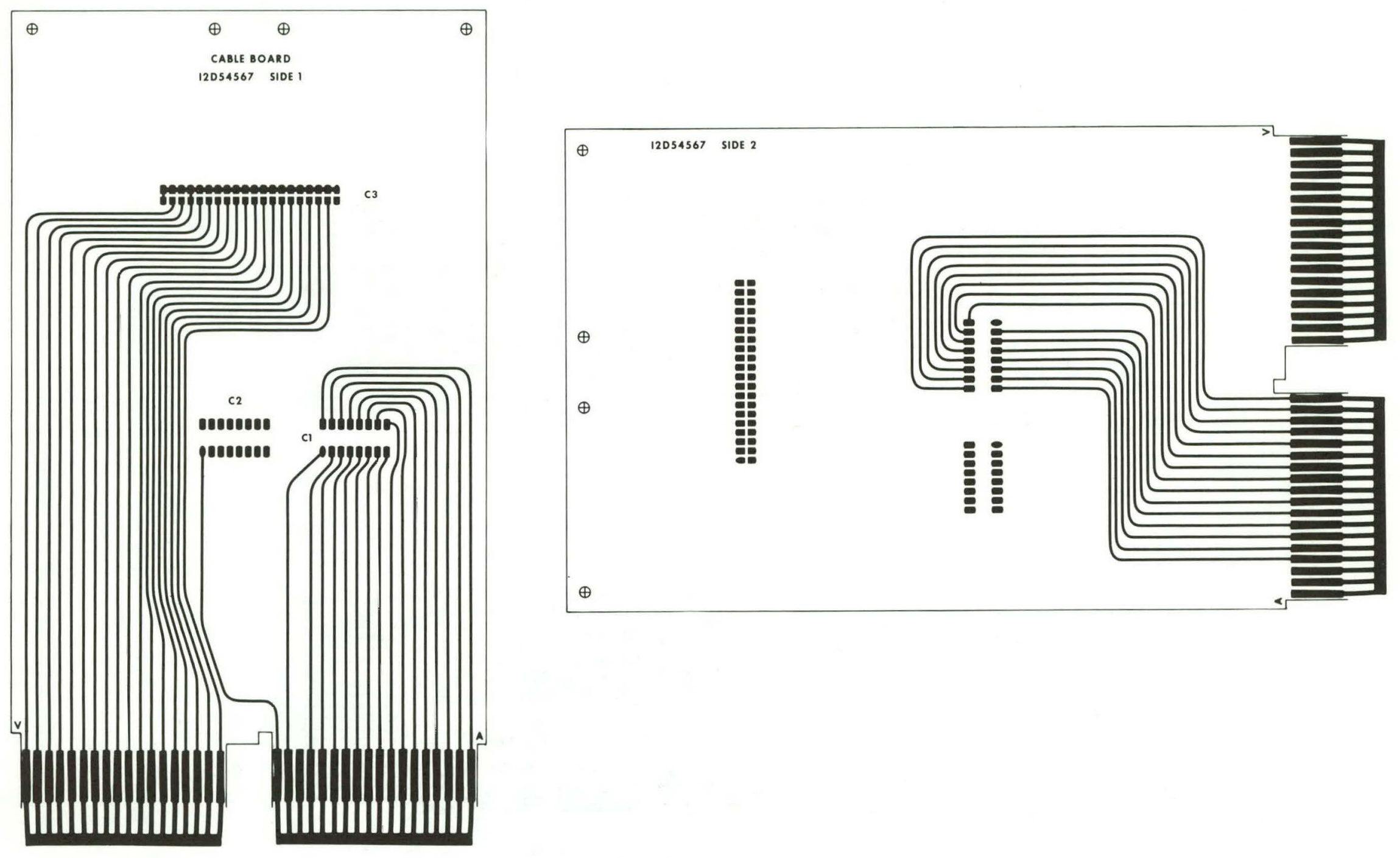

Figure F-28. LASER ERROR CORRECTION. (Cable PC/Board) 


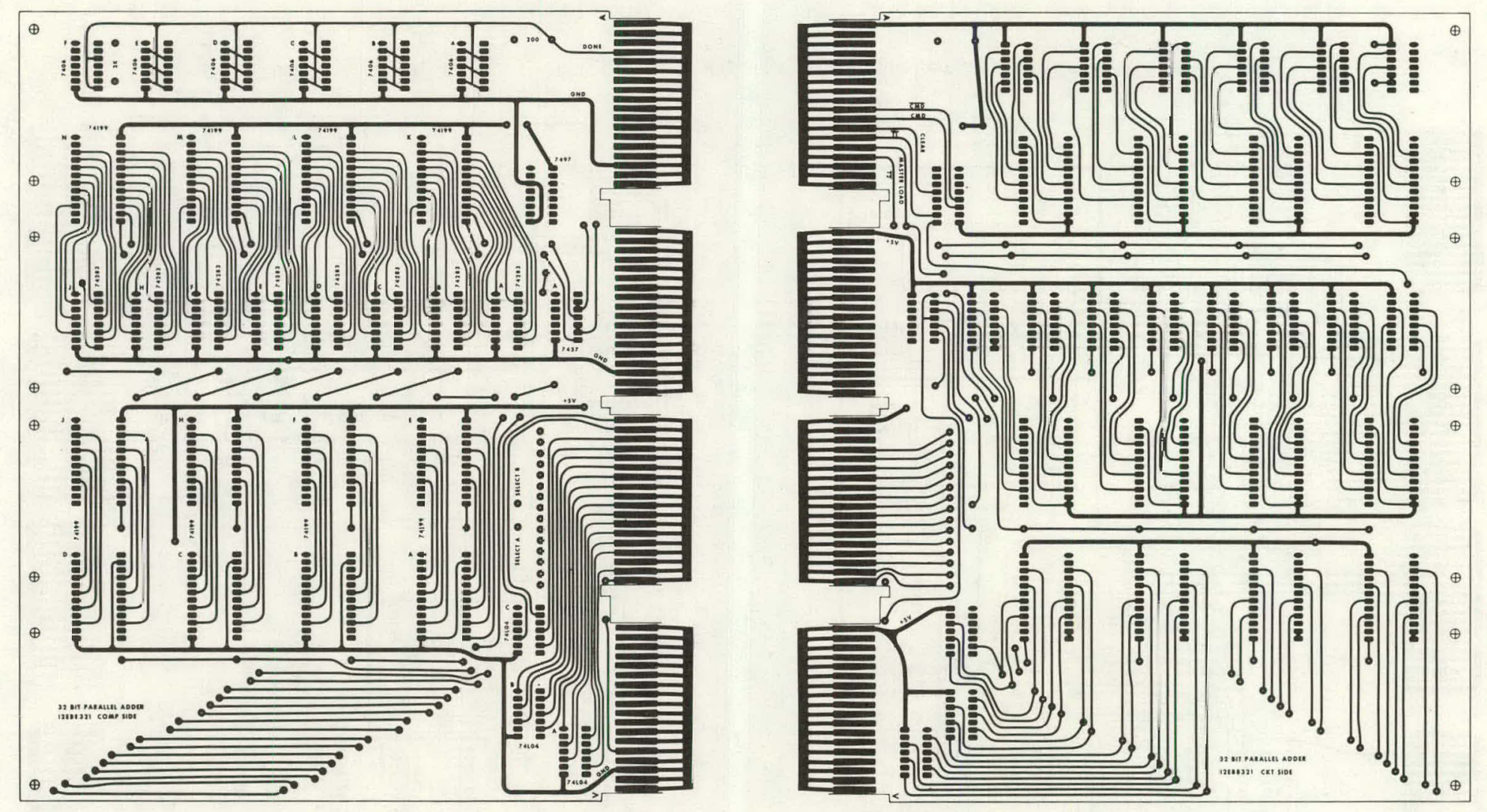

Figure F-29. LASER ERROR CORRECTION. (32-Bit Adder PC/Board) 

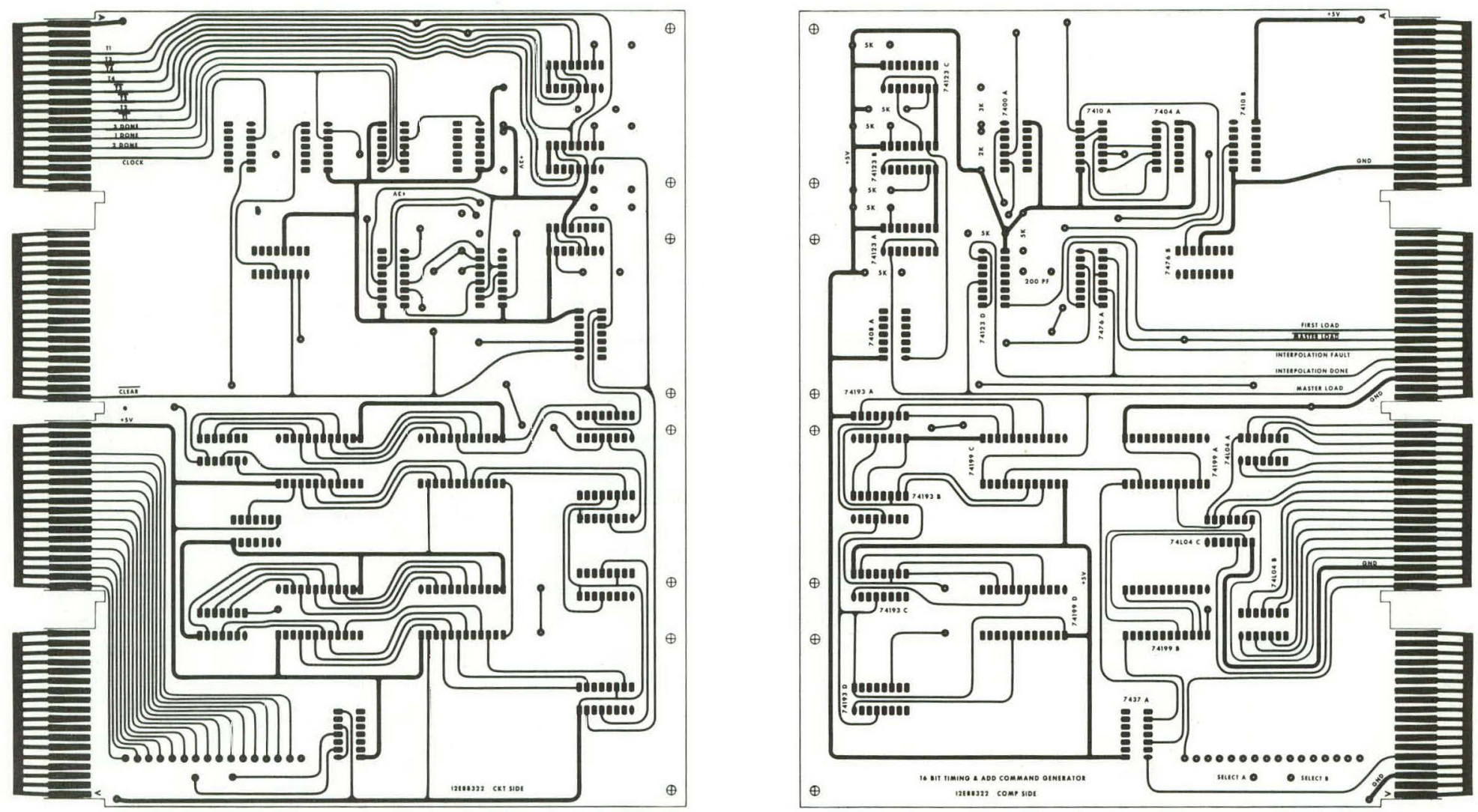

Figure F-30. LASER ERROR CORRECTION. (Timing and Add Command Generator PC/Board) 

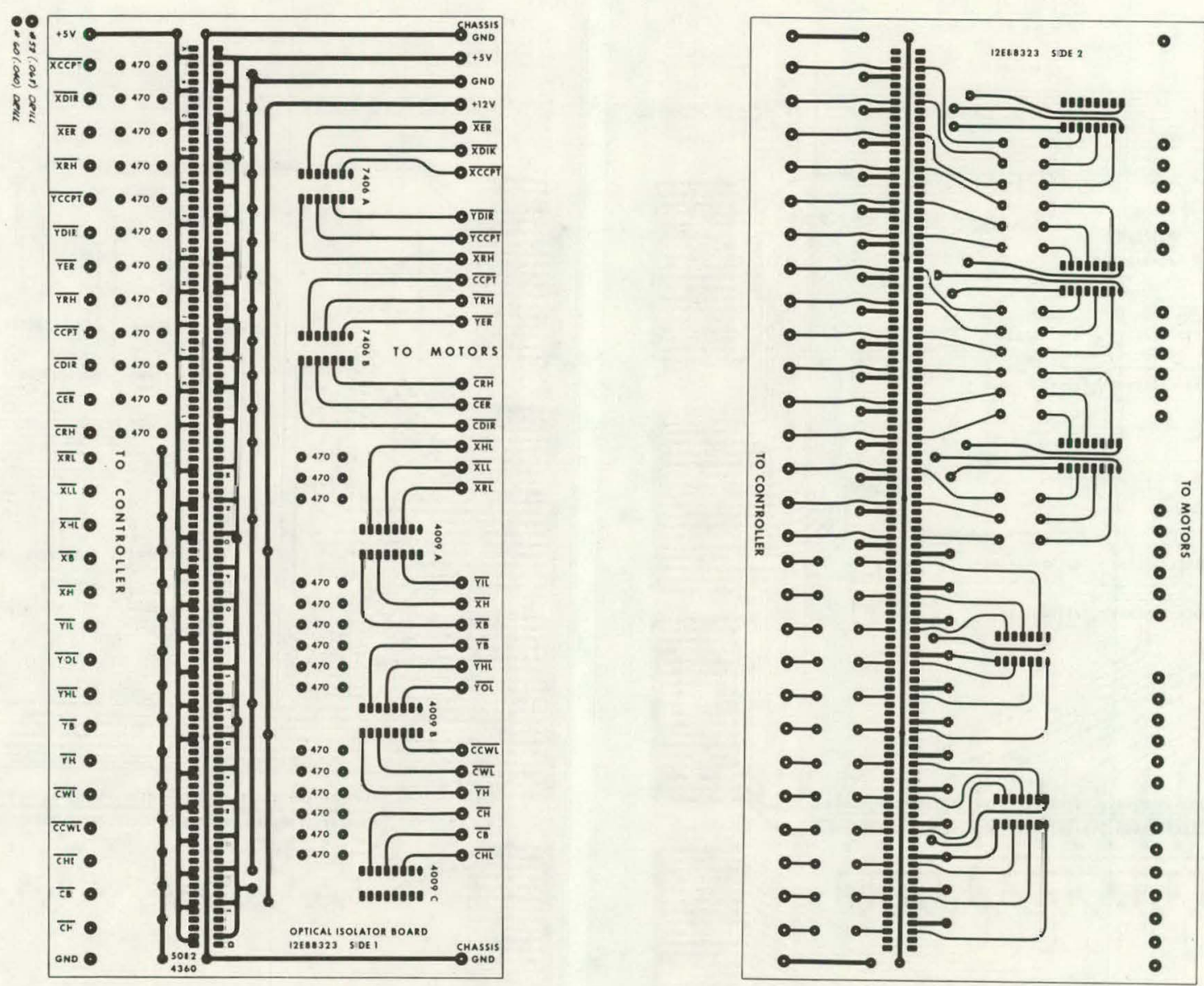

Figure F-31. LASER ERROR CORRECTION. (Optical Isolator PC/Board) 

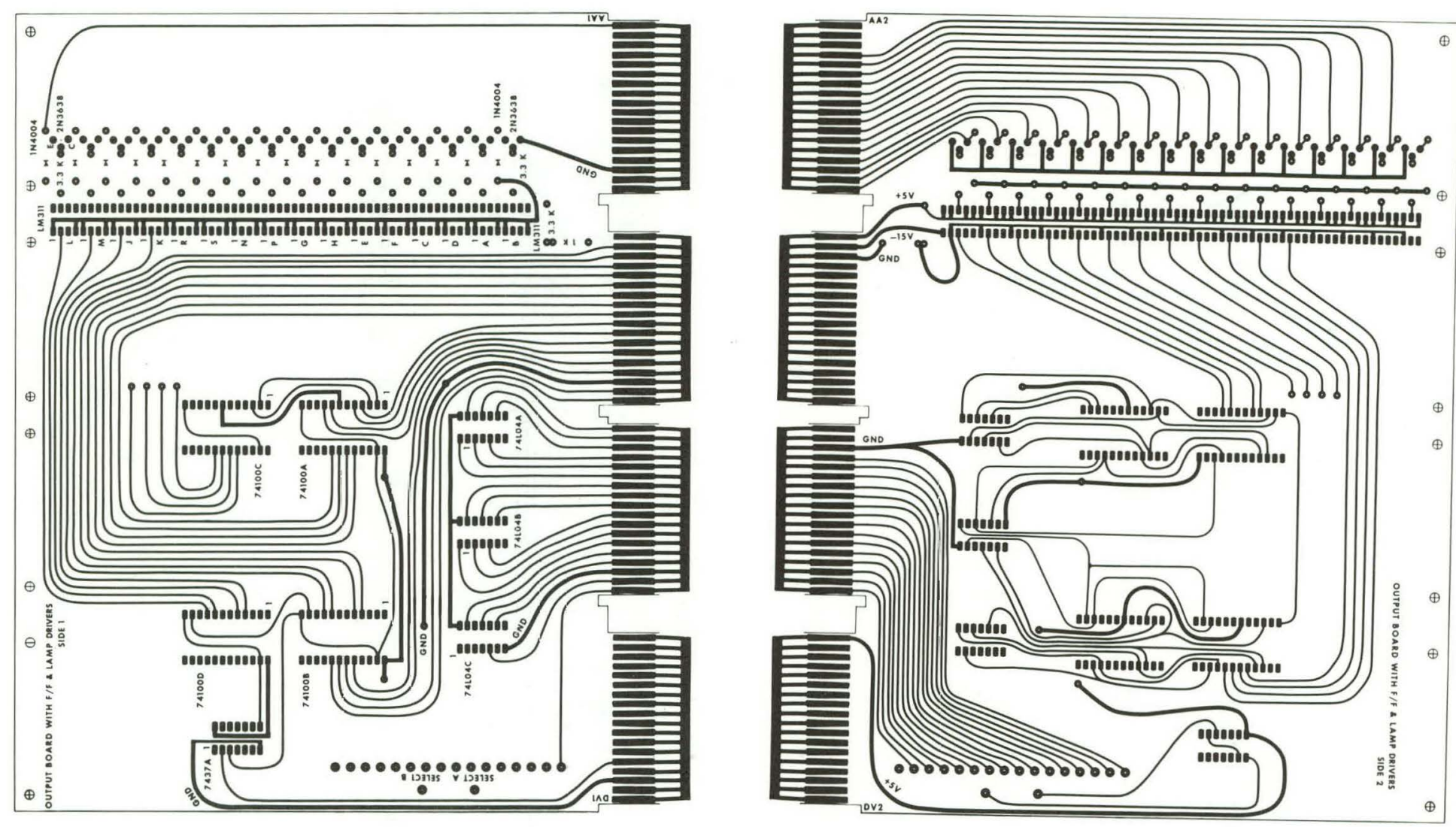

Figure F-32. LASER ERROR CORRECTION. (Output W F/F and Lamp Driver's PC/Board) 

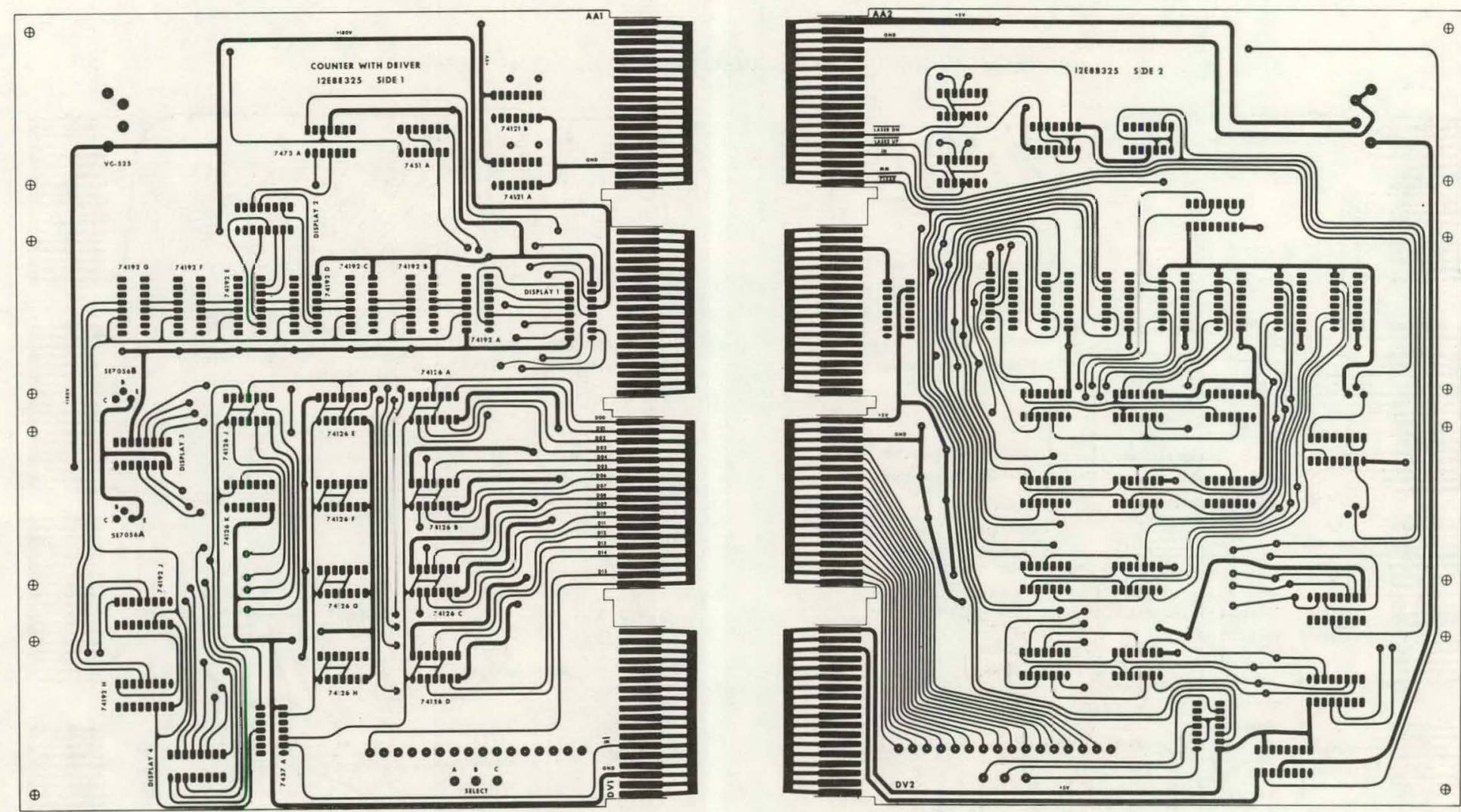

Figure F-33. LASER ERROR CORRECTION. (Counter W Driver PC/Board) 

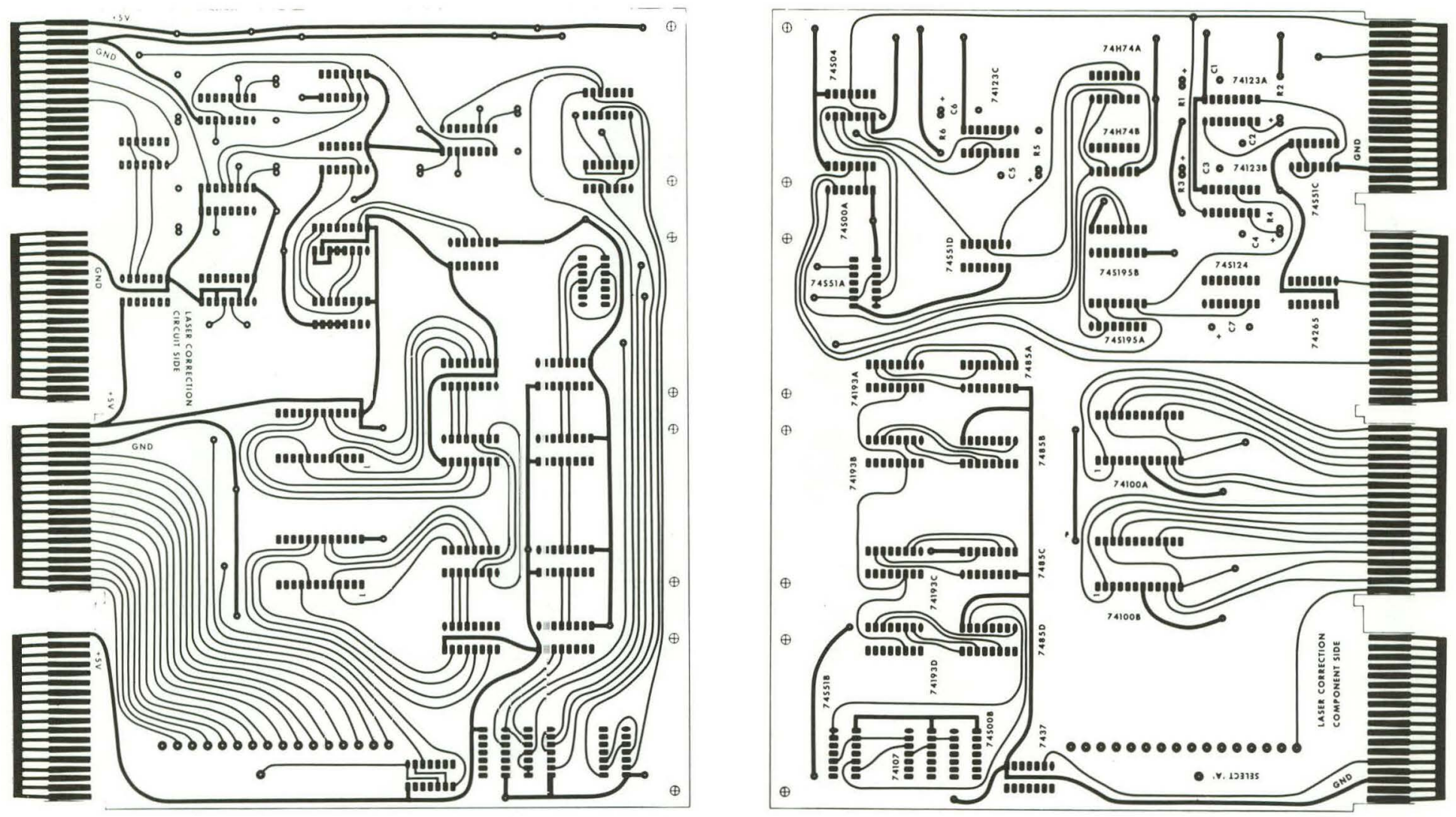

Figure F-34. LASER ERROR CORRECTION. (Laser Correct PC/Board) 

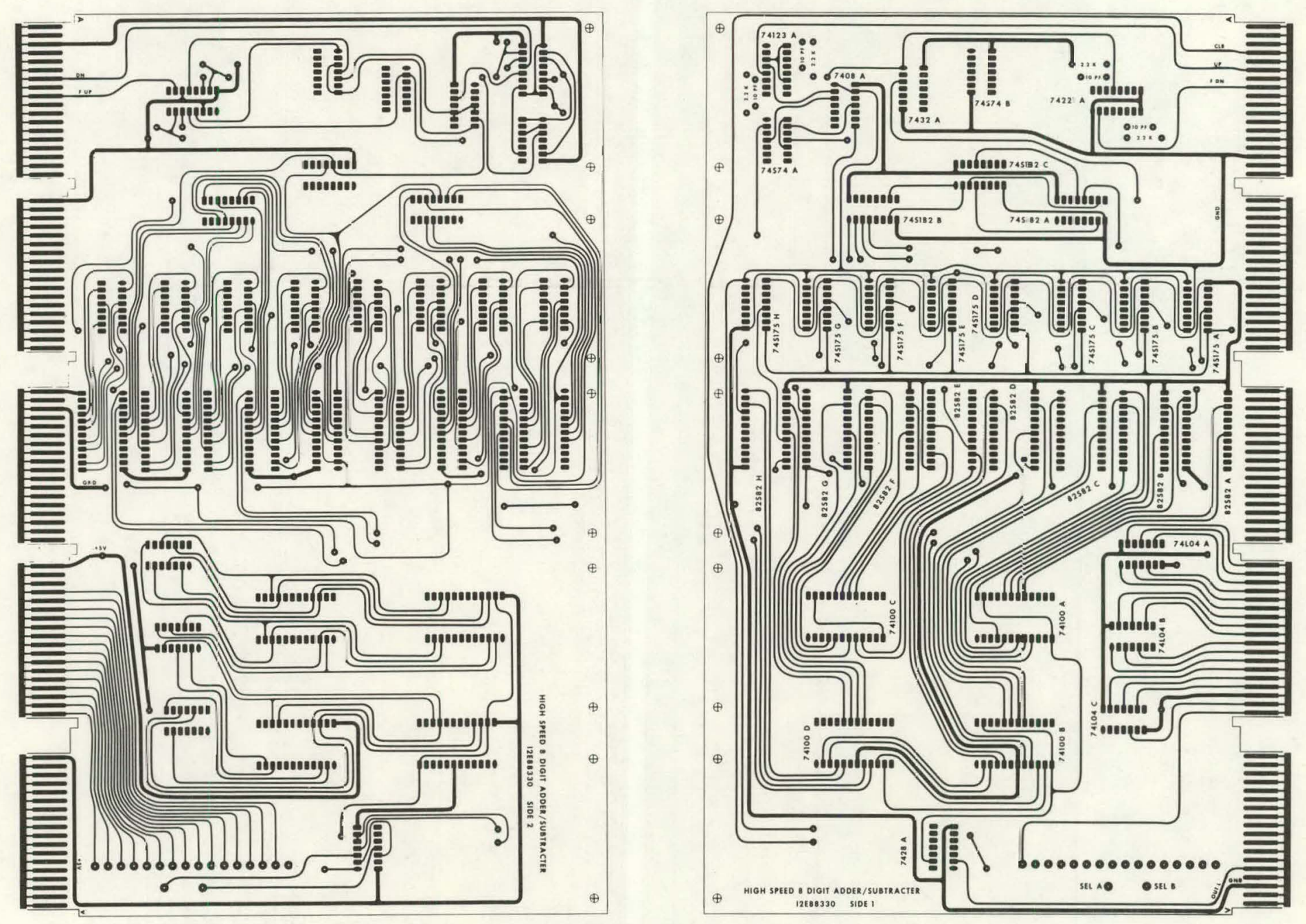

Figure F-35. LASER ERROR CORRECTION. (8-Digit Add/Sub PC/Board) 


\section{THIS PAGE , \\ WAS INTENTIONALLY \\ LEFT BLANK ;}

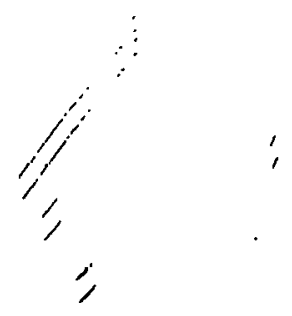




\section{Distribution}

Air Force Materials Laboratory - LT

Saito, T. T., Maj

Air Force Weapons Laboratory - ALO

Hanlon, J. A.

Air Force Weapons Laboratory - LRE

Bettis, J. R., Maj

Charlton, G. B.

Kyrazis, D. T., Col

Prater, R. F., Lt Col

Department of Energy - Albuquerque

Vespe, V.C.

Department of Energy - DMA

Weiss, J. A.

Department of Energy - Oak Ridge

Hickman, H. D.

Zachry, D. S.. Jr

Lawrence Livermore Laboratory

Bryan, J. B.

Carr, R. B.

Nelson, W. E.

Schuman, J. F.

Stone, R. G.

Wallerstein, E. P.

Young, $R$.

Technical Information Division Library

Los Alamos Scientific Laboratory

Baker, F. L.

Hoyt, H. C.

Reichelt, W. H.

Library Services

Naval Surface Weapons Center

Larsen, C.

Naval Weapons Center

Decker, D. L.

Fountain,C.

Oak Ridge Gaseous Diffusion Plant

Stief, S. S.

Wilcox, W. J., Jr 
Oak Ridge National Laboratory

Weir.J.R., Jr

Oak Ridge Y.12 Plant

Bernander, N. K.

Bostock, D. J.

Burditt, R. B./Schede, R. W.

Burleson, R. R. (60)

Dodson, W. H./Ludwig, R. L.

Duggan, H. G.

Fraser, R. J.

Haeusler, K. R.

Hewgley, R. E.

Igou, R. E.

Jones, F.W.

Kahl, K. G.Whitten, L. G., Jr

Keith, A.

Kite, H. T.

Marrow, G. B.

Martin, W. R./Googin, J. M.

Mason, D. L.

Mills, J. M., Jr

Neal, R. E.

Phillips, L. R.

Preuss, H. M./Bender, F. D.

Smith, H. F., Jr

Smith. R. D.

Smith, W. E.

Steger, P.J.

Stoner, H. H.

Tewes, W. E.Maldrop, F. B.

Tliviiinsuiı, C. H.

Thompson, W. H., Jr

White, J. C.

Whitson, W. K.

Williams, R. D.

Williarrs, T. L.

Wright, C. C.

Yaggi, W. J.

Y-12 Central Files (master copy)

$Y-12$ Central Files (route copy)

$Y-12$ Central Files $(Y-12 R C)$

Y-12 Central Files (5)

Paducah Gaseous Diffusion Plant

Bewley, H. D.
Redstone Arsenal - Huntsville

Norwood, T. E.

Sandia - Albuquerque

Mail Service Station

Sandia - Livermore

Technical Library

Union Carbide Corporation New York

Tinsley, S. W..

In addition, this report is distributed in accordance with the category UC-38, Engineering and Equipment, as given in the USERDA Standard Distribution Lists for Unclassified Scientific and Technical Reports, TID 4500 . 